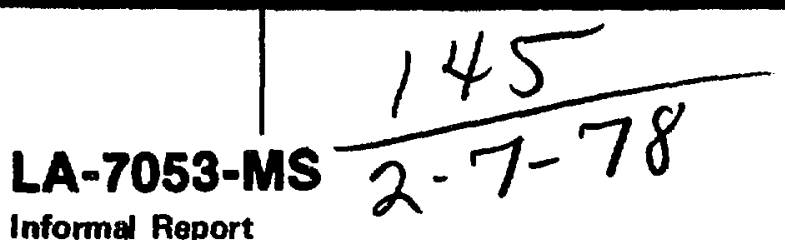

Informal Report

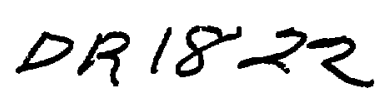

UC-20d

Issued: January 1978

\title{
TNS Doublet Tokamak Ohmic-Heating Power Supply Study
}

\author{
Compiled by \\ John D. Rogers \\ Contributors \\ H. F. Vogel \\ P. Thullen \\ W. L. Bird* \\ W. F. Woldon' \\ D. M. Weldon
}

"Center for Electromechanics, The University of Texas at Austin, Austin, TX 78712. 
This report is a compilation of several separate but interrelated studies conducted by members of Group CTR-g of the LOS Alamos Scientific Laboratory of the University of California and the Center for Electromechanics of The University of Texas at Austin. The work was undertaken in support of the tokamak TNS design group of General Atomic at San Diego, California. The primary emphasis of the work has been to examine the feasibility of a homopolar machine as an energy transfer and storage element in the circuit of the TNS doublet, to address the related switching problems, and to consider the nature of the plasma shutdown at the end of the burn cycle.

Parameters supplied for the studies set the peak current and voltage at about $3 \mathrm{MA}$ and $1 \mathrm{kV}$, respectively, with a $2-s$ start-up for the ohmic-heating phase. The stored energy in the ohmic-heating coils was estimated to be $500 \mathrm{MJ}$ and the total flux change to be $34 \mathrm{Vs}$. Of this amount, $20 \mathrm{Vs}$ supplies the plasma inductive loading and $8 \mathrm{Vs}$ the plasma resistive losses. The remainder powers the burn phase.

The six parts of the study analyze the circuit, present a minimal conceptual engineering analysis of an alr core superconducting fleld coil excited homopolar machine, provide a somparative design of an iron dominated homopolar machine, address the circist or current interruption problem as well as the connecting bus, and discuss the plasma shutdown. The work presents a quick insight to the compiexity of such a system. Approximate costs are developed for both homopolar machines.

In particular, a variable capacitance homopolar machine with superconducting field coils has been considered. Both the circuit analysis and the dynamic response of the machine and its physical limitations make clear that the variable capacitance feature, based upon sliding brushes, is not adaptable to programming both the ohmic-heating and burn portions of the tokamak cycle. A homopolar machine can act as the basic transfer element of such a system; however, augmenting power supplies will be required during the burn phase. Analysls of the current collection and relevant brush technology is an important part of the homopolar machine study.

The high current of $3 \mathrm{MA}$ demands a multiplicity of switches and a development of new breakers. Joule losses in the bus for the circuit are significant. The indication is that higher voltage, lower current homopolar machines could reduce the severity or some of these problems.

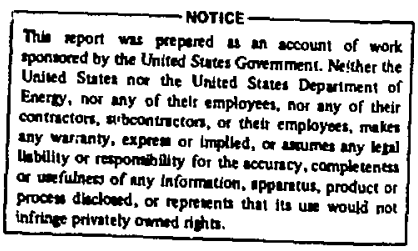

John D. Rogers

Group Leader, CTR-9 
CONTENTS

page

PAPER I. CIRCUIT ANALYSIS AND OPERATING CYCLE............. I

Abstract...................................... I

I. Introduction.............................. I

II. The IC Circuit with Variable Flux Homopolar............. 2

A. Numerical Integration...................... 5

B. Analytical Integration....................... 8

III. Operating Cycle and Numerical Analysis................ 10

A. Circuit and operating cycle................. 10

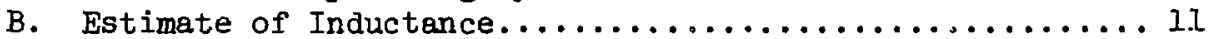

C. Estimate of Average Plasma Resistance.............. 12

D. Estimate of E-Coil Circuit Resistance............... 12

E. Transformation to the E-Coil Winding.............. 12

F. Current and Voltages........................... 13

G. Reversed Amplitude Control.................... 13

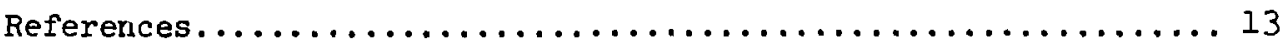

Figures.................................. 14

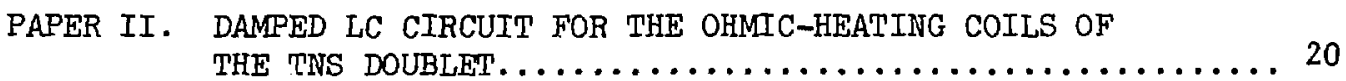

Abstract................................... 20

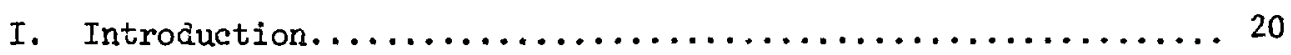

II. Case (a): Initial Energy in the Electrostatic Field....... 21

III. Case (b): Initial Energy in the Magnetic Field and Efficiency Calculations.................. 23

IV. Numerical Evaluation of the Oscillatory Circuit........... 24

Figures.................................. 26

PAPER III. HOMOPOLAR MACHINE DESIGN................... 29

Abstract....................................... 29

I. Introduction............................... 29

II. Basic Configuration, Superconducting Machine............ 30

III. Assumptions............................. 34

IV. General Conceptual Designs...................... 36

v. Point Designs............................. 38 
VI. Brush Fundamentals.................................42

VII. Electromagnetic Forces.............................48

VIII. Magnet Design Check................................49

References ........................................ 51

Figures .......................................... 53

PAPER IV. FERROMAGNETIC ROTOR HOMOPOLAR MACHINE FOR A 3.0-MA OHMIC-HEATING POWER SUPPLY .................... 61

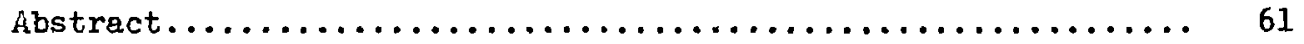

I. Introduction................................61

II. System Anelysis ..................................62

III. Homopolar Machine Configuration.......................64

IV, Homopolar Machine Desigr...........................66

A. Yoke and Field Coil..........................67

B. Rntor and Shaft.........................67

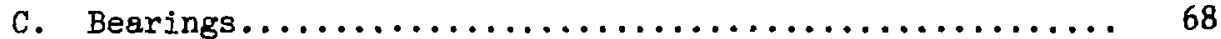

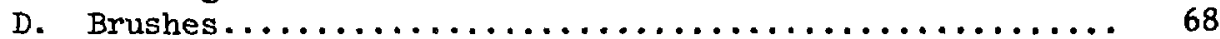

E. Cooling...................................... 69

F. Machine Saturation of Rotor..................... 69

G. Circuit Impedance............................ 70

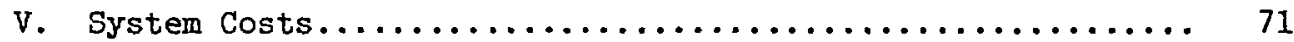

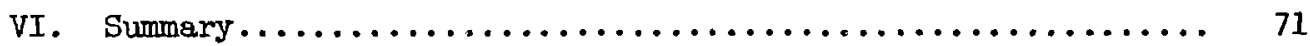

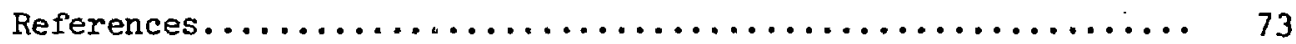

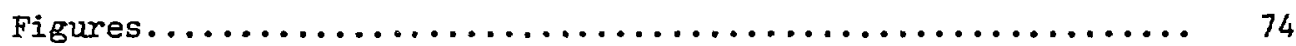

PAPER V. CIRCUIT BREAKER AND BUS.............................

Abstract ........................................ 76

I. Introduction................................. 76

II. Switch Features................................ 77

A. Stationary Contact........................... 77

B. Transient contact........................... 78

C. $1-m \Omega$ Series Resistor......................... 78

D. Hydraulic Flow................................ 78

E. Shock Wave Transmission.......................... 79

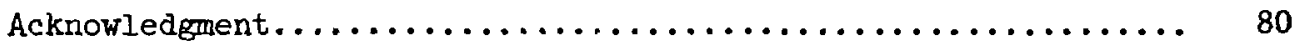

References........................................ 80

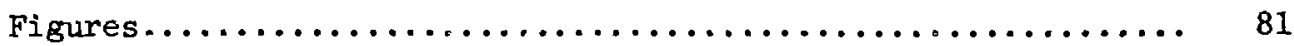


PAPER VI. SHUTDOWN PROBLEMS IN LARGE TOKAMAKS............. 82

Abstract.................................. 82

I. Introduction ............................ 82

II. Soft Shutdown............................ 83

$\therefore$ Plasma Modeling........................... 83

1. D-T Neutral Density Balance.................. 84

2. Electron Density Balance.................. 85

3. D-T Ion Power Balance...................... 85

4. Electron Power Balance................... 86

B. Shutdown scenarins....................... 87

III. Hard Shutdown............................. 88

A. Mode Structure of the Disruption................ 88

B. Interaction with the Wall................... 89

References.................................. 90 


\author{
H. F. Vogel
}

\title{
ABSTRACT
}

The E-coll circuit is analyzed numerically, where the inductance matrix is obtained from the seometry of the TNS Doublet and the average plasma resistance from the 8-Vs number reported for the current reversal.

The homopolar machine's and connecting bus's resistances are estimated and the circuit is discussed.

Design equations are derived for a homopolar machine featuring movable brushes. The circuit still requires a dedicated power supply for the burn period because the kinetic energy can only be partially transferred to the external circuit if the terminal voltage is varied by movable brushes. The energy remaining in the machine may, however, be used as a control element during the entire current reversal. The maxima in electromagnetic stress in E-coils thus become equalized over the pulse cycle.

\section{INTRODUCTION}

A homopnlar machine functioning as a capacitor in an LC circuit is discussed where the current reverses within 2 s from negative to positive before continuing to increase for the 28-s burn period. The cycle is plotted in Fig. 1. From some of the aspects being discussed, it seems doubtful that the pulse cycle could be accomplished by oscillation between just one homopolar machine and the E-coila.

Our disoussion starts with the LC circuit equations for the homopolar machine with variable brush positions for controling the effective magnetic flux and hence the output voltage at a given angular speed of the rotor.

Our attention will then focus on a circuit that includes a burn supply homopolar dedicated to generate the alowly increasing current needed for the phases 1,3 , and 5 shown in Fig. 1. The magnetic coupling of the currents between the E-coils and plasma is included in the circuit analysis.

a The Doublet tokamak ohmic-heating coil is called an E-coil. 
The homopolar machine's terninal characteristic may be changed by varying the flux, $\phi$, interacting with the rotor. Flux variation in this sense may be accomplished by changing the exciter fleld or the brush positions. An important point should be made regarding variable capacitances in general. If a charged elect:ostatic capacitance is varied, energy is exchanged because charges are being moved along an electric field gradient. Similarly, energy is required to change the exciter field of a homopolar machine or the positions of the current carrying brusines. Any variation in capacitance generates, in the electrostatic case, a charge differential $d q=k d x$, where $k$ is a constant, and $d x$ the path differential through which the electrodes are moved against the electrostatic field pressure. The resulting current $\dot{q}=k \dot{x}$ is proportional to the speed, $\dot{x}$, component of electrode motion in the gradient's direction. No equivalent of this effect exists in the homopolar machine because its performance is described by Rüdenberg's ${ }^{1}$ equations for the transient behavior of the rotating dc armature, ${ }^{a}$ i.e.,

$$
\begin{aligned}
& v_{c}=\omega \phi / 2 \pi \\
& v_{c^{1}}=J \omega \dot{\omega}+P_{\text {shaft }} .
\end{aligned}
$$

Equation (1) defines the terminal voltage as a function of the rotor's angular velocity, $\omega$, and the magnetic flux, $\phi$, which, in turn, is defined by the exciter coil and the positions of the current collectors. Equation (2) describes the power balance where $\dot{\omega}$ is the time derivative of the angular vefocity, $J$ is the rotor's noment of inertia, and $P_{\text {shaft }}$ is the power transmitted throug" " shaft. In the following, we shall always assume $P_{\text {shaft }}=0$. By eliminating $v_{c}$ between 18q3. (1) and (2), we get a relationship for the current

$$
1:=2 \pi \dot{J} / \phi
$$

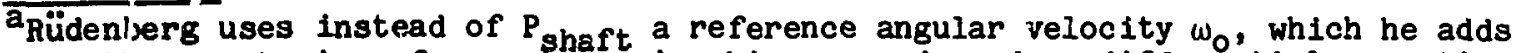
to tise restoring force term in his second order differential equation corresponding to our Eq. (5). We prefer $\mathrm{P}_{\text {shaft because of its signification and }}$ generically fitting place in the equations.
} 
If we define $C$ as the capacitance, which, at the terminal voltage, $v_{c}$, stores the same onergy as in the rotor's inertia at the angular velocity $\omega$, we get

$$
c=J\left(\omega / v_{c}\right)^{2}
$$

which implies $w \propto v_{c}$ for any set (positive, real $\cap \mathrm{C}, \mathrm{J}$ ). It is evident from Eq. (3) that $1=0$ for $\dot{w}=\dot{v}_{c}=0$, as distinguished from the corresponding case of the electrostatic capacitor for which the current

$$
i=\frac{d}{d t}\left(C v_{c}\right)
$$

vanishes not if $\forall \mathrm{dc} / \mathrm{dt} \neq 0 \neq \mathrm{v}_{\mathrm{c}}\left(\dot{v}_{\mathrm{c}}=\dot{\omega}=0\right)$.

Another relationship exists in the equation for the LC circuit loop in which the homopolar is connected, i.e.,

$$
v_{r}+L \dot{L}+R i=0 .
$$

We substitute again Eq. (1) for $v_{c}$ in Eq. (4), differentiate, and eliminate $\dot{\omega}$ with Eq. (3) to obtain the second order differential squation

$$
\ddot{L}+\left(\mathrm{R}-\mathrm{L} \frac{\dot{\phi}}{\phi}\right) \dot{1}+\left(\frac{\phi^{2}}{(2 \pi)^{2} J}-\mathrm{R} \frac{\dot{\phi}}{\phi}\right) \pm=0 \text {. }
$$

In Eq. (5) we use subsequently the abbreviations

$$
\begin{aligned}
& \overline{\mathrm{R}}=(2 \pi)^{2} \mathrm{JR} \text { and } \\
& \overline{\mathrm{L}}=(2 \pi)^{2} \mathrm{JL},
\end{aligned}
$$


where $J$ is the rotor's moment of insrtia, $R$ and $L$ being the circuit's resistance and inductance.

For defining the variable flux controlled by the brush positions, we may use any phystcally realizable function, such as

$$
\phi=\phi_{0} e^{-\delta t},
$$

where $\phi_{0}$ is the flux corresponding to the brush positions at $t i m e t=0$ and $\delta$ is the logarithmic decrement indicative of the time rate at which the current collecting brushes move.

After substituting Eq. (8) and its time derivative for $\dot{\phi}$ in Eq. (5), the latter may be integrated. He use two methods of integration, the first one being a numerical algorithm applied to the once formally integrated equation, i.e., to

$$
L i+(R+L \delta) i+\int_{0}^{t}\left(\frac{v^{2}}{2 W} e^{-2 \delta \tau}+R \delta\right) i d \tau=0
$$

where $V$ is the voltage value and $w$ the kinetic energy, both corresponding to the flux, $\phi_{0}$. The following equivalent circuit elements are defined by Eq. (9):

$$
\begin{aligned}
& C_{e q}=\left[\frac{v^{2}}{2 W} \exp (-2 \delta t)+R \delta\right]^{-1}, \\
& R_{e q}=R+L \delta, \\
& L_{e q}=L .
\end{aligned}
$$

A discussion of the computations with our numerical algoritim follows, whereas the second method just mentioned for solving Eq. (9) is discussed after the conclusion of the former. 


\section{A. Numerical Integration}

The inftial conditions for integrating Eq. (9) are given by

$$
\begin{aligned}
& i(t=0)=I_{0} \text { and } \\
& \int_{-\infty}^{0} i d \tau=0 .
\end{aligned}
$$

Numerical integration was carried out, with the flux function given by Eq. (8) and with the alternative function

$$
\phi / \phi_{0}=1 / 2-\frac{1}{\pi} \arctan [10(t / T-1)],
$$

where $T$ is a scaling factor for time similar to $\delta$ in Eq. (8). The two flux functions are plotted in Fig. 2 and show that the exponential function, Eq. (8), describes a reduction in flux mainly near the current reversal's beginning, whereas the arc tan function, Eq. (13), shows the converse tendency by reducing the flux mainly near $t=T$. $T$ may be defined to coinclde with the end of current reversal.

It might be expected that the current should continue to increase along an ascending branch of the sinusoid once it had reached an argument range of $(\pi / 4$ to $\pi / 2) \pm 2 \pi$ and after the equivalent capacitance attained a large value. Such an expectation might be based on the linear circuit-related assumption that a small sapacitance would imply a half-period of just a few seconds in the present case, whereas the unhanced capacitance value caused the half-period of oscillation to be more than $100 \mathrm{~s}$ with energy continuing to transfer out of the homopolar. A look at Eq. (9) shows, however, that the equivalent resistance, $R+L \delta$, may significantly absorb power if $L \delta / R \gg>$ (1.e., the brushes are moved fast). Otherwise, we would get $1>i \delta / R \geq 0$, which may cause ringing oscillations with a half-period of just a few seconds. The fast current oscillation is, of course, desired only for the Phases 2 and 4 of Fig. 1.

Figure 3 demonstrates this effect for a set of constants consistent with the plasma coupled E-coil circuit. The time constant for flux change, $1 / \delta$, is 
the paramete' varying from $0.1 \mathrm{~s}$ to $5 \mathrm{~s}$. The shape of the current plots varies continuously over this range and beyond.

The flux function defined by $\mathrm{Eq}$. (13) is more meaningful for discussing physical circult phenomena than that of Eq. (8) because one would expect to let the effective capacitance undergo its increase near the end of the 2-3 current reversal. It 1 , therefore, useful to write the equivalent circuit values for the flux function of Eq. (13). In using the abbreviations

$$
\begin{aligned}
& X=t / T \\
& F(X)=\frac{1}{2}-\frac{1}{\pi} \text { arctan }[10(X-1)],
\end{aligned}
$$

and substituting Eq. (13) in Eq. (5), the equivalent circuit elements are obtalned, i.e.,

$$
\begin{aligned}
& L_{e q}=L \\
& R_{e q}=R+\frac{L}{\pi T} \cdot \frac{0.1}{\left(X^{2}-2 X+1.01\right) F(X)} \\
& 1 / C_{e q}=\frac{V_{0}^{2}}{2 W_{0}} F^{2}(X)+\frac{R}{\pi T} \frac{0.1}{\left(X^{2}-2 X+1.01\right) F(X)},
\end{aligned}
$$

where $v_{0}$ and $W_{0}$ are the reference voltage and energy of the homopolar for which the moment of inertia, $\mathrm{J}$, and the reference flux, $\phi_{0}$, in Eq. (13) are defined, 1.e.,

$$
v_{0}^{2} / 2 w_{0}=\phi_{0}^{2} /\left[(2 \pi)^{2} J\right]
$$

Figure 4 shows the integral of Eq. (5) for the following set of constants $\left(T, V_{0}, W_{0}, I_{0}, 2 L / R\right)=(2.50 \mathrm{~s}, 499 \mathrm{~V}, 387 \mathrm{MJ},-3.0 \mathrm{MA}, 28.4 \mathrm{~s})$. The integral of Eq. ( 5$), 1=1(t)$, was useo to determine $L 1$ and $R d$, from which the terminal voltage, $v$, of the homopolar is obtained. Equation (1) relates the angular velocity, $w$, of the rotor to the terminal voltage and the flux. function. The 
four functions - $\phi, i, v$, and $(s)$ - are plotted in Fig. 4 as functions of time t. Comparison of these plots shows that the changing flux, $\phi$, forces the current, 1 , to reverse because the terminal voltage, $v$, is brought to zero with $\omega \phi$ in keeping with Eq. (1), where $\phi$ decreases rapidly and wincreases slowly to pick up most of the magnetic field energy in the rotor's inertia as the current, $i$, decreases. Because of this mechanism, it is not feasible to obtain, by means of the moving brush feature, a slow and monotonic increase ir current beyond its first peak. Table I lists the constants used for generating tho pluts of Figs. 3 and 4.

He conclude the special homopolar with moving brushes is not suitable' for serving as a variable capacitance device for a dual transfer tiwe operation covering both $2 \mathrm{~s}$ and $28 \mathrm{~s}$.

It is feasible, though, to use the feature of moving brushes for adjusting the current amplitude resulting at the end of the 2-s current reversal (1.e., phases 2 and $4 \mathrm{in} \mathrm{Fig.} \mathrm{1).} \mathrm{In} \mathrm{this} \mathrm{application,} \mathrm{the} \mathrm{circuit} \mathrm{functions} \mathrm{wuch} \mathrm{like}$ one with a damping resistance in series with $L$ and $C$. The cost and complexity of the moving brush feature might compare favorably with those of a 3-MA variable rheostat alternative. Equation (9) shows that $\mathrm{R}_{\mathrm{eq}}$ and $\mathrm{C}_{\text {eq }}$ are both being varied by the moving brushes, and the time function controlling the brush motion must be chosen so the reversal time is maintained at $2 \mathrm{~s}$ while the reversed current amplitude is parametrically adjusted.

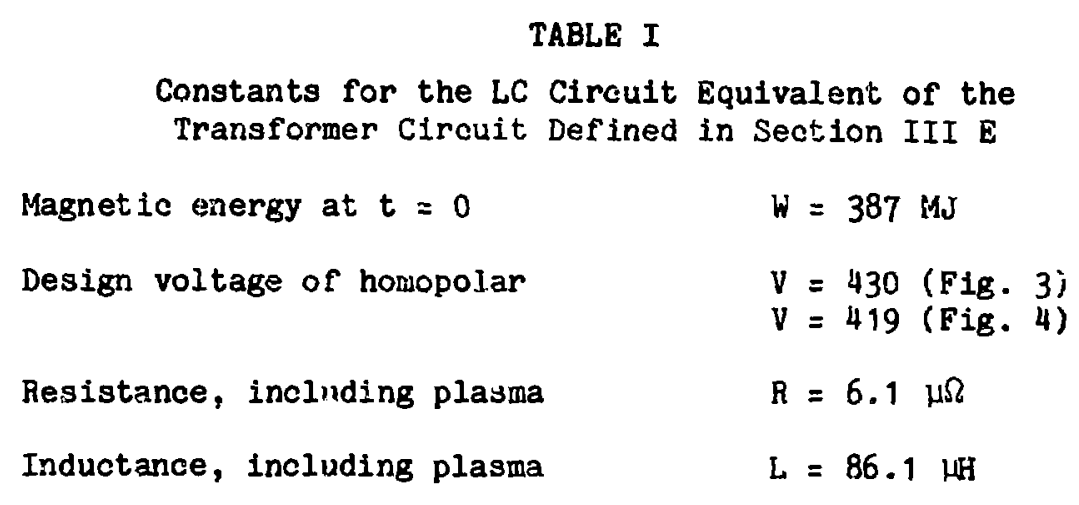




\section{B. Anslytical Integration}

The analytical method for solving Eq. (5), with $\phi$ substituted by Eq. (8) consists of reduoing the second-order differential equation to a first-order one which way then te integrated after one more transformation.

It is useful to state the equation to te integrated explictly, 1.e.,

$$
0=\ddot{i}+(R / L+\delta) i+\left[\left(\phi_{0}^{2} / \bar{L}\right) e^{-2 \delta t}+\delta R / L\right] 1 .
$$

Transformation from the $1=1(t)$ space to a dimensionless $y=y(x)$ space in which the 1mage of Eq. (17) exists as a first-order differential equation is obtained by

$$
\begin{aligned}
& x=e^{-\delta t} \\
& y=-\frac{e^{-\delta t}}{\delta}\left(\frac{i}{i}+\frac{R}{2 L}\right),
\end{aligned}
$$

with the inverse transformation equations

$$
\begin{aligned}
& t=-\frac{1}{\delta} \ln x \\
& \frac{\cdot 1}{I_{0}}=e^{-y / x} x^{R / 2 L \delta} .
\end{aligned}
$$

Following is the transformed equation

$$
y^{2}+y^{\prime}=A+\frac{1}{4} \frac{4 B-1}{x^{2}}
$$

which is Riccati's equation of the general kind. The constants in Eq. (20) are given by 


$$
A=\left(\frac{\phi}{2 \pi}\right) 2 / J L \equiv V^{2} J / 2 W
$$

and

$$
B=-(1-R / L \delta)^{2} \text {. }
$$

No further transformation seems able to reduce Eq. (20) to Riccati's equation of the special kind lending itself to direct integration. A particular integral of Eq. (20) must, therefore, be found by intuition. It can easily be verified that such an integral is given by

$$
y_{1}=-\frac{1+2 \sqrt{B}}{2 x}+\sqrt{A} \text {, }
$$

where the subscript is to indicate the partial nature. The rest is straight forward. The complete integral is given by

$$
y=y_{1}+1 / v,
$$

where $v$ can be obtained from Bernoulli's differential equation

$$
\frac{d v}{d x}-\left(\frac{1+2 \sqrt{B}}{x}+\sqrt{A}\right) v=1
$$

Hence, the complete integral becomes

$$
y=\frac{1 \pm 2 \sqrt{B}}{2 x}+\sqrt{A}-\frac{1}{(1 \pm 2 \sqrt{B})}[1 \pm 2 \sqrt{B}+C \exp (\sqrt{A x})]^{-1},
$$


where $C$ is the constant to be determined from the initial conditions set ( $x=1$, $\mathbf{y}=0$ ).

The results were discussed in the section on numerical integration of the second-order equation and no point is seen in substituting Eqs. (18) and (19) in Eq. (24) because the three equations constitute a parametric set, which is easier to interprete than the corresponding explicit nonparametric equation in $i=i(t)$.

III. OPERATING CYCLE AND NUMERICAL ANALYSIS

\section{A. Circuit and operating Cycle}

Operation of the circuit consists of the six distinct phases described below and in the current diagram Fig. 1. A ciraut diagram is given in Fig. 5, which shows the 30 parallel superconducting coils of TNS Doublet. Each coil is coupled electromagnetically with all the other coils, and each coil is connected to a circuit breaker unit, $S_{1}$, with its counterpulse circuit, as well as the homopolar generators, $\mathrm{C}_{\mathrm{O}}$ and $\mathrm{E}_{\mathrm{B}}$.

Duling Phase 1 the current in the sum of all $\mathrm{L}_{0}$ coils is driven by the homopolar $E_{B}$ from 0 to -3 MA.

Phase 2 is initiated by opening all $S_{1}$ breakers, thus transferring the current to the homopolar, $C_{0}$, acting as a capacitor. By oscillation between $\mathrm{C}_{0}$ and $\mathrm{L}_{0}$, the current is reversed to $+2 \mathrm{MA}$ (the difference from the $3 \mathrm{MA}$ accounts for the resistive loss and the effect of the brush movement).

Phase 3 is initiated by closing the breakers, $s_{1}$. This is followed by driving the current from the homopolar machine, EB, and increasing the current to $3 \mathrm{MA}$ over a $28 \mathrm{-s}$ period.

Phase 4 is essentially a repetition of Phase $2,1 . e$, the breakers, $s_{1}$, are opened again and the current is reversed to drive the plasma current to zero.

Phase 5 is designed to drive the current towards zero by operating the howopolar, $E_{B}$, in motor mode after the breakers, $S_{1}$, have been closed.

Phase 6 is a dead-time of $200 \mathrm{~s}$ between subsequent pulse cycles, Phases 1 through 5 . 
The counterpulse circuit consists of a capacitor, $C_{2}$, connected to each of the circuit breakers and a saturable inductor core, $\mathrm{L}_{2}$, surrounding one leg of the bus shown in Fig. 5. The energy of the capacicor bank of ail $\mathrm{C}_{2}$ 's is approximately 19 of the total stored energy of $500 \mathrm{MJ}$. The loop inductance of loop $\mathrm{C}_{2}-\mathrm{L}_{2}-\mathrm{S}_{1}-\mathrm{E}_{\mathrm{B}}$ and the requirement to bring the current to zero determine the size of $\mathrm{C}_{2}$. By properly sizing the flux of $\mathrm{L}_{2}$ and its magnetic circuit, the $t$ ime interval, $\Delta t$, is determined for holding the current near zero with two zero crossings. The arc clearing properties of the circuit breakers are, therefore, important quantities for optimizing the circuit cost because the flux of $L_{2}$ is proportional to $\Delta t^{2}$ as is the size of the counterpulse capacitor bank.

The repetition rate of the circuit is 100 per day. A one-year operating schedule is expected and inspection and replacement of the circuit breaker contacts is permissible at discrete operating intervals. It will no doubt be necessary to have two interchangeable sets of breakers available.

\section{B. Estimate of Inductances}

The TNS E-coil dimensions were obtained from Ref. 2 and are shown in Fig. 6. The plasma cross section was assumed to be rectangular witr a mean radius of $3.5 \mathrm{~m}$, radial thickness of $1.5 \mathrm{~m}$, axial height of $3.6 \mathrm{~m}$, and a uniform current distribution. Though basically nonrigorous, this assumption results in computed inductance values sufficient for computations witli constant "average" plasma resistance. Table II lists the inductance matrix elements for the geometry given.

TABLE II

One-Turn Inductance Matrix for E-Coil and Plasma

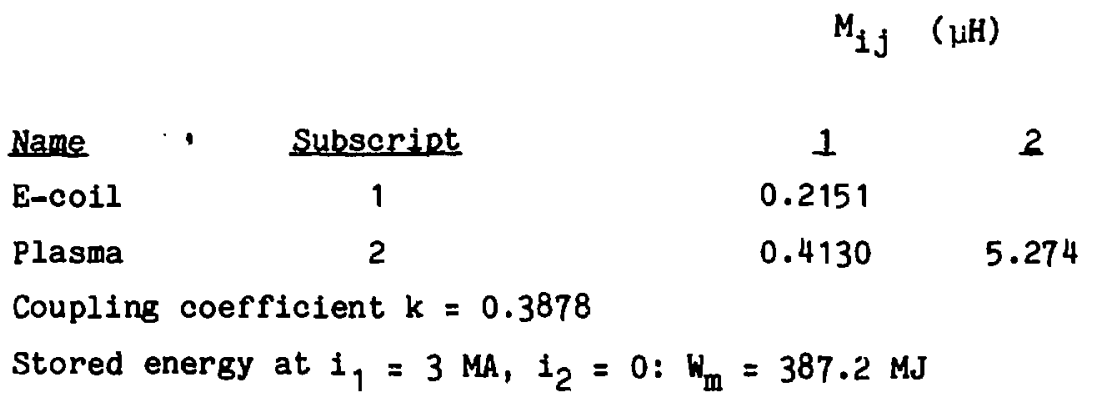




\section{Estimate of Average Plasma Registance}

For a given resistive vs requirement for the current reversal, 1.e., for 8 Vs, one may write

$$
\int R_{p} i_{p} d t=\left\langle R_{p}\right\rangle \frac{I_{p \max }}{2 \cdot \omega} \int_{0}^{\pi}(1-\cos \omega t) d(\omega t),
$$

there $I_{\mathrm{pm}}=10 \mathrm{MA}$ is the maximum plasma current and $\pi / \omega=2 \mathrm{~s}$, which yield $\left\langle R_{p}\right\rangle=0.8 \mu \Omega$.

\section{Estimate of - -Coll circult Resiatances}

The brush loss is estimated at approximately $2 \mathrm{MJ}$, which corresponds to an average resistance of $0.22 \mu \Omega$. We assume a total length of the connecting bus of $50 \mathrm{~m}$ and a copper cross section for the bus of $0.4 \mathrm{~m}^{2}$. For room temperature copper, this results in a resistance of $2.5 \mu \Omega$. We add to this $1 \mu \Omega$ for the connections yielding a total resistance for the E-coil circuit of $3.72 \mu \Omega$.

\section{E. Transformation to the E-Coif Winding}

Basis for the circuit analysis is the 20-turn primary side of the E-Coils. The plasma's one-turn base values of $L$ and $R$ may be transformed accordingly. The circuit values listed in Table III are then obtained.

TABLE III

20-Turn Based Circuit Values

$$
\begin{array}{lll}
C_{1}=4.687 \mathrm{kF}-\text { assumed constant } & \\
R_{1}=3.72 \mu \Omega & R_{2}=0.32 \mathrm{~m} \Omega \\
L_{1}=86.1 \mu \mathrm{H} & L_{2}=2.11 \mathrm{mH} \\
M=0.165 \mathrm{mH} &
\end{array}
$$

\footnotetext{
* See paper III of this report.
} 


\section{E. Currents and Voltages}

Currents and voltages during the $2-s$ current reversal are shown in Figs. 7-10. The plasma current is 20 times that shown in Fig. 8, because of the turns ratio, which woul', yield $8 \mathrm{MA}$ peak current. The integral of the plot of Fig. 9 is $21 \mathrm{Vs}$ if quoted on a one-turn basis.

For the same "average" plasma resistance, 6.7 Vs are required for the $28-9$ burn period with the plasma current rising from 8 to $10 \mathrm{HA}$ on a one-turn basis. From the currents in Figs. 7 and 8 , and the resistances in Table III, one obtains the resistance of the one turn equivalent LCR oircuit, $R_{\text {equiv }}=8 \mu \Omega$. Of the joule loss in that resistance, $53 \%$ is due to the plasma. For the resistance quoted in Table $I, 6.1 \mu \Omega$, the assumptions were that the bus measured $0.7 \mathrm{~m}^{2}$ and the contact resistance was $0.2 \mu \Omega$.

\section{G. Reversed Amplitude Control}

Control of the amplitude of current at the end of the current reversal is possible by brush motion as pointed out in the section on numerical integration (II A). Figure 11 shows a feedback diagram of this method. At some reference times during the 2-s reversal, the current is sampled and compared with a reference signal for actuating the brush motion control. The effect of brush motion on the current level is shown in Fig. 4. Depending on whether the brushes are lifted or not, the rotor speed subsequent to the end of current reversal will have to be controlled either by braking or the burn supply voltage. The polarities are matched at the time the burn supply is switched into the circuit; hence, no series switch is needed for the homopolar. The brushes may be lifted once the homopolar has reached the burn supply voltage during the 28-s phases 3 and 5 .

\section{REFERENCES}

1. Reinhold Riudenberg, "Transient Performarce of Electrical Power Systems," MIT Press 1969, Chapter III.18.a.

2. Project Staffs, General Atomic Company and Argonne National Laboratory, "TNS Scoping Studies, Interim Status Report for the First Half of FY77 October 1, 1976-March 1, 1977", General Atomic Report GA-A 14412 UC 20. 


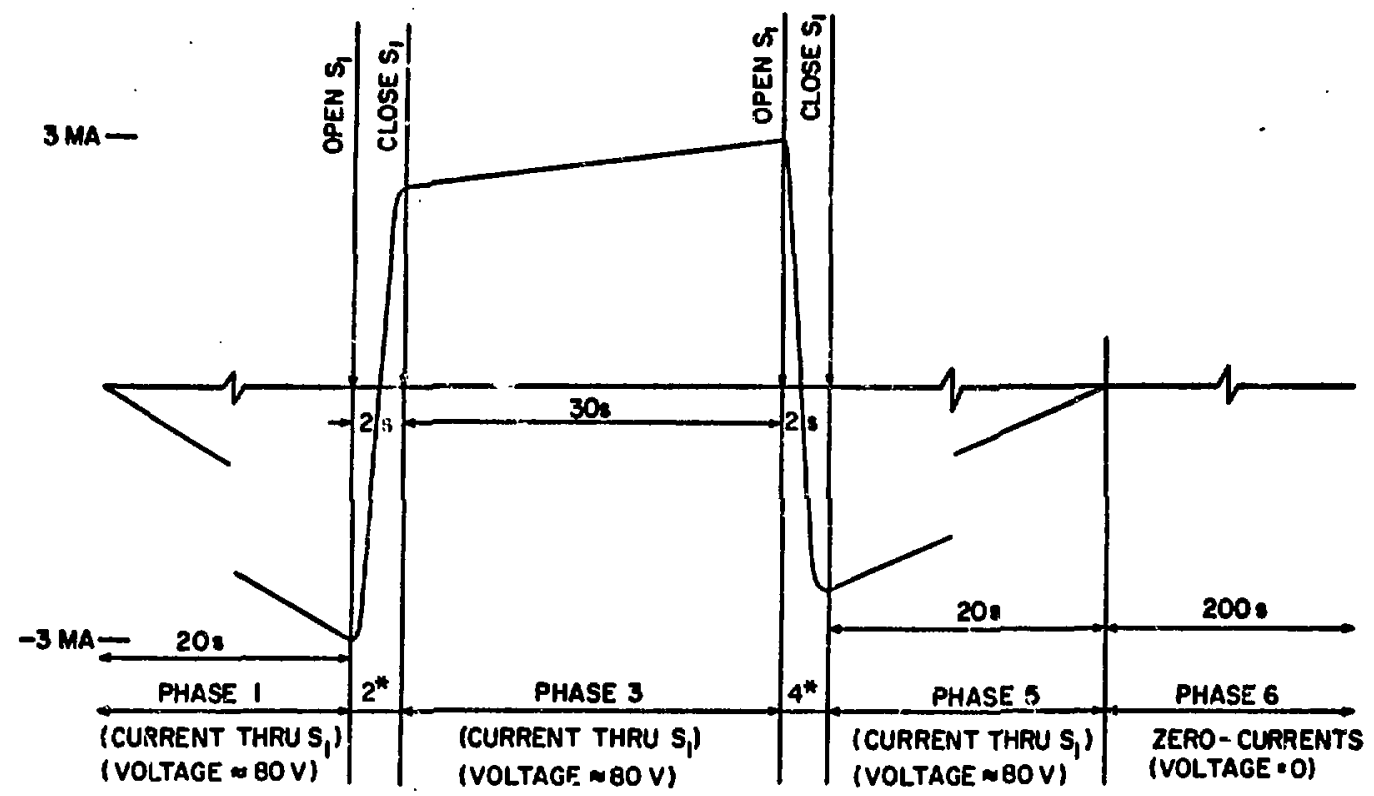

* CurRent $=0$ in S, DURING Phases 2 and 4 , The voltage $4400 \mathrm{~V}$

Fig. 1. TNS Doublet pulse cycle, E-coil current vs time.

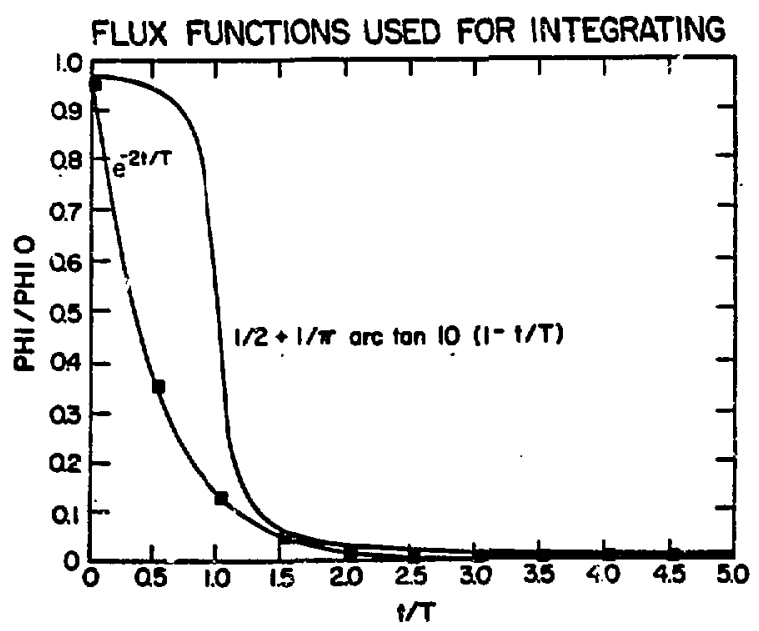

Fig. 2. Flux functions used for the circuit analysis. (These flux functions are obtained by moving the current collecting brushes defining the effective flux in the homopolar.)

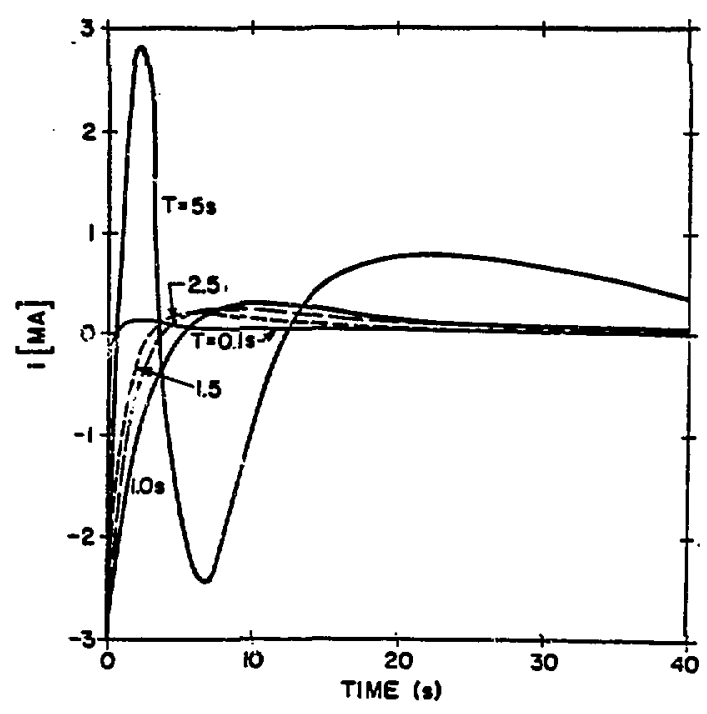

Fig. 3. Parametric plot of the current in the TNS circuit with a homopolar machine whose effective flux is changed according to $\phi \approx \phi_{0} \exp (-t / T)$ where $T$ is the parameter. 

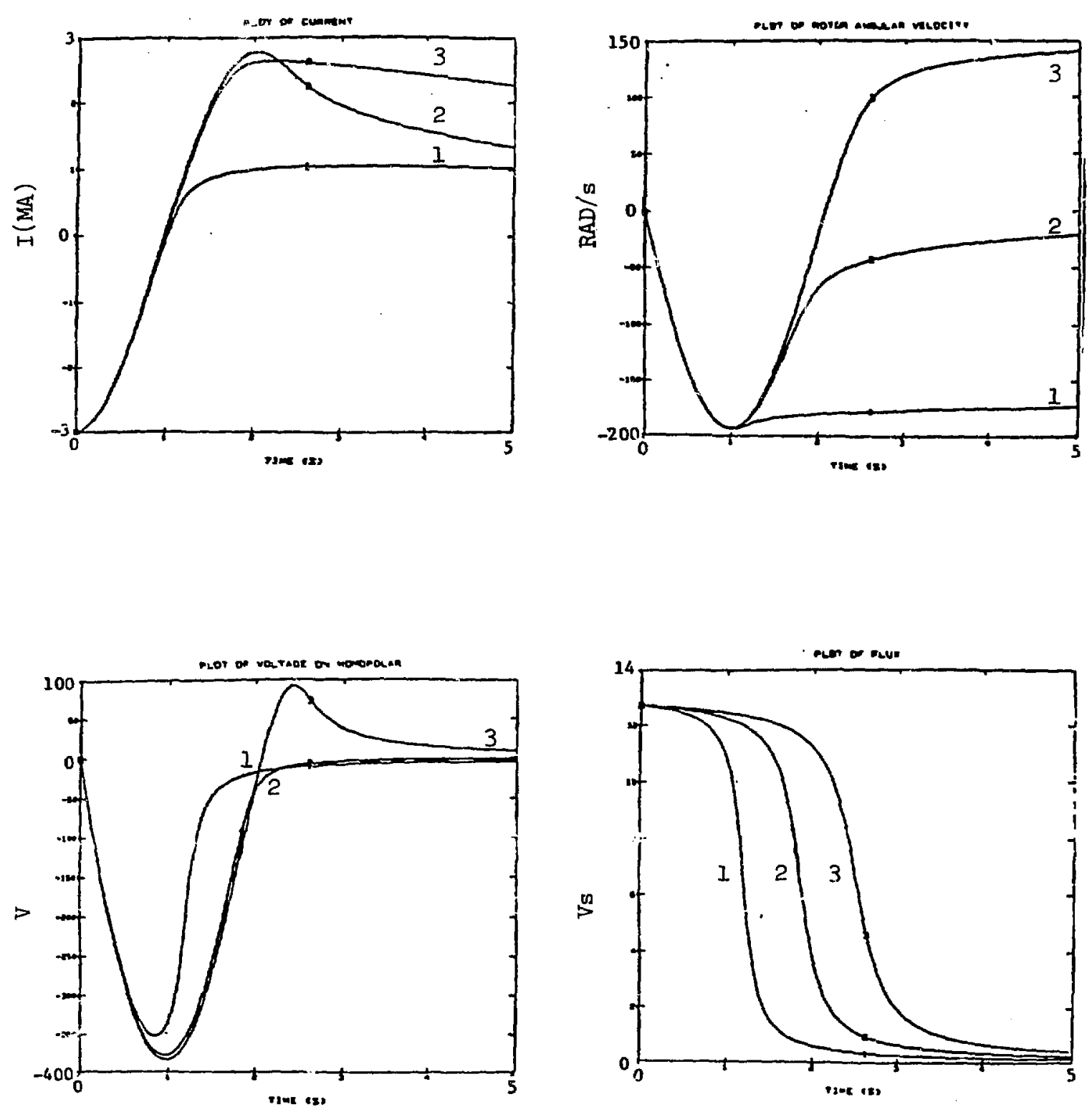

Fig. 4. Variables as function of time of the TNS circuit and the homopolar machine.

a) Current (A)
b) Angular velocity of the homopolar $\left(\mathrm{s}^{-1}\right)$
c) Terminal. voltage of the homopolar (V)
d) Effective flux (Vs) of the homopolar The curves labeiled 1,2 , and 3 refer to the flux functions with $T=1.2,1.85$, and $2.5 \mathrm{~s}$, respectively. 
30 TRANSPOSED EUSES FOR 3 MA WITH

COMMON SATURATING CORE, $0.16 \mathrm{~m}^{2}$ CROSS-SECT.

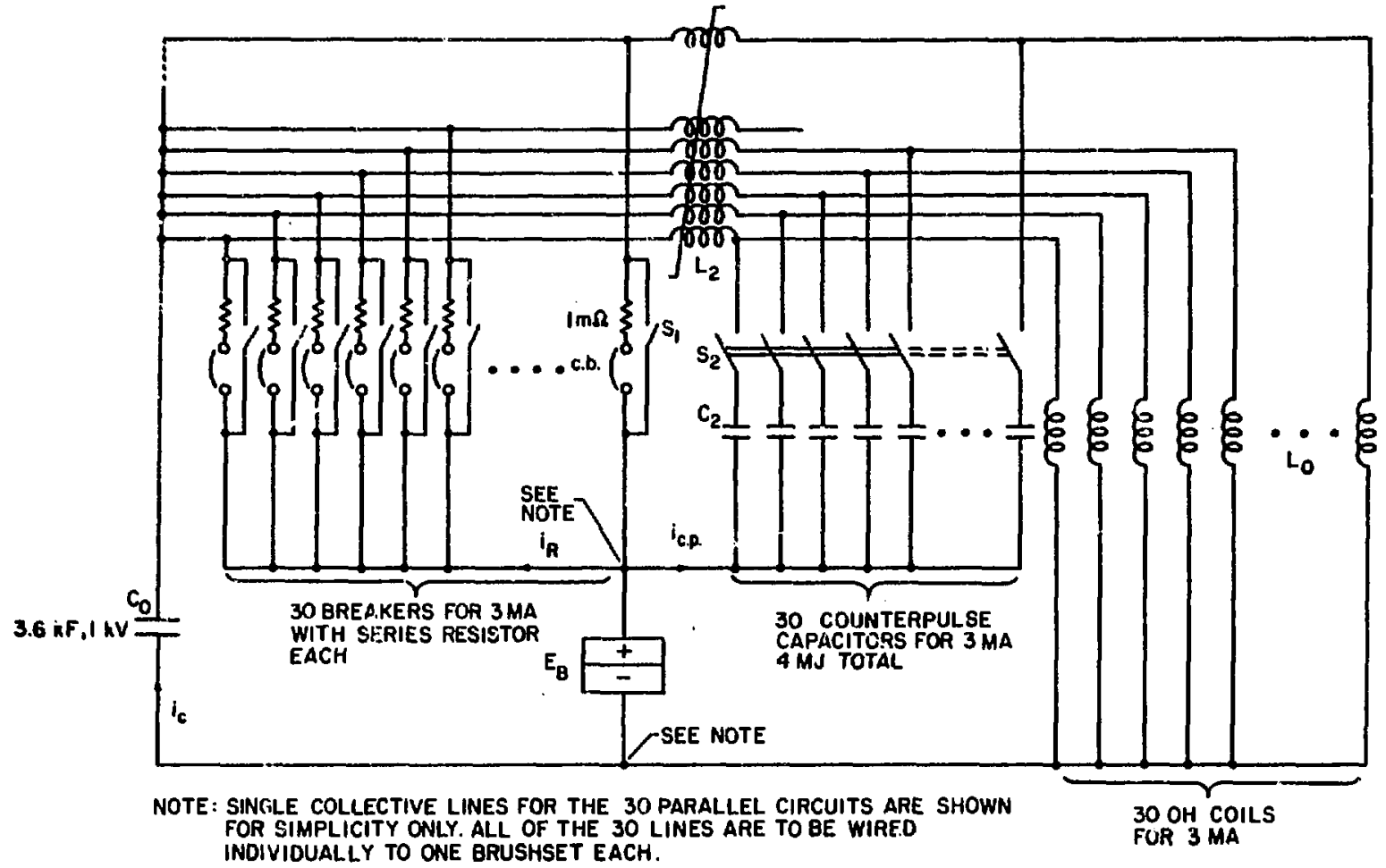

Fig. 5. Circuit diagram for TNS Doublet with burn supply homopolar $E_{B}$.

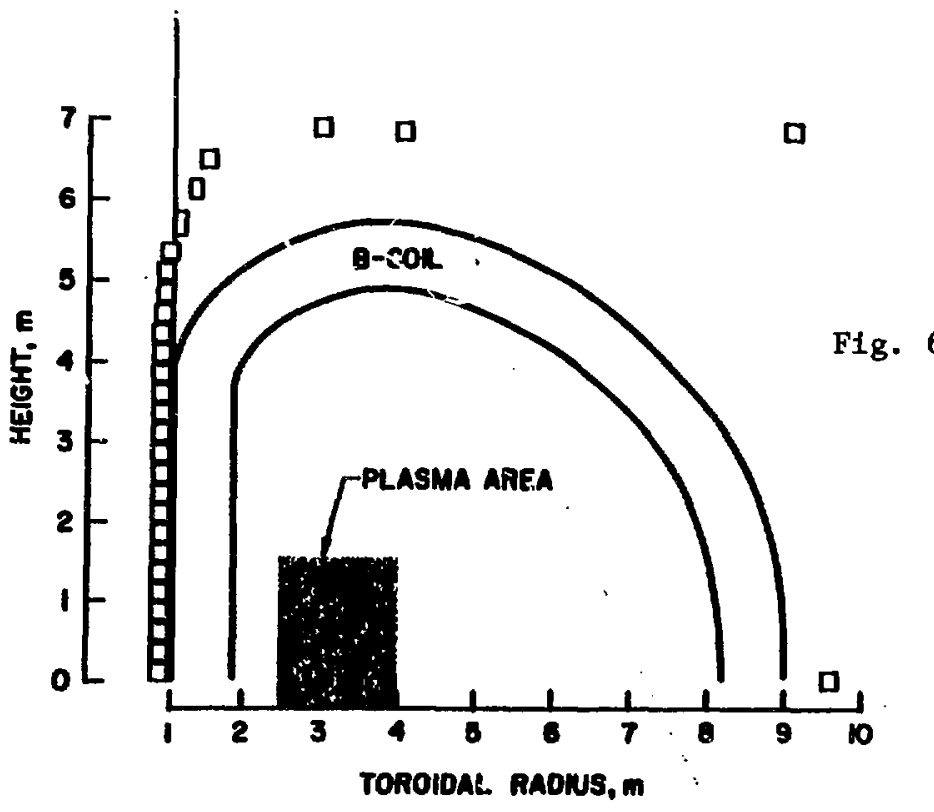

ig. 6. Configuration of the TNS Doublet used for determining the magnetic coupling. 


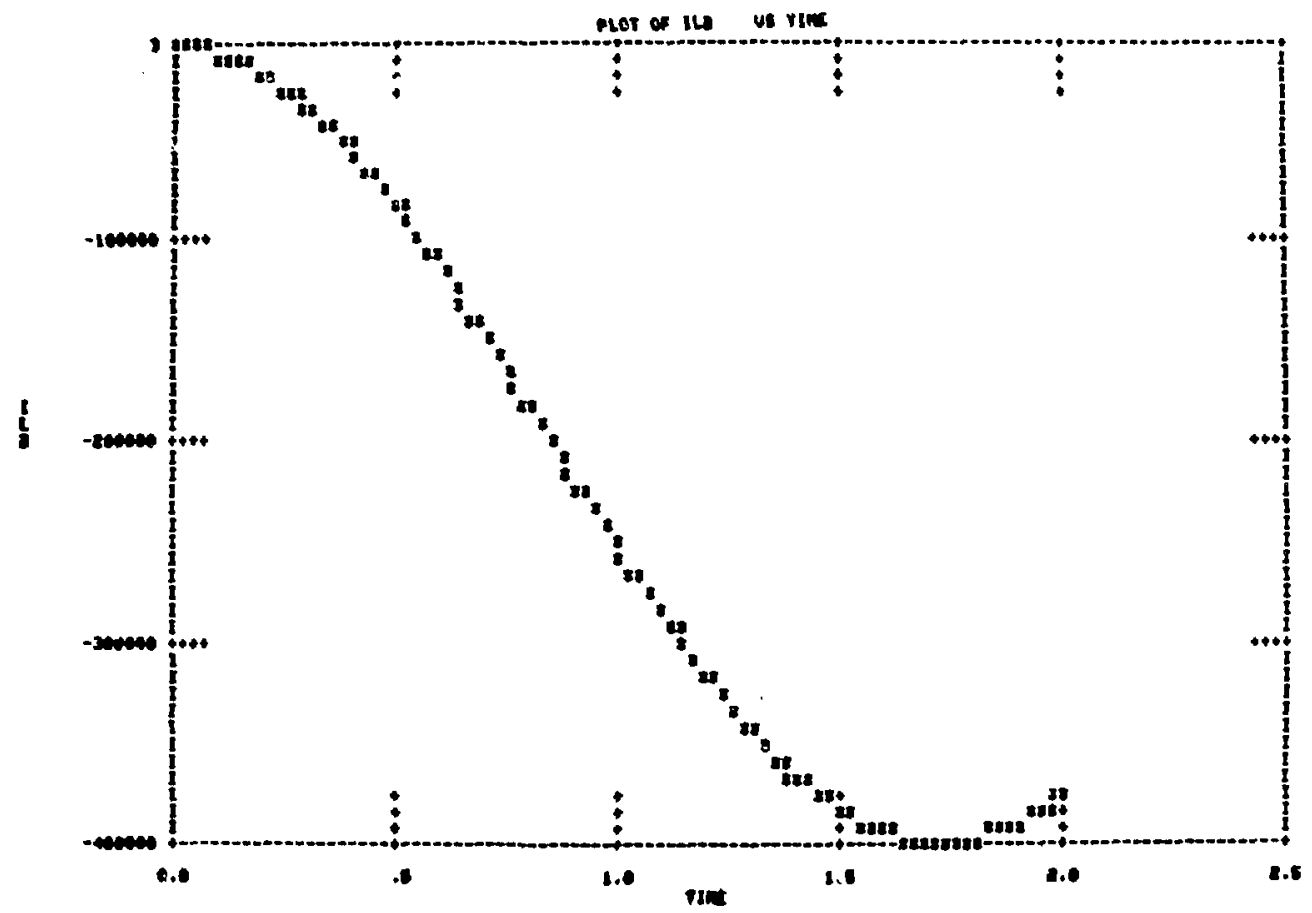

Fig. 7. Plot of the E-coil current for the 2-s current reversal at constant capcitance.

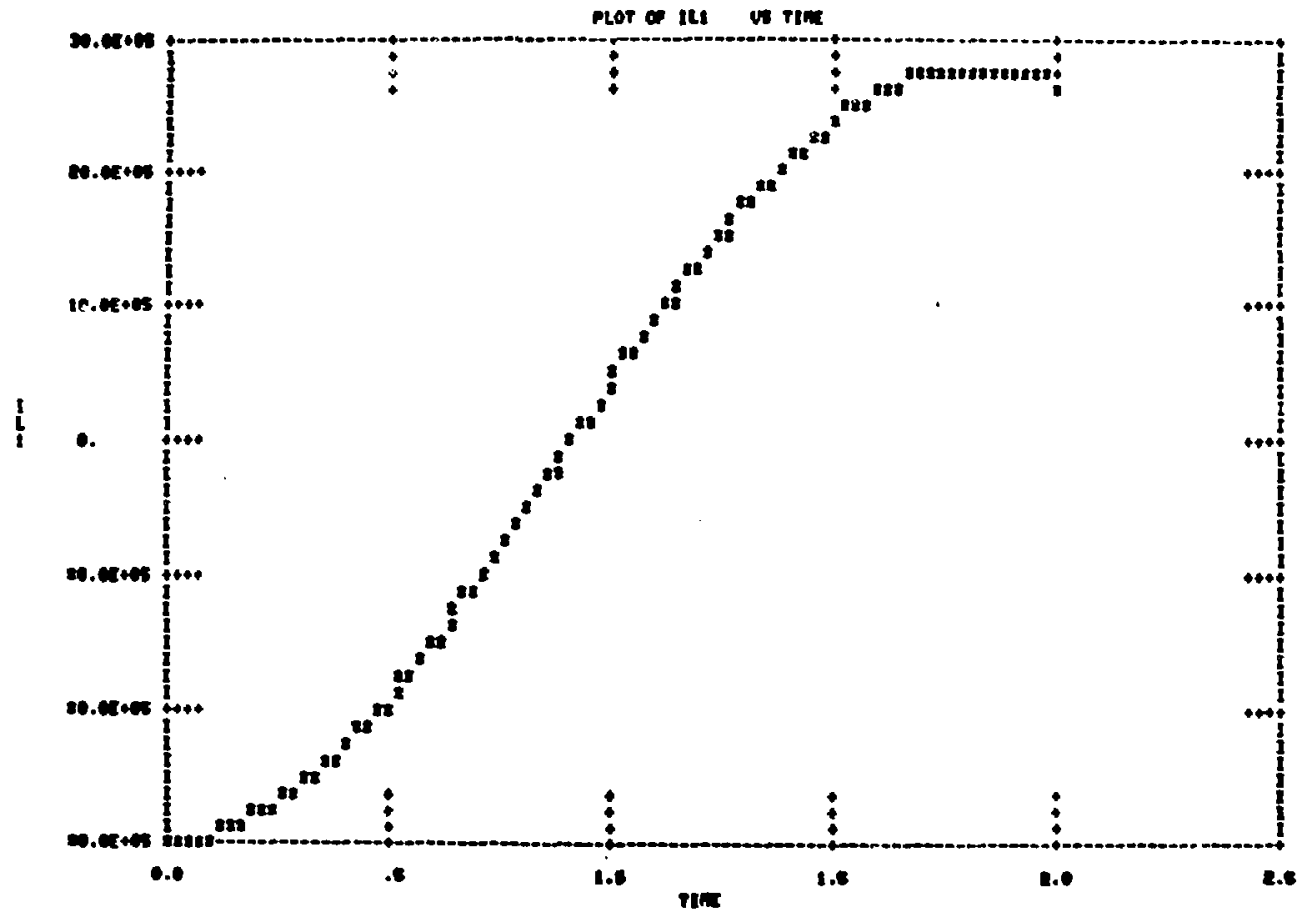

Fig. 8. Plot of the plasma current for the 2-s current reversal at constant capacitance and on the 20 turns basis of the E-coil. 


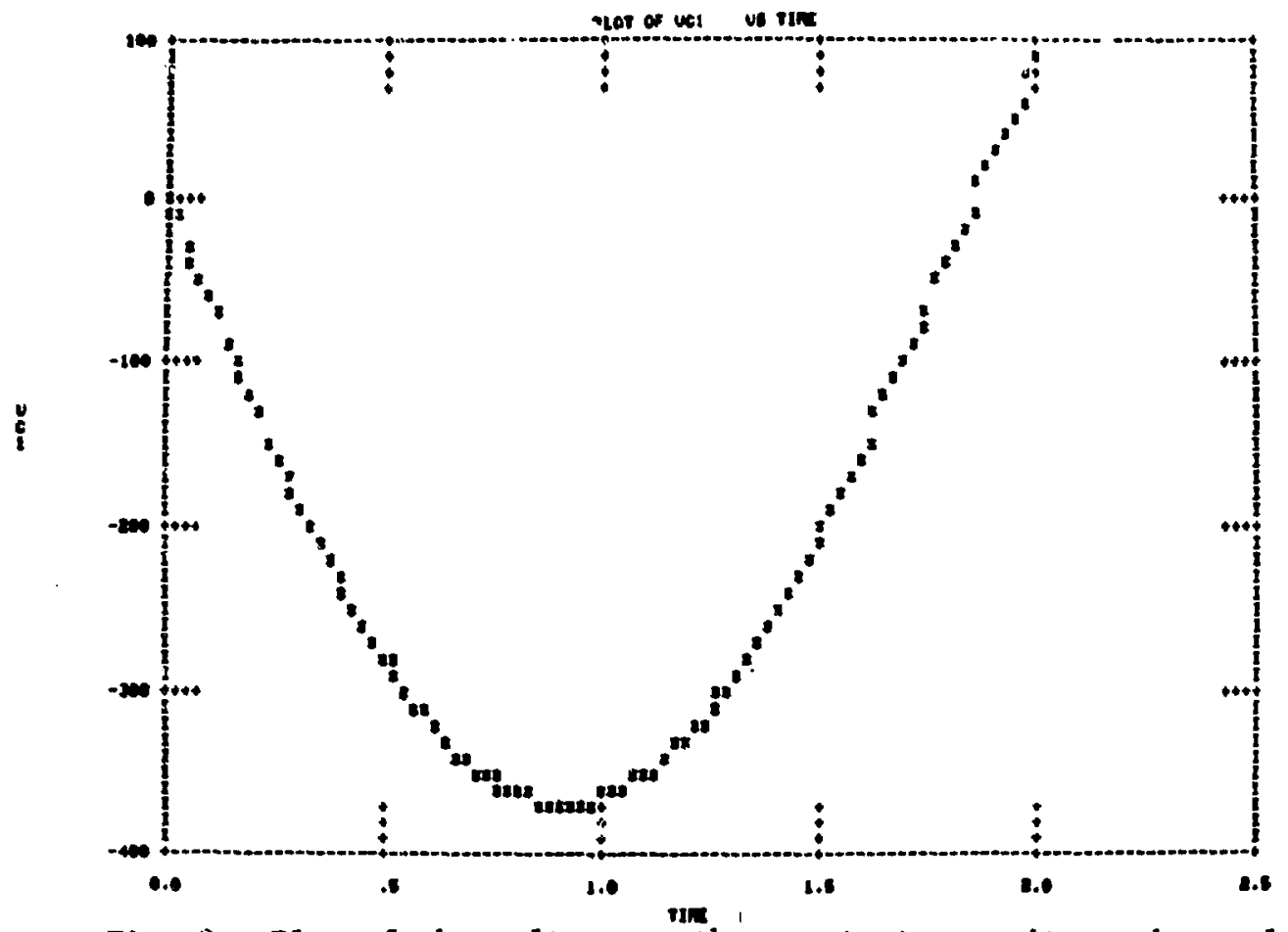

Fig. 9. Plot of the voltage on the constant capacitance homopolar during the 2-s current reversal.

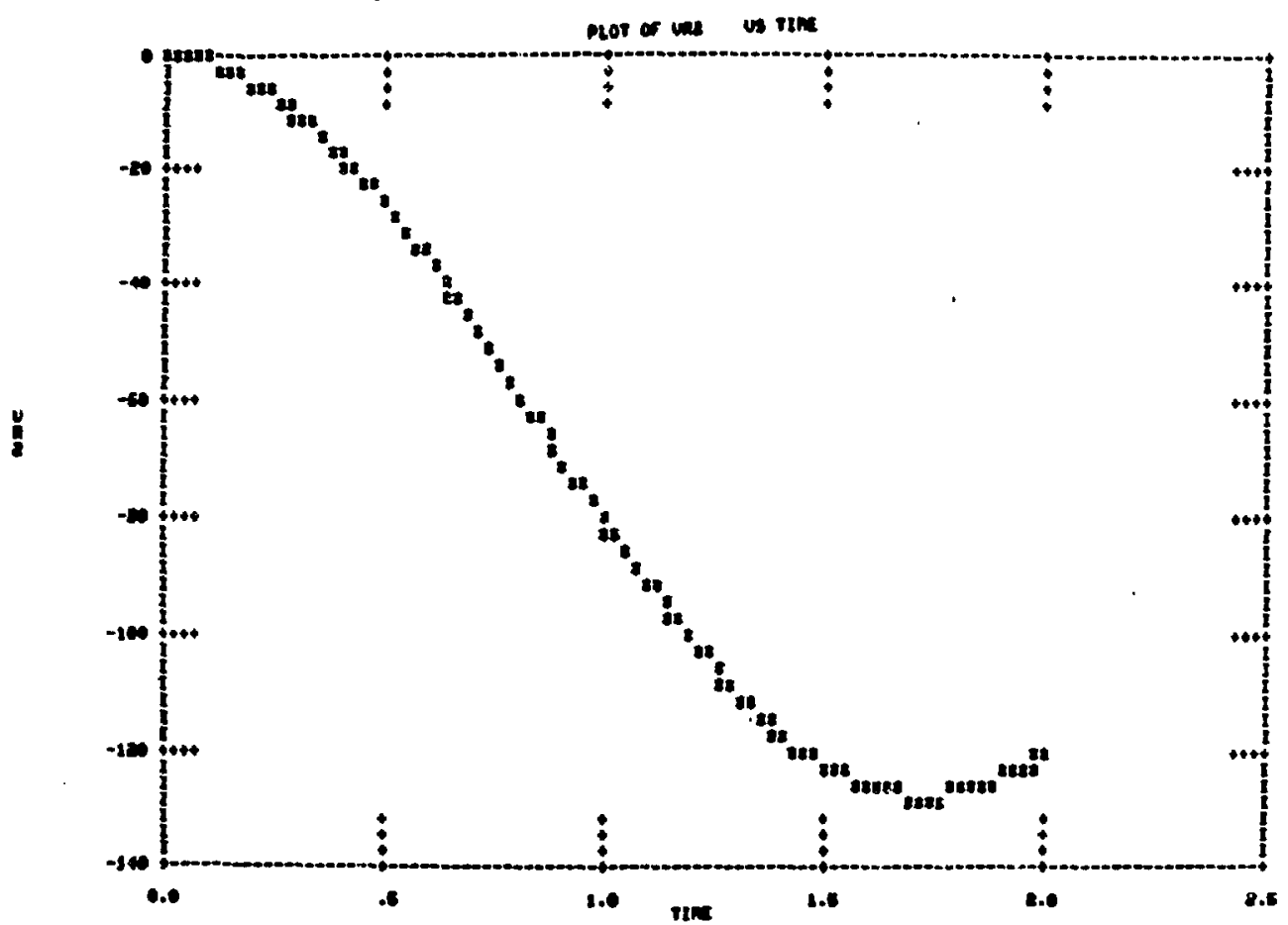

Fig. 10. Plot of the plasma voltage (multiplied by 400 for the 20 turns E-coll basis) during the $2-s$ current reversal at constant capacitance. 


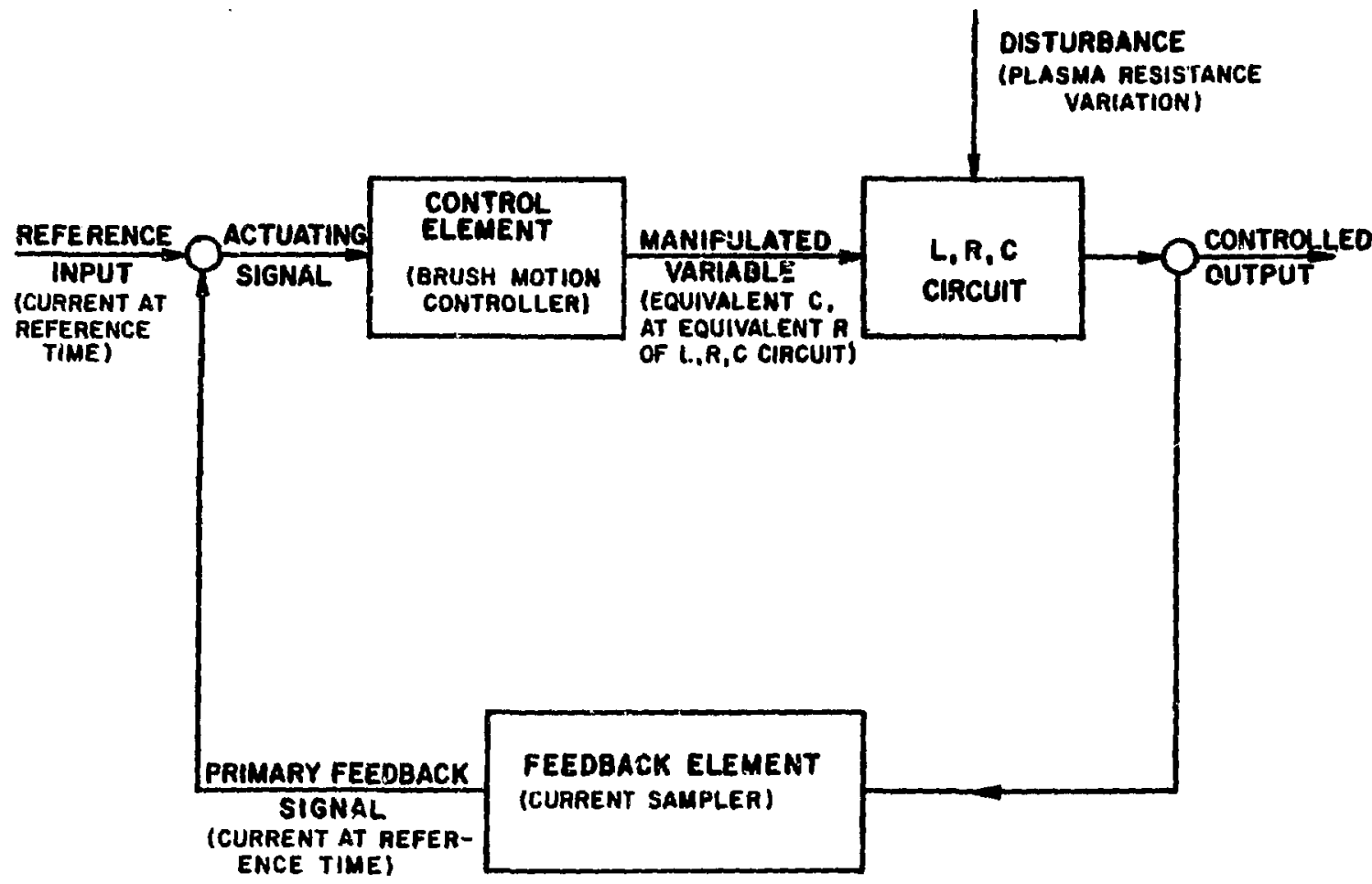

Fig. 11. Block diagram of the feedback control circult for current level control at the end of the 2-s curren reversal. Current samples are taken during the reversal period so the desired controlled output of current vs time is approximated. 
II. DAMPED LC CIRCUIT FOR THE OHMIC-HEATING COILS OF TNS DOUBLET

by

\author{
H. F. Vogel
}

\title{
ABSTRACT
}

Equations for the currents and voltages of a damped LC circuit are reviewed for the two conditions of (a) the initially charged capacitor and (b) the initially charged inductor. The energy transfer efficiency, maximum voltage, and resistance are plotted for the TNS case with 2-s energy transfer time, 500-MJ inductive energy and current maxima of 1,2, and $3 \mathrm{MA}$. The brush loss is calculated for the case that the capacitor is a homopolar maohine.

\section{INTRODUCTION}

The state variables of the LC circuit shown in Fig. 1 are considered for two different sets of their initial conditions. These are the set $(a)=\left(v_{c}=\right.$ $\left.v_{\max }, 1=0\right)$ and the set $(b)=\left(v_{c}=0, i=I_{\max }\right)$. The differential equation for the circuit of Fig. 1 can obviously be written as

$$
\ddot{i}+2 \delta \dot{i}+\omega_{0}^{2} i=0,
$$

where $i$ is the current whose time derivatives are indicated by dots and where

$$
\delta=\frac{R}{2 L}
$$

and

$$
\omega_{0}=(L C)^{-1 / 2}
$$


The integrals of Eq. (1) are easily obtained for the stated sets of initial conditions.

II. CASE (a): INITIAL ENERGY IN THE ELECTROSTATIC FIELD

For the set (a) in which all energy rests initially in the electrostatic field, the integral of Eq. (1) is given by

$$
i=\frac{V_{\max }}{\omega L} e^{-\delta t} \sin \omega t,
$$

where

$$
\omega=\left(\omega_{0}^{2}-\delta^{2}\right)^{1 / 2}
$$

Imaginary values are assumed by $\omega$ in the overdamped case $\omega_{0}^{2}-\delta^{2}<0$. The voltage $v_{c}=\frac{1}{c} \int i d t$ may be obtained in the convenient form

$$
\mathbf{v}_{c}=\mathbf{v}_{\max } \frac{\omega_{0}}{\omega} e^{-\delta t} \sin (\omega t+\alpha)
$$

where

$$
\alpha=\arctan \frac{\omega}{\delta}
$$


So that $\alpha$ is uniquely determined, Eq. (7) 1s rewritten with the principal value

$$
\alpha=\pi-\operatorname{Arc} \tan \frac{\omega}{\delta} \equiv \pi-\operatorname{Arcsin} \frac{\omega}{\omega_{0}}
$$

where $\pi$ is needed for a physically realizable system consistent with our premise that all energy rests in the electrostatic field for $t=0$. Substitution of Eq. (8) in Eq. (6) yields

$$
v_{c}=v_{\max } \frac{\omega_{0}}{\omega} e^{-\delta t} \sin \left(\omega t-\operatorname{Arc} \sin \frac{\omega}{\omega_{0}}\right) .
$$

Equations (6) and (9) may be written in the alternative form satisfying the physically reallzable system with our initial conditions

$$
v_{c}=-v_{\max } e^{-\delta t}\left(\frac{\delta}{\omega} \sin \omega t-\cos \omega t ! .\right.
$$

From the general theory of elementary functions, it is known that the principal
value Arc $\tan z$ of the infinitely many-valued function $W=$ arc $\tan z$ means the
function values in the str-ipe $-\frac{\pi}{2}<\operatorname{Re}(W) \leq \frac{\pi}{2}$. Equation (9) 1s thus valid for $-\infty<\omega_{0}^{2}-\delta^{2}<\infty$. The physically meaningful range of $\omega$ is thus entirely included. Use the identity Arc $\tan z=-\frac{j}{2} \log \frac{1+j z}{1-j z} \equiv-\frac{j}{2} \ln \left|\frac{1+j z}{1-j z}\right|+$ $+\frac{1}{2} \operatorname{arc} \frac{1+j z}{1-j z}= \begin{cases}\text { Arc } \tan x & \text { for } z=x=\text { real } \\ -\frac{J}{2} \ln \frac{1-y}{1+y} & \text { for } z=j y=\text { imaginary. }\end{cases}$

Similarly, Arc $\sin z=\left\{\begin{array}{l}\text { Arc } \sin x \text { for } z=x=\text { real } \\ -j \ln \left(\sqrt{1+y^{2}}-y\right) \text { for } z=i y \text { 1maginary }\end{array}\right.$

Note that, $\sin (\pi+j \Omega t-j \phi)=j \sinh (\Omega t-\phi)$, and $\sin (j \Omega t+j \phi)=j \sinh (\Omega t+\phi)$, where $\phi \equiv \operatorname{Arctan}(\omega / \delta)$. 
Setting the first derlvative of Eq. (4) with respect to time equal to zero gives the maximum current

$$
I_{\max }=\frac{V_{0}}{Z} e^{\frac{-A r c}{\tan x}}
$$

for wt $=\operatorname{Arc} \tan x$ where $Z=\sqrt{L / C}$ is an abbreviation. Similarly,

$$
v_{m}=\left\{\begin{array}{l}
v_{\max } \text { for } t=0 \\
v_{\max } \exp \left(-2 \frac{\arctan x}{x}\right) \text { for } \omega t=\operatorname{Arctan} x
\end{array}\right.
$$

III. CASU (b): INITIAL ENERGY IN THE MAGNETIC FIELD AND EFFICIENCY CALCULATION For the set $(b)$ in which all energy rests initially, $1 . e$. , for $t \leq 0$, in the electromagnetic field, the integral of Eq. (1) is

$$
i=-I_{0} \frac{\omega_{0}}{\omega} e^{-\delta t} \sin (\omega t+\alpha)
$$

where $\alpha$ is given by Eq. (8). For the voltage $v_{c}=\frac{1}{c} \int 1 d t$, the solution is

$$
v_{c}=\frac{I_{0}}{\omega C} e^{-\delta t} \sin \omega t
$$

which shows the first maximum for $\dot{v}_{c}=0$ as

$$
\left(v_{c}\right)_{\max }=\frac{I_{0}}{\omega_{0} C} e^{-\operatorname{Arc} \tan x} \frac{}{x}
$$


Similarly, the current maxima are

$$
I_{m}=\left\{\begin{array}{l}
I_{\max } \text { for } t=0 \\
\cdot \\
-I_{\max } \exp \left(-2 \frac{\operatorname{Arctan} x}{x}\right) \text { for } \omega t=2 \operatorname{Arctan} x
\end{array}\right.
$$

where $x=\omega / \delta$, which is defined for $x>0$.

The similarity between the integrals obtained for the two different sets of initial conditions (a) and (b) should be noted. The energy transfer efficiencies are thus identical, which can easily be verified by calculating $\left(V_{m} / V_{\max }\right)^{2}$ from Eq. (12) and $\left(I_{m} / I_{\max }\right)^{2}$ from Eq. (16) where both yield the half-cyole effictency

$$
n_{1 / 2}=\exp \left(-4 \frac{\operatorname{Arctan} x}{x}\right) \text {, }
$$

which is defined for $x>0$. Similarly, we get for the quarter-cycle efficiency from Eq. (11) or Eq. (15)

$$
n_{1 / 4}=\exp \left(-2 \frac{\operatorname{Arctan} x}{x}\right)
$$

Figure 2 shows currents and voltages plotted as a function of time for the osolllatory cases of the two sets of initial conditions discussed. Some of the Eqs. (1) through (18) are repeated in Fig. 2 for convenience.

IY. NUMERICAL EVALUATION OF THE OSCILLATORY CIRCUIT

Flgure 3 shows a plot of the maximum voltage on $c, v_{0}$, and of the circuit resistance $B$ over the transfer efflciency for the Initial conditions set (b), which is the set of interest for TNS ohmic heating. Transfer time and 
efficiensy are defined in accordance $w 1$ in the current reversal $t i m e, T=2 / \omega$ Arc tan $(\omega / \delta)$ with $T=2 \mathrm{~s}$. The magnet1c energy at time $t=0$ is $W=500 \mathrm{MJ}$. The maximum current $I_{\max }$ is a parameter, $1 . e . I_{\max }=1,1.5,2,3 \mathrm{MA}$.

Figure 4 shows the estimated brush loss plotted over the same abscissa as that of Fig. 3. This brush loss is for two series-connected sets of parallel brushes as they might be if a homopolar machine were used as a capacitor. The brushes are of the high current, continuous duty type tesied for the Advanced Research Projects Agency (See Ref. 5 of the paper In this report on "Homopolar Machine Design"). Those brushes are made of silver-graphite with a wear rate of $10.5 \mathrm{~mm}$ per $\mathrm{Mm}$ of slide. The voltage drop $\Delta V$ versus current characteristic assumed in calculating the brush loss is shown in Fig. 5 for a current density of $2.33 \mathrm{~A} / \mathrm{mm}^{2}$ corresponding to $I_{\max }$. The curves in Fig. 4 are obtained by numerical integration of

$$
\int_{0}^{\frac{2}{\omega}} \operatorname{Arctan} x d v \perp d t
$$

where i is given by Eq. (13).

The brush loss plotted in Fig. 4 shows an increase with increasing circuit efficiency. This can be explained easily as follows. The current increases with increasing energy transfer efficiency similarly as seen for Vo in Fig. 3 , and the brush voltage drop is approximately $0.15 \mathrm{~V}$ over a substantial range in current as seen in Fig. 5 .

The brush losses are not very significant in terms of the total circuit loss. They are very significant, however, in their absolute magnitude, which may cause a brush cooling problem. 


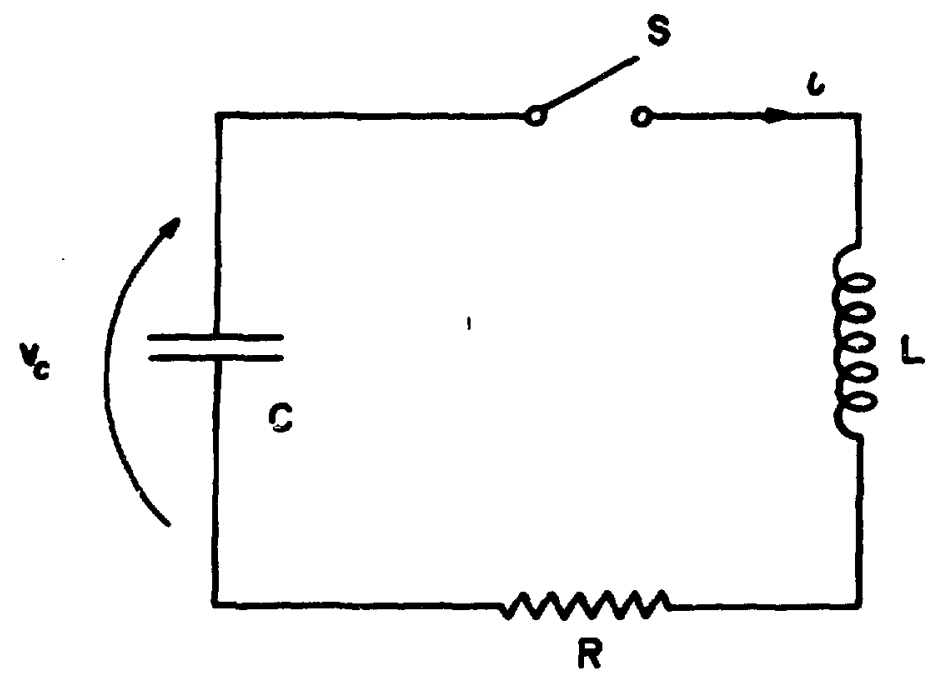

Fig. 1. Diagram for the LC circuit equivalent of the homopolar machine connected to the tokamak transformer. 


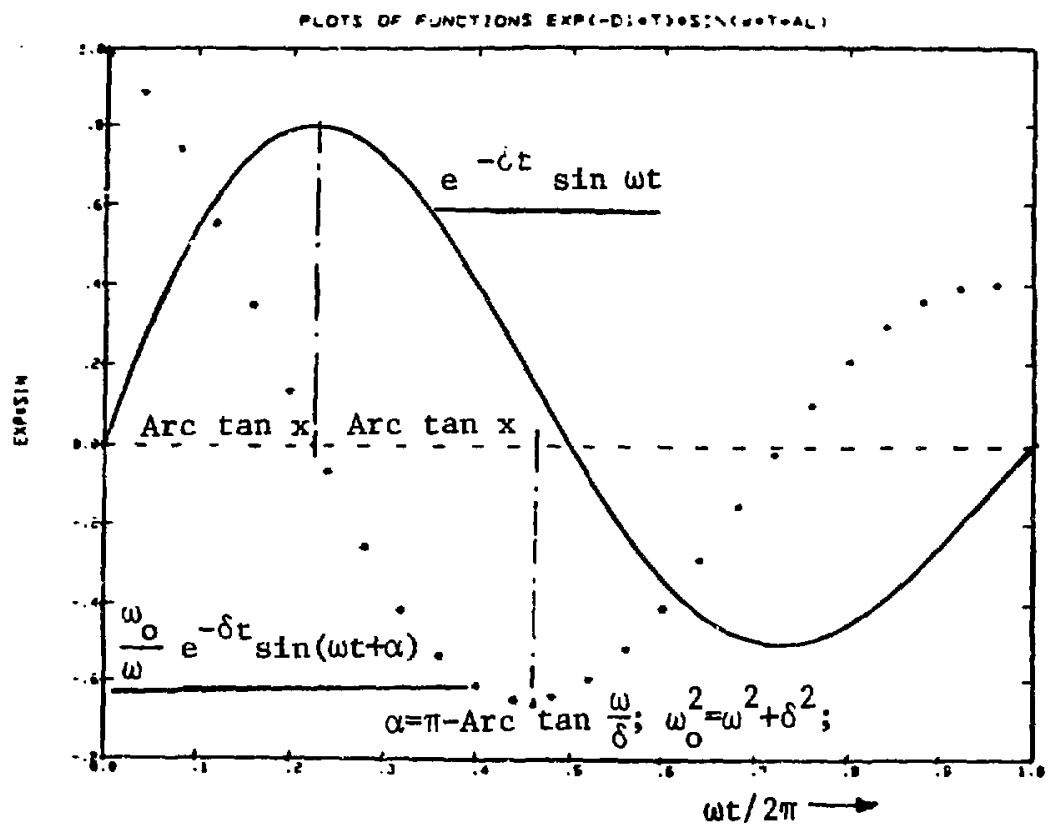

$$
\begin{aligned}
& \text { Case (a) } \\
& I=\frac{v_{\max }}{\omega L} e^{-\delta t} \sin \omega t \\
& v_{c}=v_{\max } \frac{\omega_{o}}{\omega} e^{-\delta t} \sin (\omega t+\alpha) \\
& I_{\text {mi }}=\frac{V_{\text {max }}}{Z} \exp \left(-\frac{\operatorname{Arctan} x}{x}\right) \text { for } \\
& v_{m}=\left\{\begin{array}{cc}
\omega t=\operatorname{Arc} \tan x \\
v_{\max } & \text { for } \omega t=0 \\
-v_{\max } & \exp \left(-2 \frac{\operatorname{Arc} \tan x}{x}\right) \text { for }
\end{array}\right. \\
& \omega t=2 \operatorname{Arctan} x \\
& z=\sqrt{L / C} \quad x=\omega / \delta \\
& I=I_{\max } \frac{\omega_{0}}{\omega} e^{-\delta t} \sin (\omega t+\alpha) \\
& v_{c}=\frac{I_{\max }}{\omega C} e^{-\delta t} \sin \omega t \\
& I_{m}= \begin{cases}I_{\max } & \text { for } t=0 \\
-I_{\max } & \exp \left(-2 \frac{\operatorname{Arc} \operatorname{ten} x}{x}\right) \text { for }\end{cases} \\
& \omega t=2 \text { Arc } \tan x \\
& v_{m}=I_{\max } z \exp \left(-\frac{\operatorname{Arc} \tan x}{x}\right) \text { for } \\
& \omega t=\operatorname{Arc} \tan x
\end{aligned}
$$

Fig. 2. Plot of the normailzed atate variables in the damped LC circuit. Coliection of formulae. 


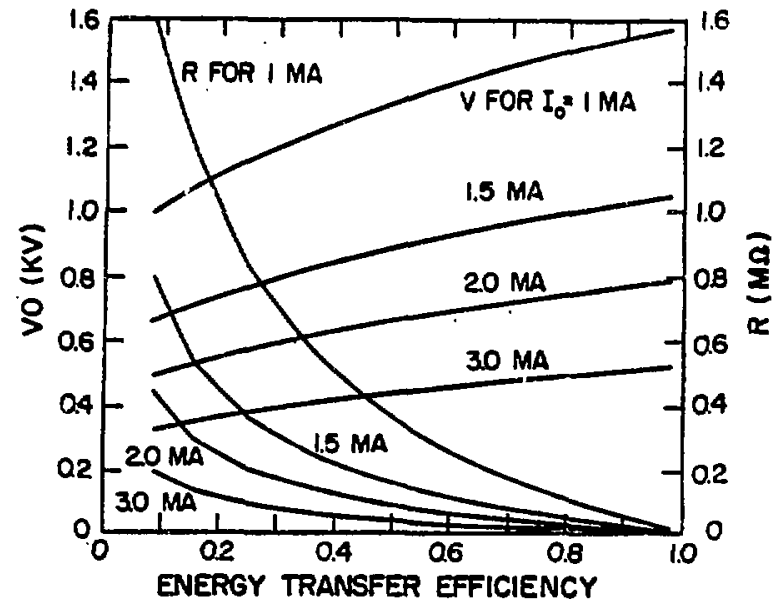

Fig. 3. Maximum voltage $v_{0}$ and resistance $\mathrm{R}$ plotted as a function of the energy transfer efficiency, $\eta_{1 / 2},(v . E q .17)$. Note the unit for resistance is the $\mathrm{m} \Omega$ and is based on the 500-MJ circuit with $\mathrm{T}=2 \mathrm{~s}$.

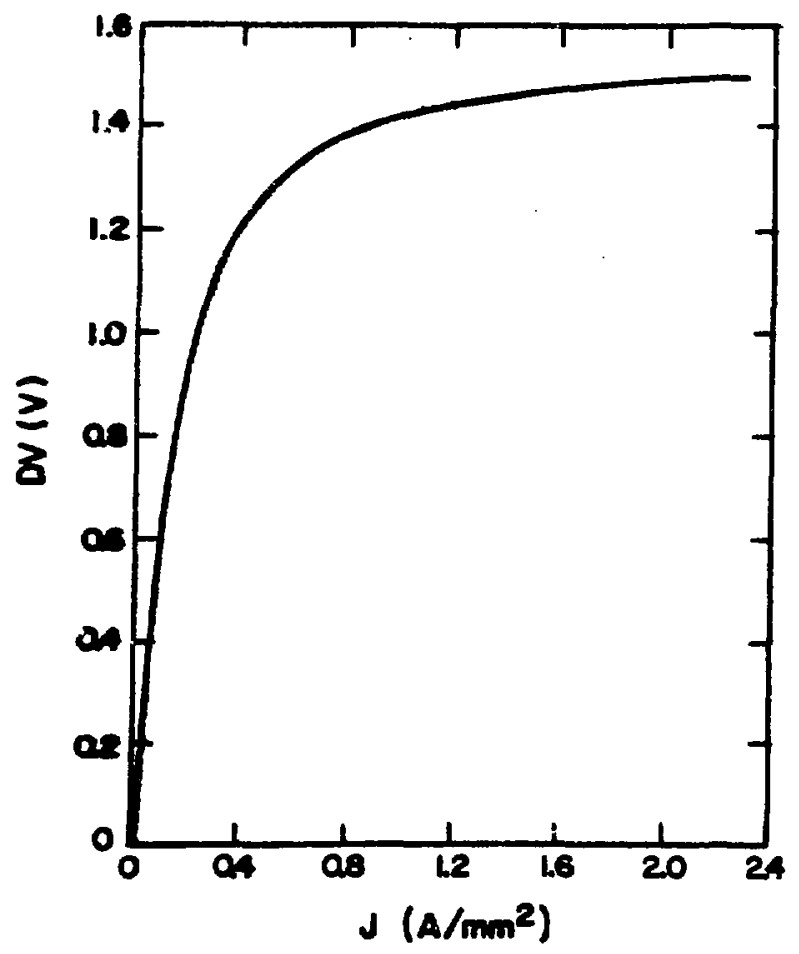

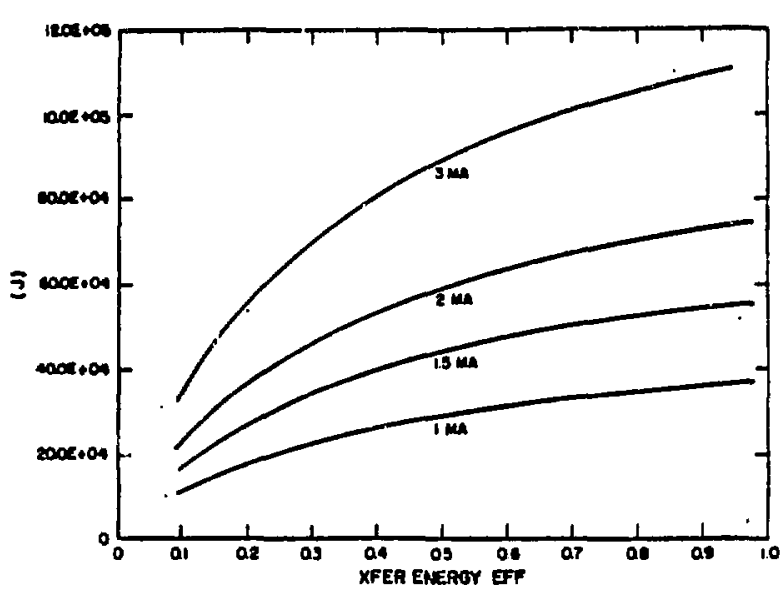

Fig. 4. Brush loss as a function of the energy transfer efficiency, $\eta_{1 / 2}$, (v. Eo. 17) based on the 500-MJ circuit with $\mathrm{T}=2 \mathrm{~s}$. Note the ordinate unit is the J (joule).
Fig. 5. Brush voltage drop function used for the brush loss calculations. 
III. HOMOPOLAR MACHINE' DESIGN

by

P. Thullen

\begin{abstract}
A general conceptual design for a disc-type homopolar machine is presented. This machine uses a superconducting, aj.r-core, solenoidal field winding with a peak field of $8 \mathrm{~T}$. A total energy of $500 \mathrm{MJ}$ is stored in two counter-rotatirg disc rotors that operate at a surface speed of $200 \mathrm{~m} / \mathrm{s}$. Terminal voltages of 500 to $2000 \mathrm{~V}$ are obtained over the range of designs studied. Brush systems to collect $3 \mathrm{MA}$ are investigated. Various brush materials are discussed to determine their usefulness in this application. Sufficient information on operating characteristics in high-power applications is only available for copper-graphite brushes. The use of sliding brushes for terminal voltage regulation is discussed. This feature cannot provide a great deal of flexibility in this particular application although it may be useful during start-up. The brush system is the most demanding feature of this design. Few systems in the million ampere range have been constructed, consequently, it is not possible to predict the behavior of this brush system with great certainty. A detailed design of the brushes should be undertaken. It is estimated that the cost of such a machine will range from 0.5 to 1.5 cents per joule.
\end{abstract}

I. INTRODUCTION

This section discusses the design of an air core, disc type homopolar machine. The machine employs two counter rotating discs, which store a total of 500 MJ. Significant features of the design are an unusually high average magnetic field provided by superconducting field coils and sliding brushes that interconnect the discs and provide some measure of control of the terminal voltage. In effect, the sliding brushes allow the machine to function as a power amplifier over some range of operation. Major components of the machine are the rotor, the field coils, and the brush system. The rotors are solid cylindrical metallic discs. The coils are a split solenoidal pair. The current colleci ion system and, in particular, the sliding brush system represent the most difficult design problem. The high cost of silver may require the use of copper graphite brushes rather than silver graphite or carbon fiber brushes. 
The design of an iron-dominated homopolar machine with copper excitation coils, based on the design of the TEXT ${ }^{1}$ machines is presented in the following paper of this report. This design has been produced by the center for" Electromechanics at The University of Texas at Austin. Presented in this paper are fundamental corsiderations, design assumptions, general trends, point designs, and. brush design fundamentals for the superconducting homopolar machine. All of this information is based on a comprehensive computer design code. The code calculates field coll constants, the field distribution, and the voltage distribution on the rotor surface. A check case for the coll design section of the program is included.

II. BASIC CONFIGUNATION, SUPERCONDUCTING MACHINE

Homopolar machines can be made to function as capacitors in resonant circuits. They are attractive in such applications because they are anticipated to be less expensive than static capacitors and do not require controllable rectifiers as do ac machines.

Perhaps the most famous homopolar capacitor is the machine at the Australian National University, Canberra, Australia. ${ }^{2-4}$ That machine uses two counter-rotating, mild steel discs to store a total of $560 \mathrm{MJ}$. Each rotor is $1.83 \mathrm{~m}$ in diameter and weighs $3.64 \times 10^{4} \mathrm{~kg}$. Maximum tip speed $1 \mathrm{~s} 172 \mathrm{~m} / \mathrm{s}$ and the average magnetic field is $1.72 \mathrm{~T}$. This produces a terminal voltage of $450 \mathrm{~V}$ when consideration is taken of the brush locations. The energy may be taken out electrically in a time as short as a second or as long as a minute or more. In the former case currents of up to $1.6 \mathrm{MA}$ are drawn from the machine.

Various currrent collection systems, both liquid metal and solid, have been employed on this machine. Presently solid copper-graphite brushes are used.

Sliding brushes, as shown in Fig. 1, were installed and operated at one time. The average current density in the sliding brushes was $1.8 \times 10^{6}$ $\mathrm{A} / \mathrm{m}^{2}\left(1160 \mathrm{~A} / \mathrm{in} .^{2}\right)$ with a corresponding contact drop of $0.17 \mathrm{~V}$ per brush and a friction coefficient of 0.2 . A brush load of $1.96 \times 10^{-2} \mathrm{~N} / \mathrm{A}$ was required to prevent sparking. The combined losses amounted to $0.29 \mathrm{MH} / \mathrm{m}^{2}$. The enirire installation carried up to $26 \mathrm{kA}$. On this basis, 115 identical installations would be required to collect $3 \mathrm{MA}$. Unfortunately, the brushes were destroyed w'thin one year of their installation and have never been replaced. Marshall 4 gives many important details of their design and construction in one of his reports. 
The machine design described herein has many features similar to the Canberra machine It employs two counter-rotating discs with brush positions as shown in Fig. 1 . Superconducting field coils with an air flux circuit are employed rather than copper coils with an iron flux circuit. By this means the average magnetic flux density is increased to about $5.2 \mathrm{~T}$ with a consequent increase in terminal voltage.

The field coil design is similar to that of a large bubble chamber magnet. Its design is discussed extensively because it constitutes a major element of the machine. The design is scaled from existing coils of proven capability so Its feasibility is assured. Weight estimates are thought to be reasonably accurate.

The brush design, although not done in greatest detail, is most crucial to the successful operation of the machine. On small scale tests, high efficlency solj.d brushes are being demonstrated; ${ }^{5}$ but on the scale of this design, it is unclsar that technology has advanced much beyond Canberra. Thus presently achievable but optimistic values have been chosen for brush parameters.

When this study was begun, it was anticipated that the homopolar capacitor would remain an active circuit element in the onmic-heating ( $\mathrm{OH}$ ) circuit during start-up and burn. Furthermore, it was anticipated that it would be necessary to increase the capacitance (decrease the terminal voltage) to produce the desired variation in $\mathrm{OH}$ current. Analysis of a simple circuit containing a homopolar capacitor with sliding brushes and an inductor indicates that neither anticipated result can be realized in practice.

The equation governing the behavior of a simple series LC circuit with a homopolar capacitor is

$$
1+\frac{L}{2} \frac{d C}{d t} \frac{d i}{d t}+L C \frac{d^{2} 1}{d t^{2}}=0,
$$

where

$$
C=4 \pi^{2} \mathrm{~J} / \phi^{2}
$$


arid

$$
\begin{aligned}
& J=\text { polar mass moment of Inertia of the rotor } \\
& \phi=\text { total flux linked by brushes. }
\end{aligned}
$$

The capacitance $C$ and consequently the brush position (represented by $\phi$ ) need not be constant.

Problems associated with this scheme may be seen by nondimensionalizing this equation and considering the order of magnitude of its termi.

Let

$$
\begin{aligned}
& \hat{i}=\frac{1}{i_{\max }}, \quad I_{\max }=3 \mathrm{MA} ; \\
& \hat{t}=\frac{t}{\sqrt{L C_{0}}}, \sqrt{L C_{0}}=1 \mathrm{~s} ; \\
& \hat{C}=\frac{C}{C_{10}^{-}} \text {; and } \hat{C}=1 \text { at } t=0 .
\end{aligned}
$$

Then the nondimensional equation is

$$
\hat{i}+\frac{1}{2} \frac{d \hat{c}}{d \hat{t}} \frac{d \hat{i}}{d t}+\frac{d^{2} \hat{i}}{d t^{2}}=0 .
$$

During the burn portion of the cycle the nondimensional quantities have the following magnitudes: 
order $(1)+\frac{1}{2} \operatorname{order}\left(\frac{0.5}{3.0} \cdot \frac{1}{30}\right) \frac{\mathrm{d} \hat{c}}{d \hat{t}}+\operatorname{order}\left(\frac{1}{30} \cdot \frac{0.5}{3.0} \cdot \frac{1}{30}\right)=0 \quad$

In forming these orders of magnitude the assumption is made that the current changes from 2.5 to $3.0 \mathrm{MA}$ during a burn cycle which lasts $30 \mathrm{~s}$. The start-up phase, which sets $C_{0}$, is assumed to be represented by a half cosine with a period of $4 \mathrm{~s}$. The nondimensional current is roughly one, the nondimensional current change is 0.17 , and the nondimensional burn time is 30 . The second derivative term is second order and need not be considered. The first derivative of the capacitance must be negative indicating that capacitance should be decreased (the terminal voltage increased). The rate of change of capacitance is of the order -360 and the time over which this rate must be maintained is of the order of 30 . Thus the capacitance must change from +1 to $-10^{4}$, which is clearly impossible. The fact that the capacitance must reach large negative values is an indication of the need for an active, constant voltage source or burn supply in the circuit.

On the basis of this order of magnitude analysis, the assumption is made that the variable brush position option would only be used during the start-up portion of the cycle.

The flexibility of a moveable brush machine is limited to some extent by brush design considerations. Because the brushes must operate at a limited current density, they must extend over a sizeable portion of the rotor surface. Large voltage gradients exist over the surface of the rutor caused in part by field variations and in part by surface speed variations. Thus, brushes located at various positions on the rotor cannot, in general, be operated in parallel. Because the terminal brushes must be operated in parallel, they must be located on an equipotential to prevent circulating currents. Constant voltage surfaces are more or less cylindrical so the terminal brushes must be located on the cylindrical surfaces of the discs. Only brushes that interconnect the discs may be located in a voltage gradient, and they must be connected by transposed electrical leads as shown in Fig. 1.

The problem of rotor surface voltage gradients is so severe that the brushes themselves must be subdivided very finely to preverit circulating currents in their faces. Th1s problem is present, to some extunt, in all dc rotating machines. In the Canberra machine the sliding brushes were made very 
small in the radial direction $(1.5 \mathrm{~mm})$ to combat this problem. On the basis of the high fleld in chis machine, the brushes should be even smaller (0.5 $\mathrm{mm})$.

The general configuration that evolved from these circuit and brush considorations is shown in Fig. 2. The fleld coll consists of a split solenoidal pair. The terminal brushes are located on constant voltage lines, and the sliding brushes are located between the rotor faces in the voltage gradient. The sliding brushes have transposed interconnections.

\section{ASSUMPTIONS}

Various assumptions were made during the course of the design. These were necessary to provide a tractable mathematical model and to prevent the number of free parameters from becoming overwhelmingly large. These assumptions are listed here to aid the reader in critical evaluation of the results.

It is assumed that the magnet design should be an extrapolation of existing successful designs and, in particular, of successful bubble chamber magnets. To obtain a rough estimate of the proper region in design space in which to search, a relationship between the stored energy and the overall average current densily has been assumed, namely,

$$
E J^{r}=c
$$

Various authors have provided information for the evaluation of the constants in this equaticn. Brechna ${ }^{6}$ shows a line for which $r$ is 2.5 and $c$ is $1.8 \times 10^{26}$ in mks units. This line is judged to be too conservative. Large bubble chamber magnets of recent design seem to lie on a line with $r$ of 4.29 and c of $2.47 \times 10^{6}$. These two lines intersect at a stored energy of $10 \mathrm{MJ}$, so all designs considered in this study lie on the steeper curve. This is illustrated in Fie. 3 .

In the final evaluation of the coll design an operating point must be chosen for the superconductor. Niobium-titanium is the superconducting material used in this design. The state equation for this material, illustrated graphically by Brechna, 6 is shown in Fig. 4. The 4.2-K critical current 1sotherm has been approximated in mks units by a straight line as

$$
J_{c}=2.2 \times 10^{9}-\left(2.14 \times 10^{8}\right) \mathrm{B} .
$$


The value of current density obtalned from this equation is multiplied by 0.7 to obtain the operating current density of the superconductor in the field coils. Because all coils in this design operate at a field of $8 T$, this relationship is not really necessary. Only a point value is required. However, the relat:onship was included for purposes of checking the program at other field levels and to check trends.

The design of the conductor required further assumptions. The copper to superconductor ratio is constrained to lie between $20: 1$ and 10:1. The upper value is a constraint in the design program and the lower value represents the last acceptable design point. The aspect ratio of the conductor (height/thickness) is held at 10:1 for all designs. This is important in heat transfer considerations. A copper resistivity ratio of 150 is assumed. The magnetoresistivity effect is accounted for ty the relationship

$$
\rho=1.73 \times 10^{-8}\left(0.75 / R R+B_{\max } / 380.0\right),
$$

which is taken from Whetstone and Boom. 7 An overall. average heat transfer sate of $2.0 \times 10^{3} \mathrm{~W} / \mathrm{m}^{2}$ is used, and the foule heating muit equal this steady state surface heat transfer rate when the current is carried by the copper. The design program calculates the maximum values of the conductor height and the terminal current that meets this criterion. If actual values are less than these, the required heat transfer rate will be less than the assumed value. With these z.ssumptions, a determination is made whether or not a coil can be built using a realistic conductor.

The combined volume of stored helium and interturn insulation is never allowed to be less that $15 \%$ of the total winding volume. In some cases it is greater than this value but usually it is not far from it.

Maximum allowable itructural stresses or strains must be specified to design the structure. The conductor is assumed to be load bearing and the strain in the conductor is set equal to that in the structure. Thus, the overall stress is ilmited by the copper matrix. No allowance was made for the strength of the niobium-titanium wire. The structural density, modulus of elasticity, and maximum allowable stress are $8.02 \times 103,2.07 \times 10^{11}$, $1.17 \times 10^{8}$, respectively, whereas those of the conductor are $8.91 \times 10^{3}$, 
$1.17 \times 10^{11}, 6,6 \times 10^{7}$ all in mks units. These values are the same as those used in the design of the NAL bubble chamber magnet. 8

Stresses in tho winding were calculated using the Lame' disc formula 9 with the pressure taken to be the maximum magnetic pressure in the bore of the magnet. The winding was not checked for separation. From this formula the peak tangential stress occurs at the inside of the winding. This value was kept at the previously mentioned design value. Radial stresses were not considered in detail; but, according to the Lame formula, they should not exceed the pressure within the bore $\left(1.55 \times 10^{7} \mathrm{~N} / \mathrm{m}^{2}\right.$ or $\left.2200 \mathrm{psi}\right)$.

A window of $0.6-\mathrm{m}$ length was placed between the coils to allow brush access. The inner faces of the rotors were placed parallel to the edges of the window. Each coll was $0.6 \mathrm{~m}$ in length. The overall weight of the coil set was close to the minimum value at this length tior all bore diameters studied, so this parameter was not generally varied. A radial gap of $0.15 \mathrm{~m}$ was allowed between the outside of the rotor and the inside of the coils. This should be sufficieni space for the magnet dewar but may have to be increased to allow room for the cylindirical face brushes.

The rotor was assumed to operate at a tip speed of $200 \mathrm{~m} / \mathrm{s}$, which corresponds to a stress at a hole on the axis of $2.6 \times 10^{8} \mathrm{~N} / \mathrm{m}^{2}$ (38 kpsi).

A brush current density of $3.1 \times 10^{6} \mathrm{~A} / \mathrm{m}^{2}$ was assumed in all designs. It was also assuned that the packing factor was 0.5 . Further assumptions about brush operation will be found in Section VI below on Brush Fundamentals.

IV. GENERAL CONCEPTUAL DESIGNS

Field coil trends are shown in Figs. 5 through 9 . In all cases the parameters of Table I are held constant.

\section{TABLE I}

Design Constants

Rotor tip speed

Coil to rotor gap

coil window

Coll length

Brush current density

Brush packing factor
$200.0 \mathrm{~m} / \mathrm{s}$

$0.15 \mathrm{~m}$

$0.6 \mathrm{~m}$

$0.6 \mathrm{r}$

$3.1 \times 10^{6} \mathrm{~A} / \mathrm{m}^{2}$

0.5 
The independent variable in these figures is the inner radius of the field colls. Terminal voltage, coll weight, stored magnetic energy, rotor thickness and machine inductance are all plotted as a function of this variable. At a later point in the text, graphs are presented that show variations as a function of coll length with the magnet inner radius held constant. Teminal voltage, coil weight, and stored energy are not very strong functions of the coil length for lengths ranging between 0.6 and $1.0 \mathrm{~m}$ so the first four plots are reasonable representations for a range of coils.

Figure 5 shows the terminal voltage for two rotors in series as a function of the coil inner radius. The line marked MAXIMUM represents the voltage that would appear between brushes located on the axis and at the outer periphery of the inside rotor faces. This voltage cannot be attained in practice because of the requirsment for finite brushes. The line marked OUTER CYLINDER BRUSH represents the voltage, relative to the machine axis, which will be seen by a brush running on an equipotential, which is near the outside sirface of the rotor. Because of the gradient of the flux this is somewhat reduced from the maximum value. The line marked INNER FACE BRUSH represents the voltage seen by a face brush running near the machine axis. This is not zero for two reasons. Space has been provided for a bearing and the brush must be distributed in the radial voltage gradient. The indicated voltage is the average voltage over the distributed brush. The MAXIMUM TERMINAL voltage is the difference between the last two clirves. The MINIMUM TERMINAL voltage is obtained when the sliding brushes are in their outermost position. This voltage is not zero because the brushes are finite and some flux is always linked by the average position of the face brushes and the outer cylinder brushes.

The curves end at a finite magnet radius for a significanc reason. At this point the face brush has entirely covered the face of the rotor. The sliding brush is then incapable of motion and this feature has becoris useless. It is also evident that little regulation is possible on low terminal voltage machines.

The coil weight as a function of inner magnet ranius is shown in Fig. 6 . It is a smooth function that becomes linear for large magnet radii. With the exception of small machines, the coil is the dominant weight component in the machine. Stored energy is also a smooth function of the inrer magnet radius. As in all superconducting air core homopolar machines, the energy stored in the coil is of the same order or greater than the energy stored in the rotors. This 
is, of course, a function of the stored kinetic energy and terminal voltage required in the design. If the rotors were required to store $1000 \mathrm{MJ}$ rather than 500 at the same terminal voltage, both the rotor weight and its stored energy could be doubled without any change in the field coils.

The relationship between the rotor thickness and the coil axial length is shown in Fig. 8. When the rows becomes thinner than the coil, it is partially hidden. Locating bearings and other auxiliaries in their proper positions thus becomes more difficult. This is, however, a rather minor problem compared with others encountered in the design of this machine. A flutter instability can occur if the rotor becomes too thin with respect to its radius. This problem has been known ilince the advent of the steam turbine and has been studied by Stadola ${ }^{10}$ and other's. A most readable and direct exposition has been given by Timoshenko" in his book "Vibration Problems In Engineering". For typical rotors running at a tip speed of $200 \mathrm{~m} / \mathrm{s}$, the critical rotor radius is 32 times its thickness. This value is insensitive to the material properties because it is a function of the modulus to density ratio, which is almost constant for technical materials. No machines within the design range were troubled by flutter instability.

\section{POINT DESIGNS}

Each point design contains typical. elements that are found in all others. The coil is a split solenoid with a window $0.6 \mathrm{~m}$ in length and two coil segments each $0.6 \mathrm{~m}$ in axial length. All rotors run at a tip speed of $200.0 \mathrm{~m} / \mathrm{s}$. The brush current density is constant at $3.1 \mathrm{MA} / \mathrm{m}^{2}$ with a packing factor of 0.5 . The peak magnetic field on the inner surface of all field coils is $8.0 \mathrm{~T}$, and the average on the inner face of the rotor is about $5.2 \mathrm{~T}$ for all machines. The axis of the machine may be considered to be horizontal or vertical. The Canberra machine has a vertical axis and in all probability this machine will have to be built in a similar fashion to allow symmetric placement of the electicical leads and support for the bearings simultaneously.

The design of a machine with a magnet inner radius of $1.1 \mathrm{~m}$ is shown in Figs. 2 and 12. Details of the design are listed in Table II. With the sliding brushes in their innerwost position, this machine is capable of producing a terminal voltage of roughly $790 \mathrm{~V}$. When the brushes are in their outermost position, the terminal voltage is at its minimum value of $520 \mathrm{~V}$. The sliding brushes see a volitage span of $370 \mathrm{~V}$ at the inner position and $490 \mathrm{~V}$ when at 
their outer position. Transposed brush connections and possibly series resistors will be required to prevent circulating currents when these brushes are connected in parallel. The cost of this machine is given in Table III.

TABLE II

MACHINE CHARACTEAISTICS

\begin{tabular}{|c|c|}
\hline Inside radius & $1.105 \mathrm{~m}$ \\
\hline Outside radius & $1.76 \mathrm{~m}$ \\
\hline Axial length & $0.6 \mathrm{~m}$ \\
\hline Wintow length & $0.6 \mathrm{~m}$ \\
\hline Average field current density & $2 .: 4 \times 10^{7} \mathrm{~A} / \mathrm{m}^{2}$ \\
\hline Current density in superconductor & $3.81 \times 10 \mathrm{M} / \mathrm{m}^{2}$ \\
\hline Total ampera turns & $1.68 \times 10^{7}$ \\
\hline Maximul terwinal current & $1,14 \times 10^{4} \mathrm{kA}$ \\
\hline Maximum conductor height & 0.066 is \\
\hline Maximum conductor width & $0.0066 \mathrm{~m}$ \\
\hline Minimus inductance & $4.4 \mathrm{H}$ \\
\hline Minimum number of turns & 1470 \\
\hline Stored energy & $2.87 \times 10^{8} \mathrm{~J}$ \\
\hline Peak field & $8.00 \mathrm{~T}$ \\
\hline Central fleld & $5.69 \mathrm{~T}$ \\
\hline Fraction structure & 0.0332 \\
\hline Fraction superconductor & 0.0562 \\
\hline Fraction helium & 0.151 \\
\hline Fraction copper & 0.760 \\
\hline Copper-superconductor ratio & $13.5: 1$ \\
\hline Structure mass & $1.8 B \times 10^{3} \mathrm{~kg}$ \\
\hline Conduct or mass & $5.15 \times 10^{4} \mathrm{~kg}$ \\
\hline Total mass & $5.33 \times 10^{4} \mathrm{~kg}$ \\
\hline Structural stress & $1.17 \times 10^{8} \mathrm{~N} / \mathrm{m}^{2}$ \\
\hline Winding stress & $6.6 \times 10^{7} \mathrm{~N} / \mathrm{m}^{2}$ \\
\hline Helium heat transf $t_{2}$ coefficient & $2 \times 10^{3} \mathrm{w} / \mathrm{m}^{2}$ \\
\hline \multicolumn{2}{|l|}{ Desten of Rotor } \\
\hline Outside radius & $0.955 \mathrm{~m}$ \\
\hline Axtal length & $1.09 \mathrm{~m}$ \\
\hline Stored energy & $5.0 \times 10^{8} \mathrm{~J}$ \\
\hline Rotor mass & $5.0 \times 10^{4} \mathrm{~kg}$ \\
\hline Brugh current density & $3.1 \times 10^{6} \mathrm{~A} / \mathrm{m}^{2}$ \\
\hline Brush packing factor & 0.5 \\
\hline Brush area ( 4 ring total) & $3.87 \mathrm{~m}$ \\
\hline
\end{tabular}




\begin{tabular}{lll} 
& \multicolumn{1}{c}{$\begin{array}{l}\text { s's } \\
\text { Field coils }\end{array}$} & $\$(10)^{6}$ \\
Rotor & $64.00 / \mathrm{kg}^{13}$ & 3.41 \\
Copper-graphite brushes & $48(10)^{3}$ to $364(10)^{3} / \mathrm{m}^{2}, 12,13$ & 0.16 \\
Total & $(7.5$ to $10 \mathrm{mils} / \mathrm{J})$ & 0.19 to 1.4 \\
& & 3.76 to 4.97 \\
Brush operation & $50000 / \mathrm{yr}$. & 0.14
\end{tabular}

Coil cost is estimated on the basis of work done on the HETS machine by McNab. 13 Rotor ceist is estimated on the basis of rough costs for the rotors of the TEXT ${ }^{1,14}$ machines. Brush costs are most variable. The lower cost is based on information from $\mathrm{McNab}^{13}$ and Weldon, ${ }^{14}$ which appears to result from experience with the 5-MJ Homopolar Motor Generator ${ }^{15}$ built at Texas. The higher cost is based upon the cost of the brush system in the TEXT machines. The cost of the brush system is potentially a major portion of the machine cost. As the inner radius of the coils is increased the cost of the coll increases. The design of a machine with an inner magnet radius of $1.35 \mathrm{~m}$ is shown in Figs. 13 and 14. Detalls are listed in Table IV. On the same basis as the previous design the coil cost will rise to $\$ 5.22$ million. The remaining costs, rotors, brushes, and brush operation will remain more or less the same because the cost of these components is determined by the stored energy and the terminal current, not the coll size. The total machine cost will rise to $\$ 6.8$ million or 1.4 cents per joule. 
Design of Field Coils

Inside radius

Outside radius

Axial length

Hindow length

Average field current density

Current density in superconductor

Total ampere turns

Maximum terminal current

Maximum conductor height

Maximum conductor width

Minimum inductance

Minimum number of turns

Stored energy

Peak field

Central field

Fraction structure

Fraction superconductor

Fraction helium

Fraction copper

Copper-superconductor ratio

Structure mass

Conductor mass

Total mass

Structural stress

winding stress

Helium heat transfer coefficient

Design of Rotior

Qutside radius

Axial length

Stored energy

Rotor mass
$1.35 \mathrm{~m}$

$2.65 \mathrm{~m}$

$0.6 \mathrm{~m}$

$0.6 \mathrm{~m}$

$1.91 \times 10^{7} \mathrm{~A} / \mathrm{m}^{2}$

$3.79 \times 10^{8} \mathrm{~A} / \mathrm{m}^{2}$

$1.87 \times 10^{7}$

$1.72 \times 10^{4} \mathrm{kA}$

$0.0866 \mathrm{~m}$

$0.00866 \mathrm{~m}$

$3.22 \mathrm{H}$

1090

$4.73 \times 10^{8} \mathrm{~J}$

$8.01 \mathrm{~T}$

$5.55 \mathrm{~T}$

0.0188

0.0503

0.152

0.779

$15.5: 1$

$1.63 \times 10^{3} \mathrm{~kg}$

$7.98 \times 10^{4} \mathrm{~kg}$

$8.15 \times 10^{4} \mathrm{~kg}$

$1.17 \times 10^{8} \mathrm{~N} / \mathrm{m}^{2}$

$6.6 \times 10^{7} \mathrm{~N} / \mathrm{m}^{2}$

$2 \times 10^{3} \mathrm{w} / \mathrm{m}^{2}$ 
Although cost per foule is usually used as a figure of merit when disoussing energy storage devices, it is not clear that this is proper when considering an $\mathrm{OH}$ system. The least expensive homopolar may in fact, fit into the most expensive system. Because the coll weight dominates the oost of the homopolar, and all remaining costs are smaller and constant, and because the coil weight and terminal voltage are smooth functions of the coil inner radius, a simple relationship between the terminal voltage and the homopolar cost could be used in an overall system optimization program. In this way, a more realistic evaluation of the desirability of homopolar machines in this application can be made.

VI. BRUSH FUNDAMENTALS

Data for brushes operating at high current densities are most readily available for copper-graphite brushes. Copper-graphite is less expensive than other brush materials and, under nonideal conditions, performs as well. Relatively little data are present in the open literature on the performance of silver-graphite or carbon-fiber brushes in high power applications. Whereas such brush materials perform well in instrumentation applicatione, their performance under ordinary conditions of operation do not appear to warrant their high cost.

Some early work on silver-graphite brushes by Johnson ${ }^{12}$ at Westinghouse is presented in Table $V$. This work has been continued by him under an ARPA

TABLE V

SILVER ERUSH PERFORMANCE

Ring material

Surface speed

Brush material

Brush area

Brush pressure

Current density

Load cyole

Brush temperature

Double contact drop

Coefficient of friction

Wear rate
Copper

$56-64 \mathrm{~m} / \mathrm{s}$

WNS 162

$0.88 \times 10^{-4} \mathrm{~m}^{2}$

$0.1-.14 \mathrm{MPa}$

$14 \mathrm{MA} / \mathrm{m}^{2}$

6-30 s on, 1-5 min off

$<100 \mathrm{C}$

$0.1 \mathrm{~V} / 1.55 \mathrm{MA} / \mathrm{m}^{2}$

0.2

$2 \times 10^{-9}$ 
contract5, but the data appear to be proprietary. Low-voltage drops have been obtained ( $0.09 \mathrm{~V} / \mathrm{brush}$ ) under well controlled operating conditions. It is not clear that such conditions can be maintained in a 3-MA homopolar or that the data can be extrapolated to this machine design.

Carbon fiber brushes have been under study since their application in the Fawley machine. This work is being continued by McNab at the Westinghouse Research Laboratory. McNab13 has pointed out that under high-current operation the fibers in the brushes are bound together by magnetic forces, and the brushes begin to function as a solid unit. Furthermore, data obtained from research done under the same ARPA contract 5 show performance which is little better than that of copper graphite under similar conditions (Fig. 15). Additional experimental evaluation of fiber brushes by Welcon ${ }^{12}$ at U.T. Austin confirms the data of McNab. Weldon determined that a brush drop of $0.7 \mathrm{~V}$ per pair is typical for fiber brushes carrying high-current densities. Low brush drops are obtained at unacceptably low-current densities, which result in unduly large friction losses. On this basis the application of carbon fiber brushes to a large pulsed homopolar machine cannot be recommended without further research; unless their performance is improved markedly, their use will probably not be economically justifiable.

Current densities in normal current collection systems are quite low. In general, brushes are run no higher than $0.155 \mathrm{MA} / \mathrm{m}^{2}$. The TEXT machines designed at The University of Texas at Austin will operate at $2.7 \mathrm{MA} / \mathrm{m}^{2} .1$ The brushes in the Canberra machine operate at various current densities. The stationary brushes 2,3 , depending on their location, operate at densities of $10.0 \mathrm{MA} / \mathrm{m}^{2}$ to $18.0 \mathrm{MA} / \mathrm{m}^{2}$. The sliding brushes ${ }^{4}$ operate at $1.9 \mathrm{MA} / \mathrm{m}^{2}$. The HETS ${ }^{16}$ machine, which was to deliver a 30-ms pulse of current, was to operate at $15.5 \mathrm{MA} / \mathrm{m}^{2}$. All of these machines use or plan to use copper-graphite brushes principally because of their lower cost. This design assumes a current density of $3.1 \mathrm{MA} / \mathrm{m}^{2}$.

Only the terminal voltage and the voltage span over the sliding brushes are affected by the cholce of brush-current density and packing factor in this general conceptual design. Many important detalls must be considered in the final detalled design. These include brush-shunt placement and interconnection as well as heat removal to mention only two. Some of these considerations will be discussed following the presentation of the general design results in Table VI. 
TABLE VI

BRUSH CHARACTERISTICS

$\begin{array}{lll}\text { Type } & \text { Copper graphite } & \text { Silver graphite } \\ \text { Cost } & 0.283 \text { to } 0.915 \$ / \mathrm{cm}^{3} & 3.45 \text { to } 4.07 \$ / \mathrm{cm}^{3} \\ \text { Normal force } & 0.01 \mathrm{~N} / \mathrm{A} & 0.01 \mathrm{~N} / \mathrm{A} \\ \text { Current density } & 3.1 \times 10^{6} \mathrm{~A} / \mathrm{m}^{2} & 3.1 \times 10^{6} \mathrm{~A} / \mathrm{m}^{2} \\ \text { Friction ooefficient } & 0.2 & 0.2 \text { to } 0.12 \\ \text { Voltage drop } & 0.2 \mathrm{~V} \text { per brush } & 0.1 \mathrm{~V} \mathrm{per} \mathrm{brush} \\ \text { Wear rate } & 10^{-8} & 2 \times 10^{-9} \\ \text { Drag length } & 255 \mathrm{~m} & 255 \mathrm{~m} \\ \text { Frictional loss } & 6.1 \mathrm{MJ} & 6.1 \text { to } 3.7 \mathrm{MJ} \\ \text { Ohmic loss } & 2.4 \mathrm{MJ} & 1.2 \mathrm{MJ} \\ \text { Tctal } & 8.5 \mathrm{MJ} & 7.3 \mathrm{to} 4.9 \mathrm{MJ} \\ \text { Wear } & 9.9 \mathrm{~cm} 3 / \text { cycle } & 2.0 \mathrm{~cm} / \mathrm{cycle} \\ \text { Cost } & 2.80 \mathrm{to} 9.05 \$ / \text { cycle } & 6.90 \mathrm{to} 8.14 \$ / \mathrm{cycle}\end{array}$

A comparison of copper-graphite and silver-graphite brushes for this application is shown in Table VI. The cost per unit volume of the brush material is based on work done for the HETS machine study, specific quote by the Stackpole Carbon Company, and information supplied by Weldon. ${ }^{14}$ Stackpole was unwilling to make a general quote on brush materlal but they were willing to quote on a scaled version of the brushes used in the Canberra machine. It is evident that the silver material may be more than 10 times as expensive as the copper material. The friction coefficients are comparable, but the voltage drop and wear rate may be lower for the silver material than for the copper. However, these differences are not significant when the scatter in the data is taken into consideration. In the final analysis, it appears that the silver brushes will cost four or five times more per cycle than the copper brushes.

The estimated brush losses, depending on brush type and data source, vary over a wide range. The friction factor and brush drop for copper brushes are taken from the work of Marshall.2 The voltage drop is shows in Fig. 16, ano the friction factor is taken from $h$ is text. Wear rate data are taken from MoNab17 as shown in Fig. 17. The total energy loss based on these data 1s $8.5 \mathrm{MJ}$ per shot. If the mean values represented by the equations of McNab are used, the friction coefficient remains nore or less the same but the anticipated voltage drop will rise to $0.64 \mathrm{~V}$ from $0.2 \mathrm{~V}$. This will increase the anticipated losses 44 
to $13.8 \mathrm{MJ}$. The brush wear will amount to $9.9 \mathrm{~cm}^{3}$ per cycle. At, the tabulated cost of the brush material, this will amount to roughly $\$ 2.80$ per cycle.

The silver-graphice data are taken from the early work of Johnson ${ }^{12}$ as listed in Table $V$. The friction losses will be substantially the same as copper but the contact drop may be somewhat lower. Thus the total losses may be as low as $7.3 \mathrm{MJ}$ per cycle, equal to or lower than those of copper. Tne reported wear rate for silver is somewhat lower than that of copper. At the tabulated wear rate, the silver brushes will wear only $2.0 \mathrm{~cm}^{3}$ per cycle at a cost of $\$ 8.14$. Because of a lack of operating experience these values are not as reliable as those for copper brushes.

As an example of the type of data available under the best conditions, the compilations of McNab have been included. These are shown in Figs. 17 to 22. There is a great deal of scatter in data from one type of binush material. Most data are for Morganite CMIS, which is generally considered to be the best copper-graphite grade available for pulsed duty. It or its equivalent have been used in all pulsed homopolar machines thus far. Unfortunately, no one has maraged to produce data that can be well correlated. It is not even clear that all of the relevant variables are known and controlled in many cases.

A dot-dash line, which represents McNab's best estimate of an analytical representation of the brush behavior, has been drawn on each of his figures. The equations and constants used are listed in Table VII. Note that the lines pass more or less through the center of the data and have roughly the proper trends. These representations have some foundation in classical contact theory. They can be combined into a single expression for brush loss per unit current collected as a function of current density. In doing this, an optimum value for the brush contact force per unit current is also found. This value is $0.01 \mathrm{~N} / \mathrm{A}$, which is quite close to the rule of thumb of Marshall, 18 which $1 \mathrm{~s} 1 \mathrm{~g} / \mathrm{A}$. The loss relationship is also given in Table VII. With McNab's constants in this equation, the line shown in Fig. 22 can be plotted. Because of the effect of brush loading on voltage drop and friction losses, the horizontal asymtote is raised for both higher and lower brush loadings. At very low brush loadings, less than $0.0345 \mathrm{MPa}$, arcing occurs. Thus, brush pressure must not be reduced further and friction losses begin to dominate at $2 \mathrm{MA} / \mathrm{m}^{2}$ and below. Losses increase inversely with current. Above this value the loss is roughly a linear function of the current density. 
TABLE VII

BRUSH CHARACTERISTICS

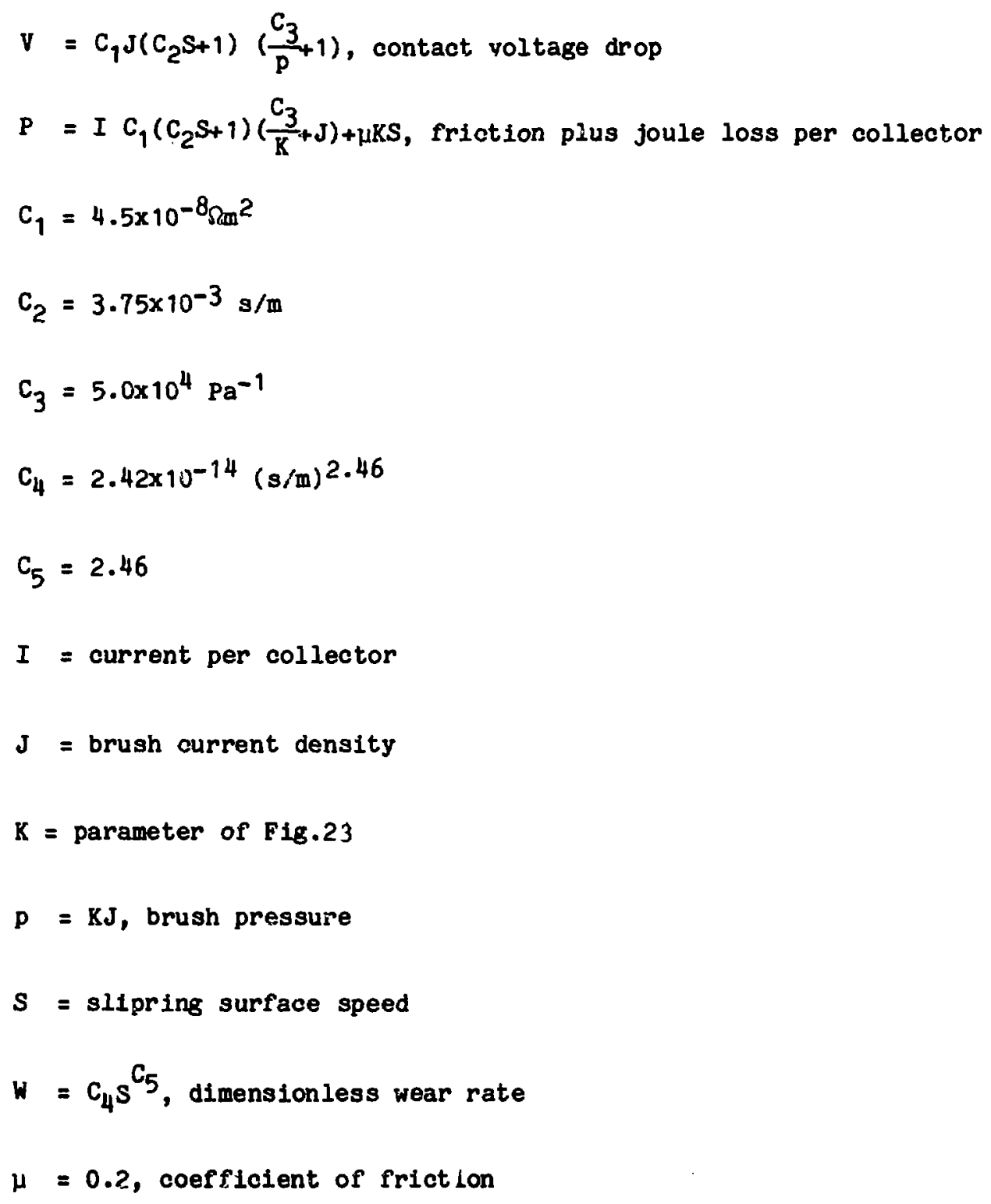


Figure 23 is based on steady operation oi a single collector sing. As a rough approximation, the steady value can be divided by two for the half cycle operation of this machine. Thus the total loss from four collectors carrying 3.0 MA for two seconds with sinusoidal spesd and current variation is about 12 MJ. This value is in reasonable agreement with other estimates in this text. The relative operating point of tinese brushes can also be seen from their position on the line in relationship to other designs.

Wear of the brushes and slip rings is a function of their thermal condition during operation. Brushes are subject to a phenomenon called dusting by many authors $^{19}$ and thermil mounding by Marshall.20 In effect, a small intensely heated area of the brusk expands and is rapidly worn off the brush face. Thic area then becomes a hollow and ceases to conduct. However, a new area has taken its place and this mound moves across the brush face. In this condition the wear rate increases by more than two orders of magnitude. ${ }^{19}$ In a similar fashion during current transfer the collector ring is intensely heated over a limited area, which causes high lowalized thermal stresses resulting in eventual thermal fatigue of the material. It is not a question of whether the brushes can carry high currents, they can. It is a question of how long they will last. The answer to this question is closely related to adequate cooling of the brush, brush pocket, and slip ring.

The design of the brust shunts and interconnections, as well as the choice of the brush dimensions, may seem to have little to do with the thermal design of the brushes; but it can have a profound effect on their thermal behavior. If for any reason a closed path through the rotor, the brushes, and the brush shunts or the rotor and the brush faces can be found for which the integrated voltage is not zero, a current will flow. This circulating current is limited by the circuit resistance and any demagnitizing effect that it may have on the main fieid. It need not flow through the load circuit. It does, however, flow through the brush faces and adds to the thermal load. The tabulated loss calculations assume perfect transposition of the brush shunts and brushes of zero thickness. In reality neither of these may be accomplished, therefore, a tradeoff must be made in the design of the brush system among cost, low iosses, and complexity.

It should be further indiagted that no account has been taken of heating as a result of resistance of the brush body. Silver brushes have a much lower specific resistance than copper and have an advantage in this case. The brush 
body resistance necessitates a shunt connection which is as close as possible to the brush face.

\section{ELECTROMAGNETIC FORCES}

A substantial magnetic field, 0.55 to $5 \mathrm{~T}, 1 \mathrm{~s}$ generated in the space between the discs as result of the load current. This results in a radial load on the brushes and brush shunts as shown in Fig. 24. The force is represented by the expression

$$
F=\frac{\mu 1 I^{2}}{4 \pi r}
$$

where $F=$ total load on brushes in radial direction

$\mu=$ farmeability of free space

1 = distance between discs

$I=$ load current, and

$r$ = radial brush position.

This force is of the order of 1 to $10 \mathrm{MN}$ as shown in Fig. 25. The brush travel range for the two point designs is also shown on this figure. It should be noted that a decrease in disc spacing will decrease this force while increasing the potential difficulty in designing the brush system.

Figure 26 shows how the brush force varies as a function of capacitance for the 1.35-m diameter point design. Once a capacitance change program is established, this figure can be used to estimate brush actuator power requirements. The power requirement for brush movement should be 1 MW or less corresponding to an energy change of roughly $0.5 \mathrm{MJ}$ for any reasonable brush position change.

The interaction between the current in the transposed brush shunts will produce a torque that must be consldered. This torque acts about a radial axis as shown in Fig. 27. The magnitude of this torque is a function of the specific actuator design but can be calculated easlly.

The load current field also acts to repel the rotors. This force is $0.25 \mathrm{MN}$ (28.1 tons) for the 1.1-m point design and $0.28 \mathrm{MN}$ for the $1.35-\mathrm{m}$ point design. The bearings, plllow blocks, and foundation must be designed to withstand this load. 
It is evident that careful attention must be paid to electromechanical forces in the design of the brush-rotor systems.

VIII. MAGNET DESIGN CHECK

Because the cost of the machine appears to be dominated by the coil, an accurate estimate of its weight is reyuired. To obtain this estimate a coll design program was written as indicated earlier in the text. Programs of this type frequently contain errors that are difficult to find because they are errors in the magnitude of constants or in judgement on the part of the programmer. To reduce the probably of such errors, the program was checked against the reported design of the NAL 15-foot bubble chamber 8 .

Table VIII lists a large number of parameters of the NAL coll design. The program inputs were made to agree with the published values whenever possible. The only variation of note on the input parameters is in the length of the individual coils. The individual variation amounts to about two percent, and the total variation to about 0.3 percent. The percent variation between the program output value and the reported value is listed in Table VIII. The maximum variation 1 s $11 \%$ and most of the parameters vary by about $5 \%$. This is considered to be sufficiently accurate for purposes of this study. 
TABLE VIII

COMPARISON OF COIL DESICN PROORAM NITH

NLL 15-pOOT BUBGLE CHARBER

(Hixs UNITS)

\section{Poreter}

WIndlag londe diwater.

ulnding outside dineter

spacing between colla

Length of bottom $\cos 1$

Length of top coil

J-8 charmateristias

Fraction or short semple

Cu:SC rat10

Conductor aspect ratio

Conductor resistivity ratio

Magnetoresistivity errect

Avg. heat tranafer coerrialent

Conductor helght

Structurad density

Structural modulus

Mx. structural streas

Conductor Dena1ty

Conductor sodulua

Max. conductor stress

Total number or turns

Neight of conduator

Welght of structure

Ampere turbs

Operating current

Current density in conductor

Average current density

Central rlezd

Mxinum exial rield

Selr inductance

Stored enerby

Fraction structure

Eraction heliue

Fraction SC

Fraction copper
Progera

Input

4.27

5.08

0.99

0.95

0.95

See FIB. 3

0.7

20:1

$10: 1$

150:1

See Bq. 10

$1.51 \times 103$

$3.8 \times 10^{-2}$

$0.02 \times 10^{3}$

$2.07 \times 10^{11}$

$1.17 \times 10^{8}$

$6.91 \times 10^{3}$

1. $17 \times 10^{11}$

$6.6 \times 10^{7}$

Program

gutout

2890

$5.45 \times 10^{4}$

$2.45 \times 10^{4}$

$15.0 \times 10^{6}$

5. $19 \times 10^{3}$

$3.59 \times 10^{7}$

$1.94 \times 10^{7}$

3.16

5.40

32.7

$438 \times 10^{6}$

0.270

0.189

0.0258

0.515
Roported

Inlue

4.27

5.08

0.99

0.972

0.933

20 to 22:1

10:1

150:1

$3.8 \times 10^{-2}$

$2.07 \times 10^{11}$

1. $17 \times 10^{8}$

$1.17 \times 10^{11}$

$6.6 \times 10^{7}$

Reported

Ylue

Percent Yorintion

2860

$5 \times 10^{4}$

$2.3 \times 10^{4}$

$+18$

$+98$

$14.3 \times 10^{6}$

$+68$

$+5 s$

$5 \times 10^{3}$

$+48$

$3.7 \times 10^{7}$

$-3 t$

9. $885 \times 10^{7}$

$+38$

3.006

$+51$

5.14

$+58$

31.7

$+37$

$396 \times 10^{6}$

$+115$ 
References

1. W. L. Bird, W. G.Dase, G. B. Grant, H. G. Rylander, K. M. Tolk, W. F. Weldon, H. H. Woodson, "Preliminary Engineering Design of A Pulsed Homopolar Generator Power Supply," Proc. Int. Pulsed Power Conf. Texas Tech University, Lubbock, Institute of Electrical and Electronics Engineers, Inc., New York, 1976, paper IIB-4, pp.1-6.

2. R. A. Marsnall, "The Design of Brushes for the Canberra Homopolar Generator" Department of Engineering Physics, The Australian National University, Report EP-RR3, Canberra, A.C.T. Australia (January 1964 and April 1967).

3. A. Stebbens, H. Ward, "The Design of Brushes for the Homopolar Generator at the Austrailian National University," ibid, Report EP-RR18 (March 1964 and September 1967).

4. R. A. Marshall, "Sliding Brushes for the Canberra Homopolar Generator," ibid Report EP-RR27 (May 1973).

5. C. J. Mole, D. L. Greene, I. R. McNab, J. L. Johnson, O. S. Taylor, W. R. Gass, P. K. Lee, "Advanced Current Collection Research," Annual Technical Report, Advanced Research Projects Agency Contract N00014-76-C-0683, ARPA Order No. 3153; Westinghouse R\&D Center Document No. 77-8B2-AMCOL-R 1 (February 1977).

6. H. Brechna, "Superconducting Magnets" in superconducting Machines and Devices, S. Foner, B. B. Schwartz, eds., Plenur Press, New York, 1974, pp.172,201.

7. C. N. Whetstone, R. W. Boom, "Nucleate Cooling Stability for Superconductor - Normal Metal Composite Conductors in Liquid Helium," in Advances in Cryogenic Engineering, K. D. Timmerhaus, ed., Plenum Press, New York (1968) 13, p. 75.

8. J. Purcell, H. Desportes, D. Jones, "Superconducting Magnet for the 15 Foot NAL Bubble Chamber," Argonne National Laboratory Report ANL/HEP 7215 (February 1973).

9. J. P. Den Hartog, Advanced Strength of Materials, McGraw-Hill Book Company, Inc., p.57.

10. A. Stadola, Steam and Gas Turbines, Peter Smith, New York, 1945, pp. 1090-1108.

11. S. Timoshenko, Vibration Problems in Engineering, D. Van Norstrand Company, Inc., New York, 1955, pp. 455-461.

12. J. L. Johnson, discussion of "Brush Gear for High Current Pulses and Rubbing Velocities," by R. A. Marshall, IEEE Transactions on Power Apparatus and Systems, PAS-852 NO.11, 1177-1188 (1966). 
13. I. R. McNab, Westinghouse Research Laboratory, personal communication, October 1977.

14. W. F. Weldon, Center for Electrumechanics, The University of Texas at Austin, personal communication, October 1977.

15. W. F. Weldon, H. H. Woodson, H. G. Rylander, M. D. Drega, "Inexpensive Inertial Energy Storage Utilizing Homopolar Motor Generators," Second Annual UMR-MEC Conference on Energy, University of Missouri-Rolla, (October $7-9,1975)$.

16. C. J. Mole, R. E. St1llwagon, K. I. Thomassen "Conceptual Design of a 10-Megajoule Fast Discharging Homopolar Machine," EPRI Research Piroject ER-469; Final Report, Westinghouse Electric Company (Aigust, 1977).

17. I. R. McNab, "Pulsed High Power Brush Research," Proceedings of the Hoim Conference on Electrical Contacts, Illinois Institute of Technology, Chicago, Illinois, November 1-3, 1977; Keys to data points on Figs. 15 thru 20 are found in this reference.

18. R. A. Marshall, Westinghouse Research Laboratory, personal communication, July 1977 .

19. E. I. Shobert, Carbon Brushes, Chemical Publishing Company, Inc., New York, (1965), p. 127 .

20. R. A. Marshall, "The Mechanism of Current Transfer in High Current Sliding Contacts," Wear, 37, 233-240 (1976). 


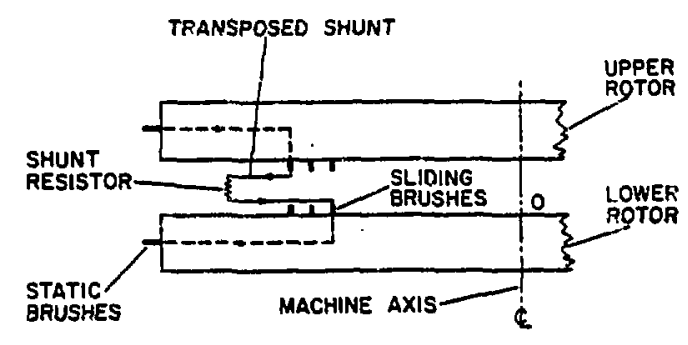

Fig. 1. Typical current path through sliding brush unit in Canberra homopolar. ${ }^{20}$

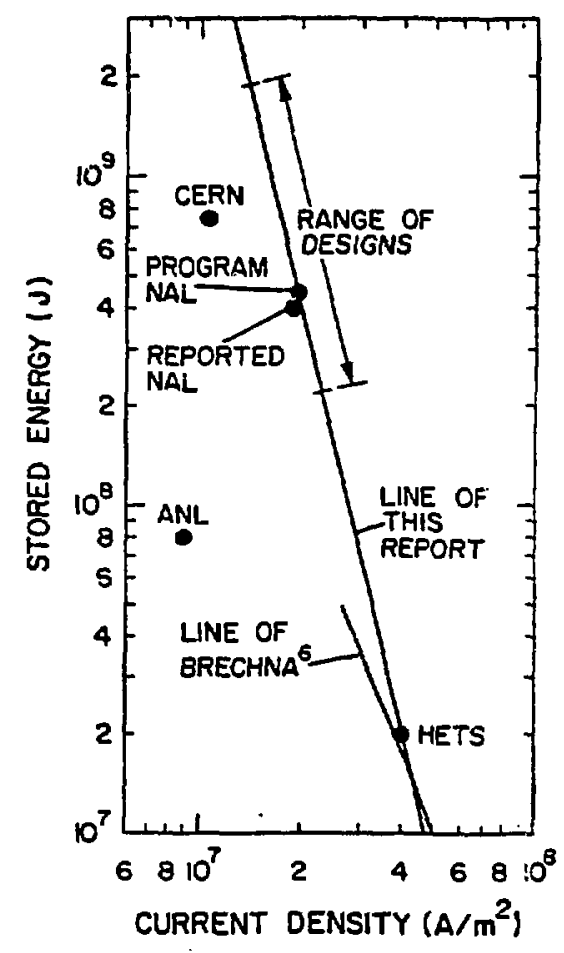

Fig. 3. Power law relationship between stored energy and overall current density for superconducting solenoids.

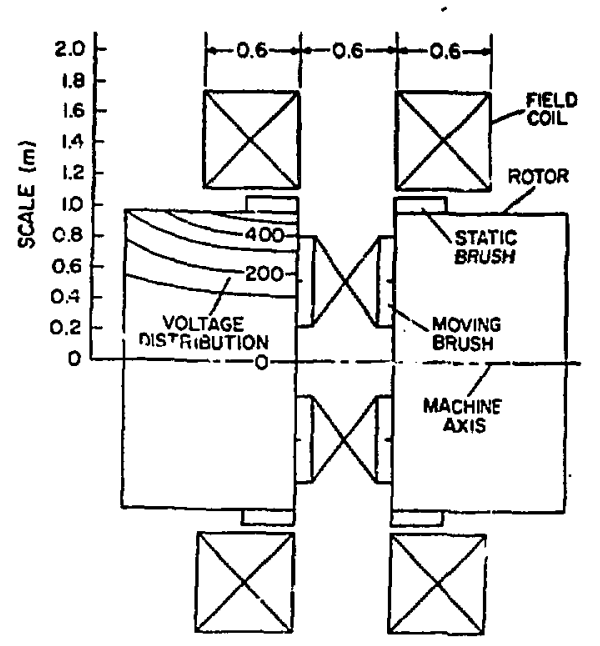

Fig. 2. Configuration of machine with 1.l-m diameter field coil.

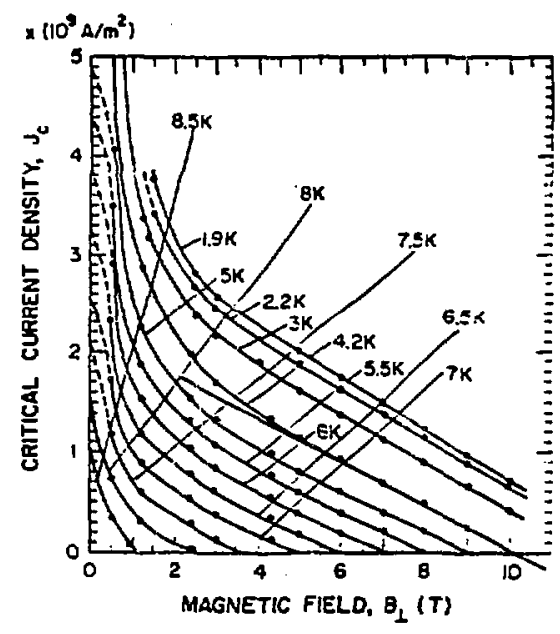

F1g. 4. Critical current density of niobium titanfum. 6 


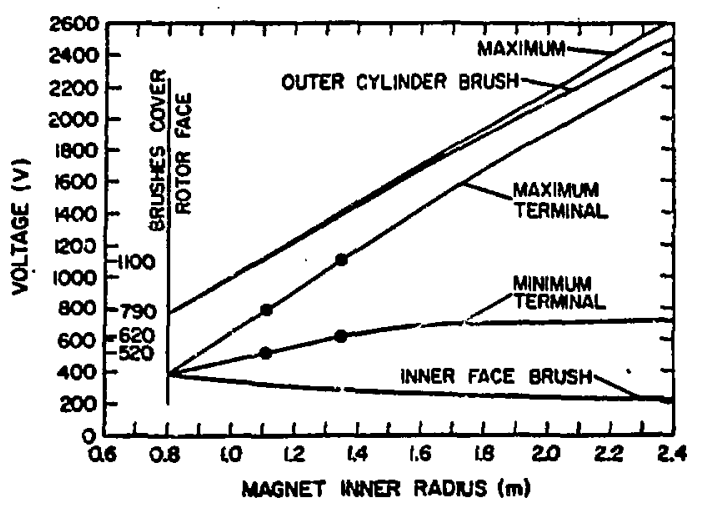

Fig. 5. Terminal voltage for machines of various sizes.

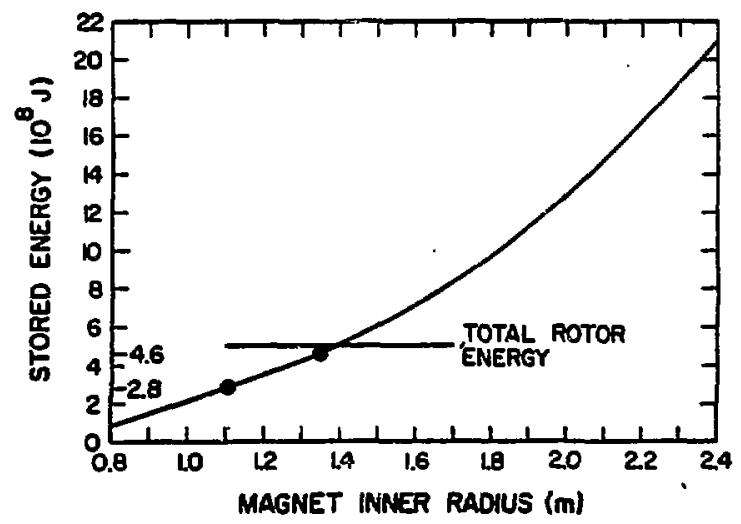

Fig. 7. Energy stored in fleld coils of machines of vartous sizes.

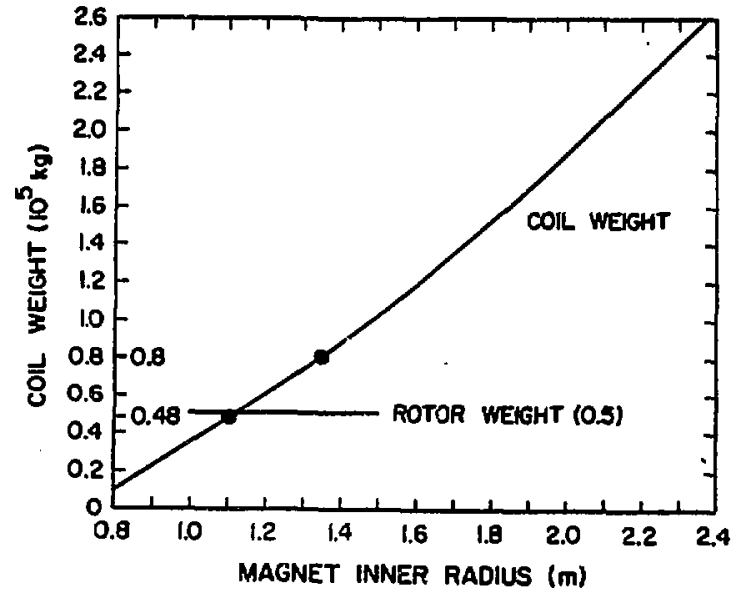

Fig. 6. Field coil weight for machines of varlous sizes.

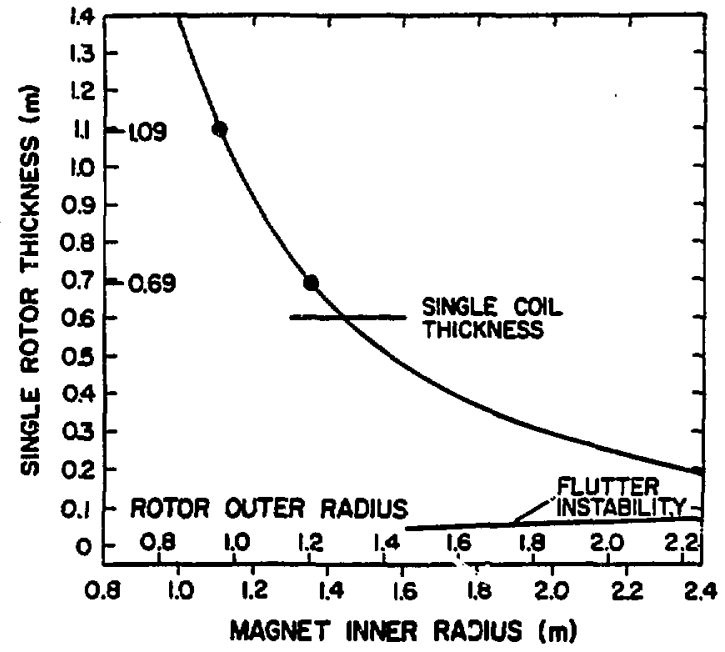

Fig. 8. Rotor thickness for machines of various size with an indication of flutter mode instability limit. 


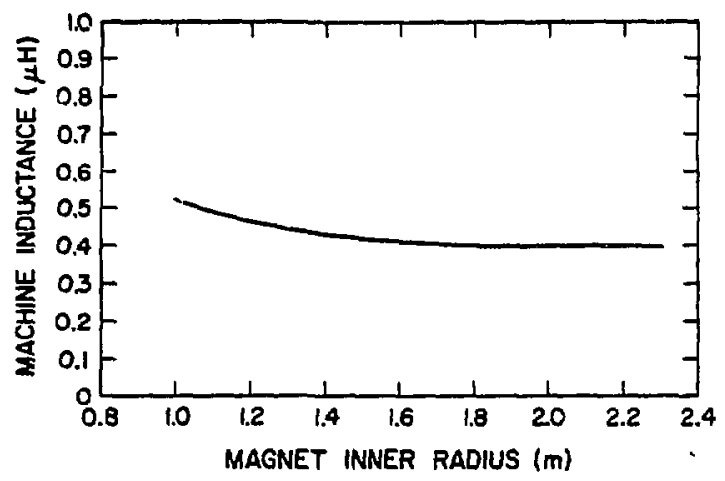

Fig. 9. Armature leakage-field inductance for machines of various size.

FIELD COIL PARAMETERS INNER RADIUS I.35 METER $10^{4} \mathrm{~kg} \begin{gathered}12 \\ 10 \\ 8\end{gathered}$ WINDOW 0.6 METER $\begin{array}{cc}18 \\ \text { RATIO } & 16 \\ \text { TO } & 14 \\ \text { ONE } & 12 \\ 10 \\ 8\end{array}$
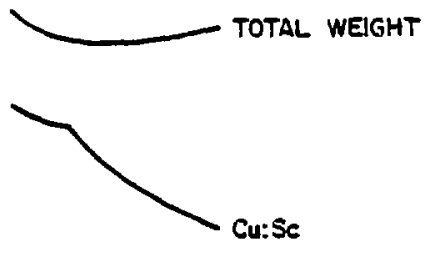

METERS 2 F

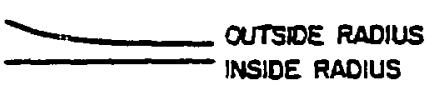

PER CENT $20 \begin{array}{r}40 \\ 20 \\ 10 \\ 0\end{array}$ JOULES

OL ROTOR
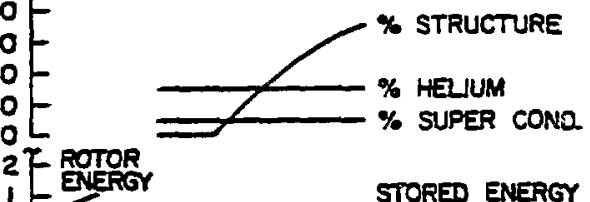

$10^{7}$ 年 AXIAL COIL LENGTH (m)

Fig. 10. Design parameter variation with axial coil length for 1.35-m coil diameter machine.

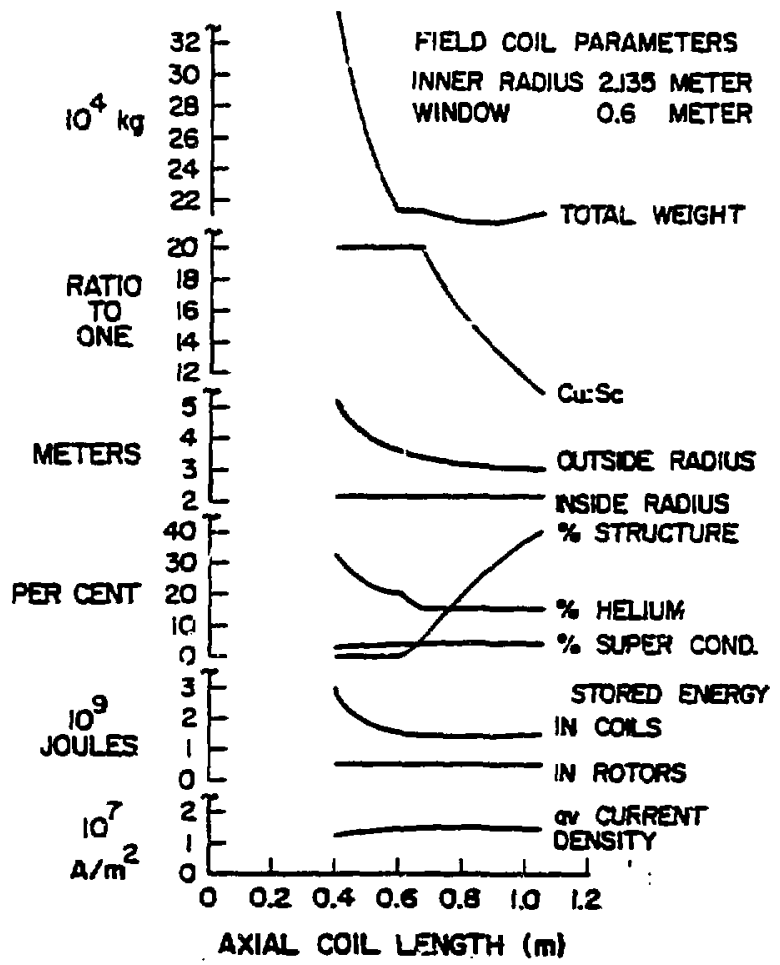

FIg. 11. Design parameter variation with axial coil length for 2.135-m coil diameter machine. 


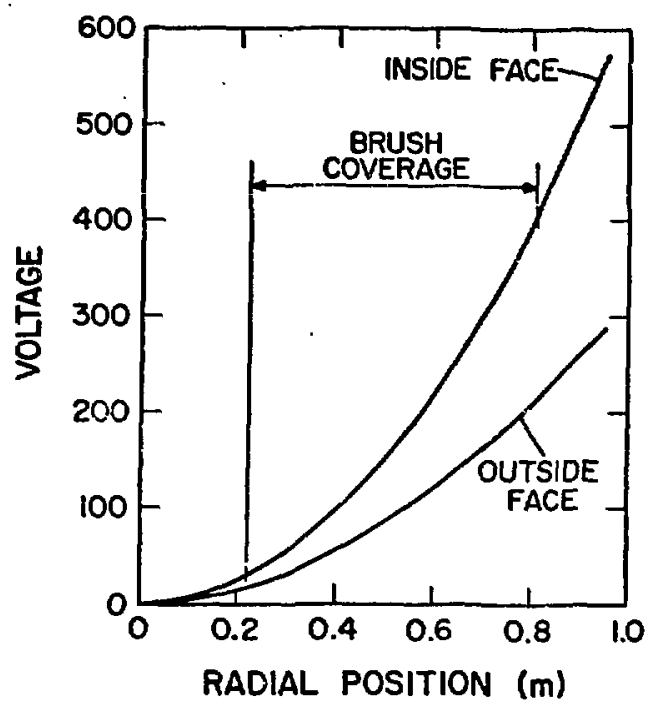

Fig. 12. Voltage distribution on inside and outside faces of rotor of $1.1-\mathrm{m}$ machine.

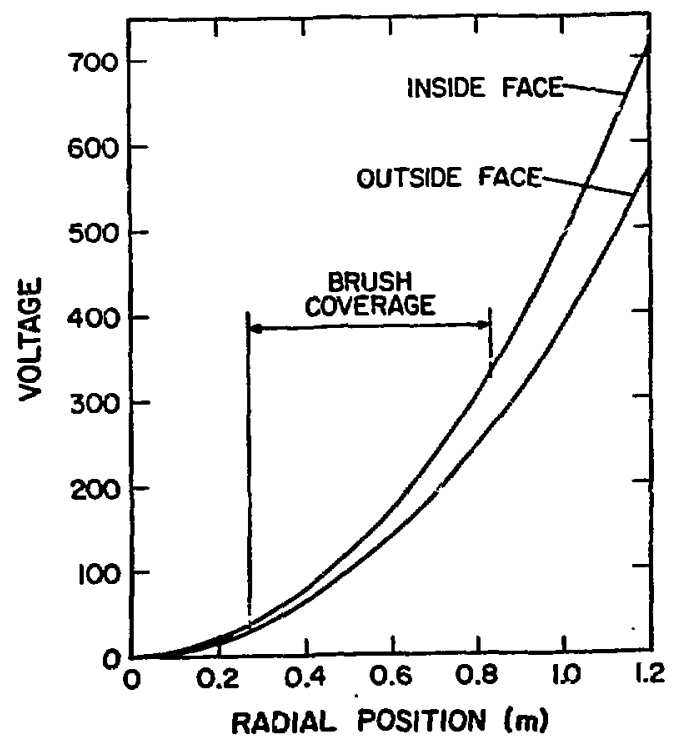

Fig. 14. Voltage distribution on inside and outside faces of rotor of $1.35-\mathrm{m}$ machine.

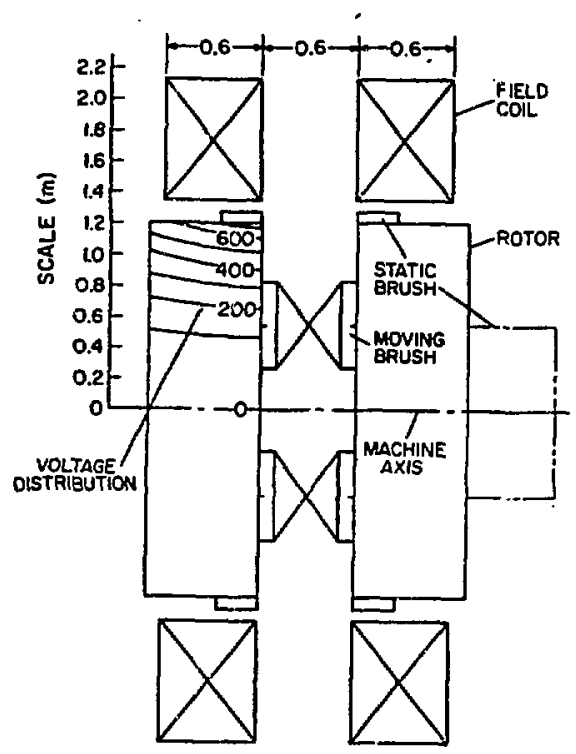

Fig. 13. Configuration of machine with $1.35 \mathrm{~m}$ diameter field coil.

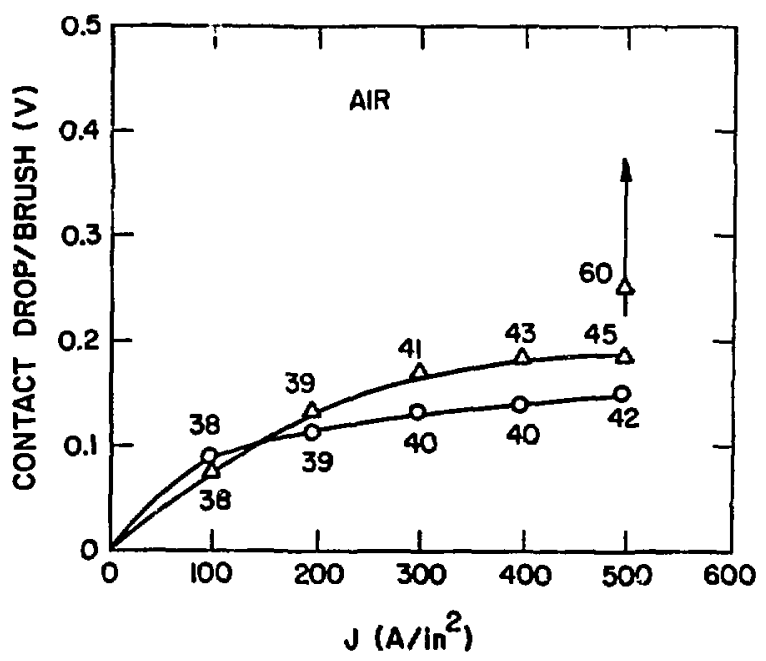

Fig. 15. Contact drop voltage versus brush current for carbon fiber brushes run on silver sliprings in alr. 5 


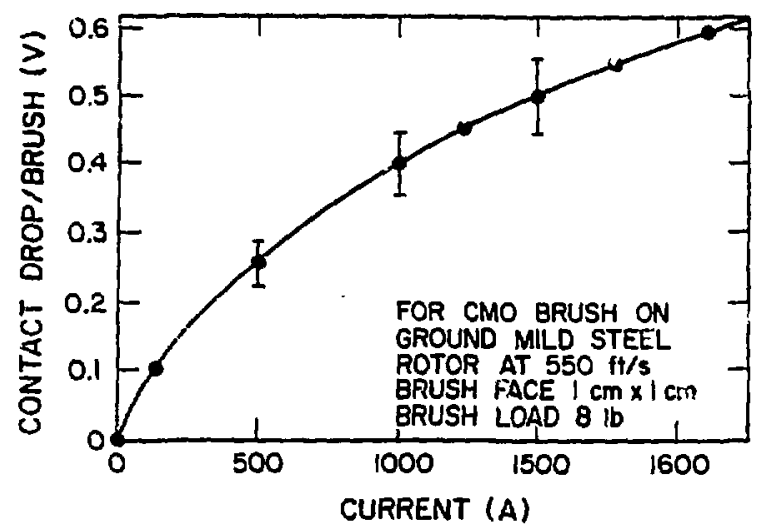

F1g. 16. Contact drop as a function of current for brush grade CMO, used on Canberra machine. 4

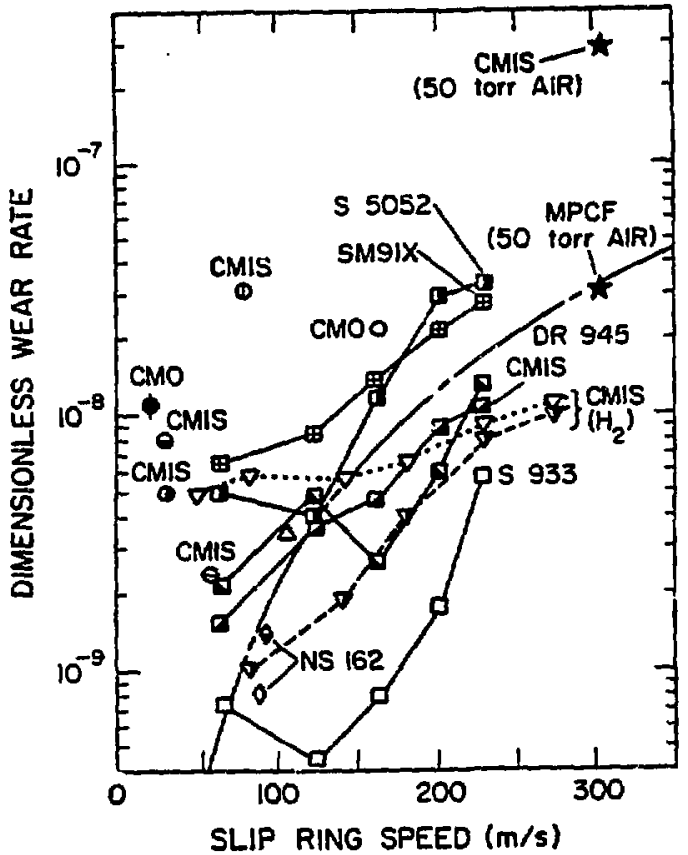

Fig. 17. Variation of wear rate with slip ring speed for several brush grades and atmospheres. 20

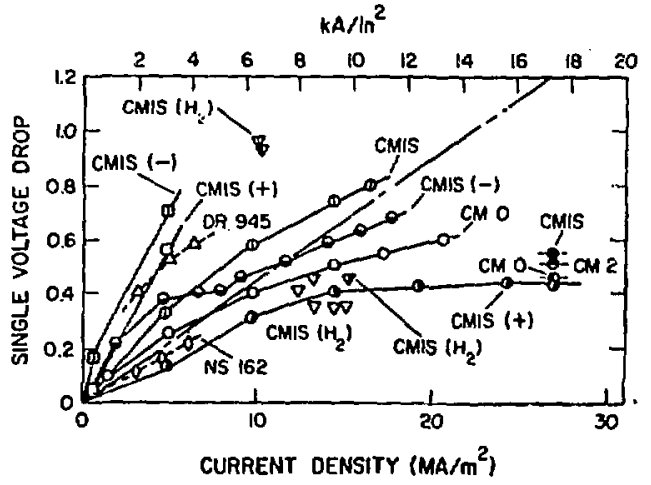

Fig. 18. Variation of voltage drop with current density for several brush grades. 20

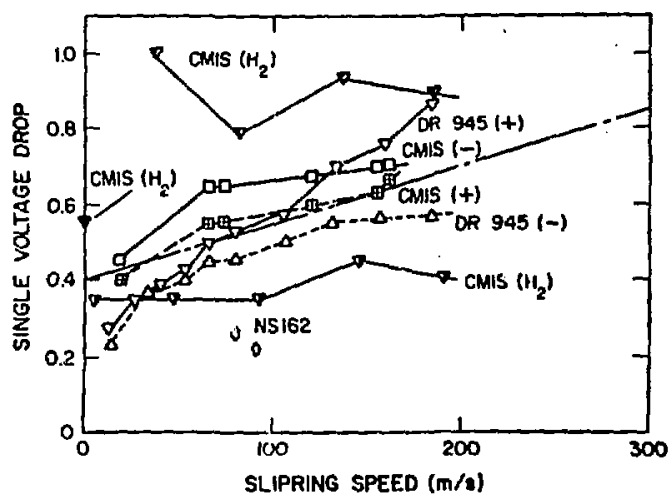

Fig. 19. Variation of voltage drop with slipring speed for several brush grades. 20 


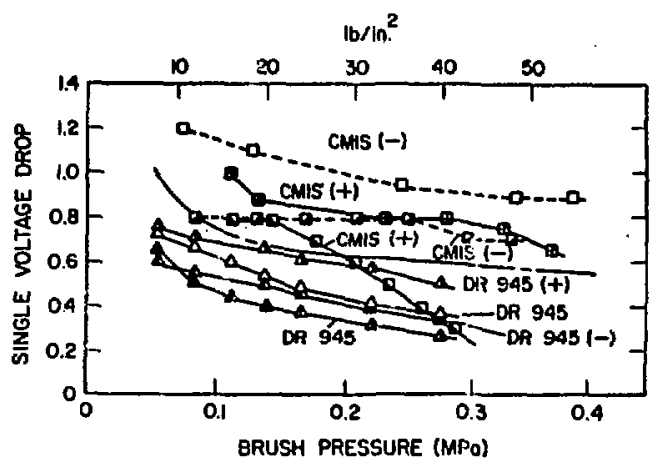

Fig. 20. Variation of voltage drop with brush pressure for two brush grades. 20

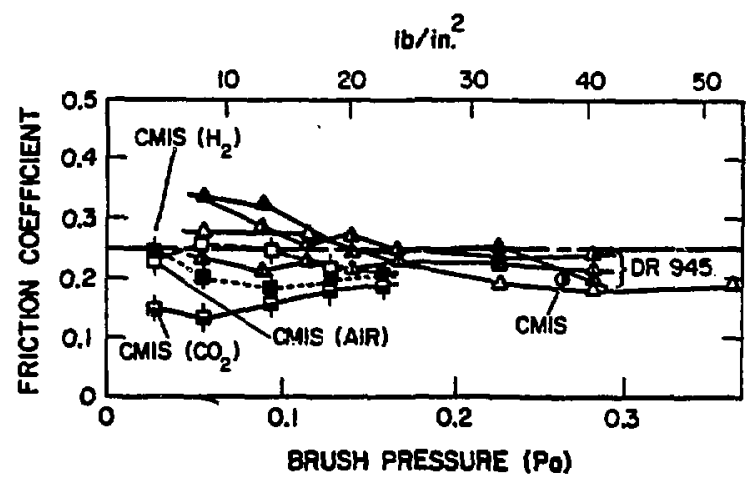

Fig. 22. Variation of friction coefficlent with brush pressure. 20

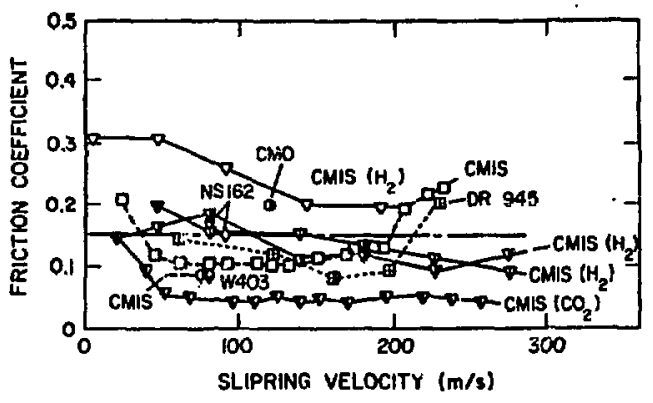

Fjg. 21 . Variation of friction coefficient with slipring speed for several brush grades and atmospheres. 20

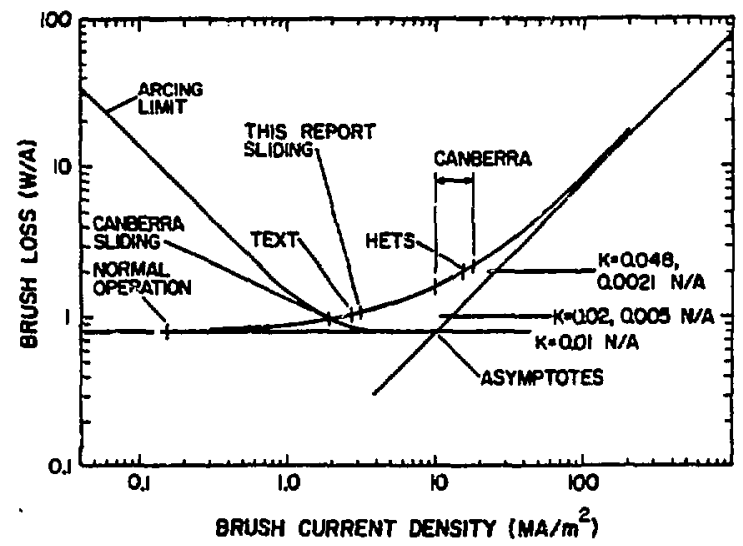

Fig. 23. Total brush loss (contact drop plus friction) per unit current collected for various brush current densities. 


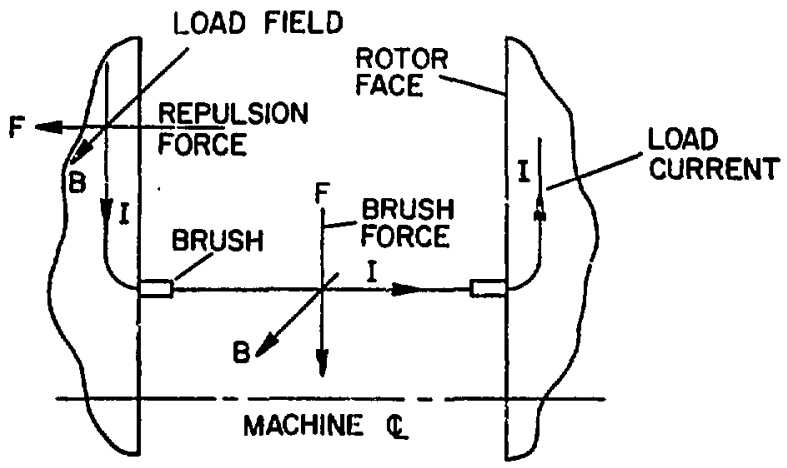

Fig. 24. Load-field, brush-shunt interaction.

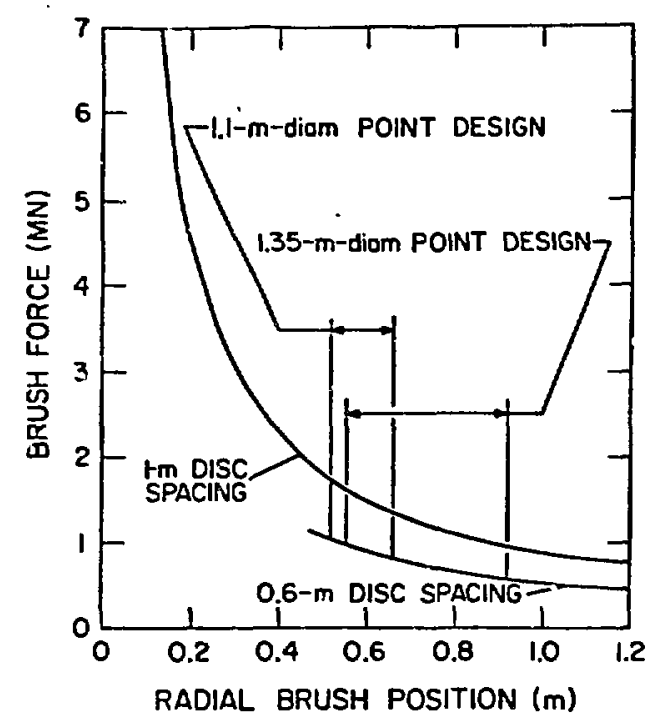

Fig. 25. Brush actuation force for various brush positions at 3-MA current.

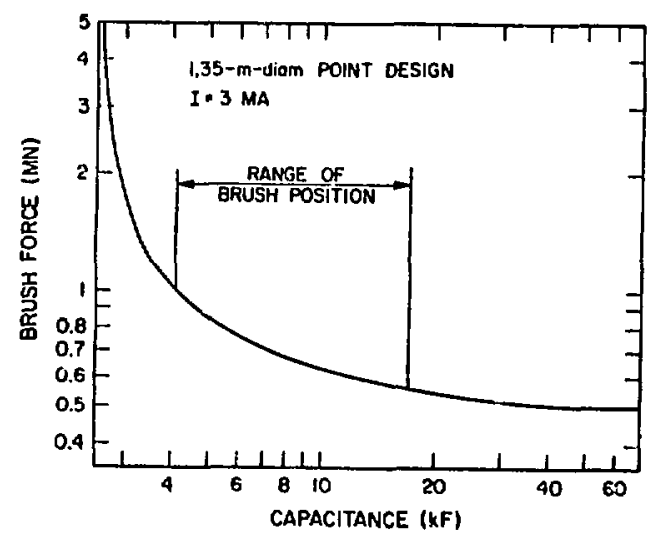

Fig. 26. Brush actuation force as a function of machine capacitance for $1.35-\mathrm{m}$ machine at 3-MA current. 


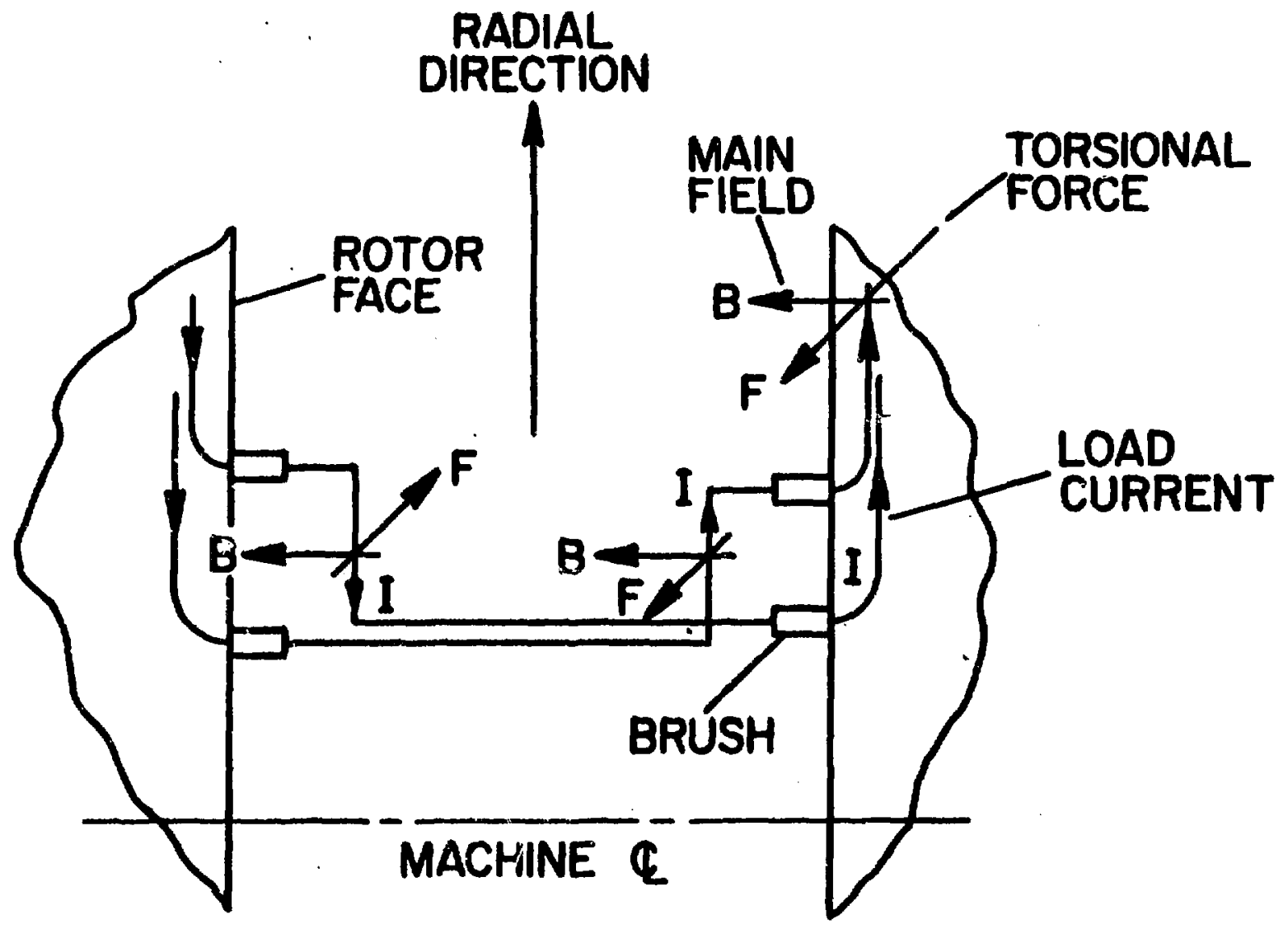

Fig. 27. Myin-fleld, transposed-shunt interaction. 


\section{FERROMAGNETIC ROTOR HOMOPOLAH MACHINE FOR A 3.0-MA OHMIC-HEATING POWER SUPPLY}

by

W. L. Bird and W. F. Weldon

\section{ABSTRACT}

A conceptual engineering design study was performed to characterize an iron dominated, normal copper field coil excited homopolar machine for the General Atomic TNS Doublet tokamak fusion reactor. Inertial energy transfer efficiency of $90 \%$ for the ohmic-heating start-up cycle was used to determine the machine parameters. The resulting pulsed power supply requires two interconnected, single rotor homopolars in the drum configuration. The $500-\mathrm{V}, 500-\mathrm{MJ}, 2-\mathrm{s}$ energy transfer period system costs range from $8.4 \mathrm{mils} / \mathrm{J}$ for the two homopolars alone to $16.4 \mathrm{mils} / \mathrm{J}$ if in the latter case rotor peripheral speed must be reduced and slot and wedge ac generator technology is used.

\section{INTRODUCTION}

A parallel connected ohmic-heating coll system has been proposed for the General Atomic TNS Doublet tokamak fusion reactor. ${ }^{1}$ In the General Atomic (GA) system, a homopolar machine is used to achieve flux reversal during stari-up and plasma current control during the burn cycle. A schematic diagram of the proposed poloidal coils circuit is shown in Fig. 1, and the ohmic-heating coil current waveform is shown in Fig. 2. In this design, the homopolar machine carries the ohmic-heating current during both the start-up and burn periods. The machine capacitance and voltage is controlled by varying the position of the rotor brushes. The Los Alamos Scientific Laboratory (LASL) has analyzed the ohmic-heating circuit and designed a homopolar machine for this duty. The howopolar features include superconducting field coils, counter-rotating disk rotors, and a variable position brush mechanism. The LASL machine is described in paper III of this report.

The Center for Electromechanics (CEM) at The University of Texas at Austin has developed pulsed homopolar generator power supplies using ferromagnetic rotors and normal copper excitation colls and has recently designed a 200-MJ, 500-V, four-module system to drive the TF coils of the Texas Experimental Tokamak (TEXT). 2 The CEM has prepared a conceptual design of a iron core, normal copper homopolar machine system for cost comparison with the LASL superconducting coil 
machine. The CEM design is based on the pulsed duty technology and does not have prorision for the variable capacitance burn cycle duty.

The conceptual design for the GA ohmic-heating system consists of two single drum, 250-MJ, 250-V drum type homopolars connected in series, rather than a modifled TEXT system. The drum design was selected because of the need to have the minimum possible internal impedance for reasonable energy transfer eff'clency at the 3.0 $\mathrm{MA}$ level. The recommended system is used for cost comparison with the LASL machine. Costs are based on proposals and bids for TEXT generator components and are given in 1977 dollars.

\section{SYSTEM ANALYSIS}

In the GA ohmic-heating system, tho homopolar is used as a capacitor to absorb energy from the ohmic-heating colls and then return the energy to the colls in an LC oscillation. The coil is initially charged to $-3.0 \mathrm{MA}$ and is chosen not to exceed the peak design magnetic field and mechanical stresses at the end of the burn cycle. A +4.5-MA current swing in 2 s provides the flux change to induce a plasma current oi $8 \mathrm{MA}$. The current in the ohmic-hesing coll is increased $1.5 \mathrm{MA}$ over $30 \mathrm{~s}$ to maintain the plasma current during the burn.

Two cases were studied to approximate the GA THS Doublet operation. Asymmetric and symmetric start-up with a total 4.5 MA current swing was used to calculate the $I^{2} t$ value for establishing the maximum circuit resistance. Both cases give essentialiy the same value, and the calculations do not include losses in the plasma.

Preliminary estimates of the machine characteristics are obtained by assuming that the ohmic-heating system is an ideal LC circuit. Given that the ohmic-heating coll set stores $500 \mathrm{MJ}$ at $3.0 \mathrm{MA}$, the circuit inductance is calculated to be

$$
L=2 E / 1^{2}=1.11 \times 10^{-4} H
$$

The equivalent homopolar capanitance is then calculated for a 2.0-s start-up time and an initial current. The system parameters calculated in this manner are listod in Table I. 
TABLE I

OHMIC-HEATING CIRCUIT PARAMETERS

Case 1

Case 2

Parameter

Ohmic-heating coll inductance, $\mathrm{mH}$ Generator capacitance, $\mathrm{F}$

Circuit voltage, $V$

Inertial store, MJ

Startup time, $s$

Ohmic-heating coil bias current, MA

Ohwic-heating current swing, MA

Generator $\int_{1}^{2} \mathrm{dt}, \mathrm{A}^{2} \mathrm{~s} \times 10^{12}$

Residual inertial store, MJ

Burn time, $s$

Max ohmic-heating coil current, MA

Max ohmic-heating coll energy, MJ
Asymmetric Start-up

0.111

8200

350

500

2

$-3.0$

4.5

$7 \cdot 1$

375

30

3.0

500

\section{Symmetric Start-up}

0.111

3700

400

280

2

$-2.25$

4.5

5.1

0

$15(30)$

30 (375)

$500(780)$

The naximum circuit resistance allowed $i$ based on an inertial energy transfer efficiency of $90 \%$ and is calculated by

$$
R_{\max }=\frac{\left(0.1 \times 500 \times 10^{6}\right)-W_{B r}}{\int_{0}^{2} i^{2}(t) d t} \text { ohms }
$$

The brush related losses, $W_{B r}$, are the primary machine losses other than $i^{2} R$ losses.

$$
w_{B r}=w_{\text {contact }} \text { op }+w_{\text {rriction }}
$$

These losses are calculated from the following values: 


$\begin{array}{ll}\text { Number of rotors } N_{r} & 2 \\ \text { Double brush contact drop } y & 1.4 \\ \text { Brush current density, } A / \mathrm{cm}^{2} & 775 \\ \text { Coefflolent of friction } & 0.2 \\ \text { Loading force, } N & 67 \\ \text { Maximum surface velocity, } \mathrm{m} / \mathrm{s} & 180 \\ \text { Start-up time, } s & 2.0\end{array}$

The maximum circuit resistance for Case 1 is $5 \mu \Omega$, which excludes the brush contact resistance. The maximum resistance for Case 2 is essentially the same. For comparison the resistance of four TEXT generators is $52 \mu \Omega$ without the brush drop. Even with modifications of conductor material and cross-sectional area, the minimum machine resistance total is $20 \mu \Omega$, which is the resistance of the stainless steel shafts and $43: 0$ steel rotors. Busbar resistance and brush drop again are not included. Therefore, a modified TEXT system is not recommended because of the low efficiency of such a system.

\section{HOMOPOLAR MACHINE CONFIGURATION}

The drum configuration is desirable for the GA system because the internal Impedance can be much smaller than a comparably sized disk or spool homopolar machine. The lower internal impedance is one reason that the drum configuration was selectel for the $95 \%$ efficient homopolar energy transfer and storage system (HETS) for the Reference Theta Pinch Reactor (RTPR).3 One disadvantage of the drum configuration is this: the number of modules required can be extremely sensitive to the brush packing factor, which can cause the active rotor length to become only a fraction of the total length of th notor. This could result in excessive inertial capacity of the individual rotor module. Wesinghouse has proposed an "I" shaped rotor to resclve this problem by reducing the inertia of the rotor at a given voltage. 4 However, this design is subject to a stress concentration due to bending of the slip ring. A solid cylindrical rotor is preferred provided that a match of energy and voltage can be obtained with a reasonable number of modules.

Two rotor configurations can be used in the ferromagnetic drum design. These configurations are shown in F18. 3. Configuration B is a higher capacitance derice because the active rotor length is only $50 \%$ of the radius. It is proposed for low-voltage welding applications. The first topology, configuration A, is a lower capacitance, higher voltage machine hacter suited for 
driving the ohmlc-heating colls, and this design is used for sizing the generator system.

The length of one current collector ring, $L_{C}$, is given by

$$
\mathrm{L}_{C}=\frac{I_{\max }}{J_{B r^{2 \pi r}{ }_{o}{ } P_{z}}} m \text {, }
$$

where

$$
\begin{array}{ll}
I_{\max }, A & 3 \times 10^{6} \\
J_{B r}, A / m^{2} & ? .75 \times 10^{6} \\
P_{\theta} \text { is circumferential packing factor } & \sim 0.24 \\
P_{z} \text { is axial packing factor } & \sim 0.85 \\
r_{0} \text { is the rotor radius, } m . &
\end{array}
$$

The total rotor length is given by

$$
L=L_{a}+2 L_{c}=L_{a}+\frac{k}{r_{0}} m \text {, }
$$

where $L_{a}$ is the active length of the rotor and $k=I_{\max } / \pi J_{B r}{ }^{P} P_{z}$ for two current collectors.

If $N_{p}$ is the number of passes per rotor, $N_{r}$ is the number of rotors, $v$ is the rotor peripheral speed $(\mathrm{m} / \mathrm{s})$, B is the average magnetic flux density (tesla), and $\gamma$ is the rotor mass density $\left(\mathrm{kg} / \mathrm{m}^{3}\right)$, the homopolar energy and voltage are given by

$$
\begin{aligned}
& E=\frac{1}{\pi} \pi r_{0}{ }^{3} v^{2} N_{r}\left(\frac{L_{a}}{r_{o}}+\frac{k}{r_{o}^{2}}\right) J \\
& V=B_{0} N_{0} N_{r}\left(\frac{L_{a}}{r_{o}}\right) v .
\end{aligned}
$$


For a uniform field flux density, $\mathrm{L}_{a} / \mathrm{r}_{\mathrm{c}}$ must be set $\leq 1.0$. To determine the system configuration, the above equations are solved for $N_{r}$ and $r_{0}$ as a function of rotor peripheral speed $v$ and the gross collector area (divided by $\pi$ ), $k$. values assumed for the other variables are

$\begin{array}{ll}\mathrm{B} & 1.5 \mathrm{~T} \\ \gamma & 7792 \mathrm{~kg} / \mathrm{m}^{3} \\ \mathrm{~L}_{\mathrm{a}} / \mathrm{r}_{\mathrm{o}} & 1.0 \\ \mathrm{~N}_{\mathrm{p}} & 1 .\end{array}$

Two values of $k$ are used. The value $k=0.6$ represents the packing factor used in the CEM 5-MJ generator. 5 The value $k=1.2$ represents the packing factor used in the TEXT module design. The number of rotors and rotor radius are plotted in Fig. 4 .

The effect of the brush packing factor on collector length and number of rotors is pronounced for the $k=1.2$ case. It is seen that approximately two rotors are required for the $k=0.6$ case over the nominal range of rotor peripheral velocities. Therefore, the lower cost system occurs at higher velocities because the rotor radius decreases with increasing speed for the same number of rotors. The speed selected for the point design is $180 \mathrm{~m} / \mathrm{s}$ based primarily on thermal limits of the brush slip ring interface rather than on rotor stresses.

IV. HOMOPOLAR MACHINE

The homopolar machine design selected for cost analysis is described in Table II. A sketch of the homopolar is shown in Fig. 5. The rotor radius and fleld flux density are adjusted because the number of rotors was reduced from 2.1 to the integral number 2. The two single rotor machines are connected electrically in series by four sets of busbars which are sized to maintain system resistance at approximately $5 \mu \Omega$.

Current enters and leaves the machines proper via two copper disks located at the axial center of the machines. A water-cooled copper cylinder mounted inside the cast steel yoke provides a low-1nductance return path for the rotor current. 
TAELE II

HOMOPOLAR MACHINE DESIGN PARAMETERS (one rotor)

$\begin{array}{ll}\text { Energy store, MJ } & 250 \\ \text { Voltage, V } & 250 \\ \text { Rotor tip speed, m/s } & 180 \\ \text { Rotor diameter, m } & 1.74 \\ \text { Rotor active length, m } & 0.87 \\ \text { Rotor total collector length, m } & 0.70 \\ \text { Brush current density, A/cm } & 775 \\ \text { Axial brush packing factor } & 0.85 \\ \text { Circumferential brush packing factor } & 0.24 \\ \text { Radial air gap, cm } & 3.8 \\ \text { Axial air gap each end, cm } & 3.8 \\ \text { Airgap flux density, T } & 1.6 \\ \text { Shaft diameter, m } & 0.36 \\ \text { Outer yoke diameter, m } & 2.8 \\ \text { Rotor mass } 4340 \text { steel, kg } & 27,700 \\ \text { Shaft mass 304 stainless, kg } & 2,740 \\ \text { Yoke mass cast steel, kg } & 94,900 \\ \text { Armature copper, kg } & 2,520 \\ \text { Field copper, kg } & 2,180\end{array}$

\section{A. Yoke and Field Coll}

The excitation coils provide the magnetomotive force to drive the flux across the reluctance of a 3.8-cm radial air gap and a 3.8-cm axial air gap. Thes axial air gap could be much smaller because no conductors are located in the gap. However, the thrust and tilt magnetic forces are inversely proportional to the gap width, and the large axial gap is maintained to allow reasonable bearing loads and manufacturing tolerances. The mag:itude of these forces are described for the TEXT disk configuration by Driga. 6 The yoke is constructed of cast steel and is designed for a magnetic flux density of 1.6-T. The excitation coils are constructed in two sets of six water-cooled copper pancake coils for each machine. The coils are similar in construction to the TEXT field coils and utilize the same conductors and insulation system. Each coil set has 132 turns at $735 \mathrm{~A}$. The homopolar machine exciter power supply is rated at $180 \mathrm{~A}$ ( $150 \mathrm{kw})$ to allow a 157 current margin.

\section{B. Rotor and Shaft}

The rotor is constructed in the same manner as the TEXT rotor. The rotor material is 4340 steel, which is shrunk fit onto a $0.36-m-d i a m$ stainless steel shaft. The shaft material is nonferromagnetic so that field flux in the bearing area is minimal. The interference fit is designed so that the interface pressure 
is greater than zero for speeds below $130 \%$ of the maximum operating speed. The shaft diameter is set by bending deflection constraints. The first system critical frequency occurs well above $130 \%$ speed. The maximum effective rotor stress occurs at the rotor shaft interface and is approximately $378 \mathrm{MPa}$ $(55,000 \mathrm{ps} 1)$. As a result of the shrink fit, the maximum stress is relatively independent of speed. Any alternating rotational stresses are smaller than 378 MPa and are well below the endurance limit of the rotor material.

\section{Bearings}

The bearings selected for the ferromagnetic homopolar machines are of hydrostatic design because of the large magnetic forces and the need for high load capacity at zero speed. (The TEXT generators have a hydrodynamic thrust bearing with hydrostatic lift for starting and stopping. However, the TEXT generators stay above $60 \%$ of the maximum operating speed at all times during the operating cycle.) The bearing load capacity is sct by the rotor weight and magnetic forces. The axial magnetic thrust force is approximately 44,000 N $(10,000 \mathrm{lb})$. Radial magnetic forces are of the same magnitude, possibly higher. Because the field coils must be excited at zero speed, hydrostatic bearings are essential to insure reliable operation, especially during starting.

One disadvantage of the hydrostatic bearing is that a relatively high-power, high-pressure $(1,000 \mathrm{psi})$ oil supply system is reruired. In a power plant, a completely redundant ofl supply system is necessary in the event of a pump or line fallure. The redundant supply must be driven from a noninterruptible power source, either station batteries or by steam.

\section{Brushes}

The pulsed homopolar machine technology is based on sintered copper-graphite brush material. The brush material used in the Texas iachines is Morganite CM1S. The brush actuation mechanism for the ohmic-heating start-up duty is more complicated because it must allow rotation in two directions. If the start-up ohmic-heating current reversal is symmetrical, the machines will start and stop from standstill so that an elaborate adjustable wear-actuation mechanism is not required. It is not necessary to lift the brushes between pulseg. However; if the start-up current swing is not symmetrical, the brushes should be lifted after current interruption to reduce brush friction, heating, and wear. In that case, a TEXT brush mechanism, modified for bidirectional rotation, is required. 


\section{E. Cooling}

A combination of water cooling and forced air ventilation is required to reject the internal losses of the TEXT generators. A similar scheme is proposed for the GA ohmic-heating machine. However, it will probably be necessary to increase the relative capacity of the blowers in the forced air system to increase the volume of air flow. For a symmetrical. reversal during start-up, the machine is at rest for $97 \%$ of the cycle. The flow must be increased to obtain higher convection coefficients because there is no relative motion as a result of the spin of the rotor.

\section{F. Machine Saturation of Roior}

One problem with the simple solid steel rotor is that the rotor may be saturated by the armature field flux at very high-current levels. The stator iron is shielded from the armature current flux by the copper return conductors. However, the rotor current path is through the outer surface of the rotor. The steady state circumferential magnetic field the rotor surface is given by

$$
B_{\theta}\left(r_{0}\right)=\frac{\mu_{r} \mu_{o} I}{2 \pi r_{0}} \text { tesla }
$$

for $I=3 \times 10^{6} \mathrm{~A}, \mathrm{r}_{\mathrm{O}}=0.87 \mathrm{~m}$, and

$$
B_{\theta}=0.7 \mu_{r} \text { tesla, }
$$

where $\mu_{r}$ is the relative permeability of the rotor steel. From the magnetization curve for 1010 steel plate, the self field $B_{\theta}$ is found to be about $3.0 \mathrm{~T}$. The total flux density is greater than $3 \mathrm{~T}$.

To accurately predict homopolar machine performance in the pulse mode, a two-dimensional transient nonlinear magnetic diffusion analysis is required. The CEM has a computer code that can be used for this analysis, but the cost of running a nonlinear 2-s problem would be prohibitive for this study. The effect of saturation has been observed in the 5-MJ generator at current levels of $200 \mathrm{kA}$. The reduction in the field flux density is only a few per cent at that magnitude of current. At the maximum discharge current,560 kA, no appreciable drop in performance was observed. However, homopolar machine performance at currents above one megampere is uncertain. 
It is desirable to clad the rotor with a copper cylinder to avoid the saturation of the rotor iron. The excitation current must be increased $33 \%$ because of the volume replaced by copper. It is also desirable to bond the copper to the rotor in a manner that allows differential thermal expansion axially without sacrificing the ability to transfer torque to the rotor steel. Because only $10 \%$ of the rotor inertia would be in a $2.5-\mathrm{cm}$ copper sleeve, $90 \%$ of the accelerating torque must be transmitted by the bond in shear. The peak reversing shear stress is small ( $1 \mathrm{MPa}-145 \mathrm{psi}$ ) because of the relatively large area of the rotor periphery. The hoop stress on a $2.5-\mathrm{cm}$ ring is $275 \mathrm{MPa}$ $(40,000 \mathrm{psi})$ at $180 \mathrm{~m} / \mathrm{s}$. The actual stress seen by the sleeve is smaller because of the bond to the higher modulus steel. The yield strength of hard 182 chromium copper is $380 \mathrm{MPa}(55,000 \mathrm{psi})$, so that a copper sleeve could be run at that speed. A complete fatigue analysis and mechanical and thermal design is required before relying on this approach. If conventional slot and wedge ac machine technology is required, the $t i p$ speed would be reduced to $145 \mathrm{~m} / \mathrm{s}$ and three modules of the same size at a field of $1.3 \mathrm{~T}$ would be required. The base system cost would be increased by more than $50 \%$.

\section{G. Circuit Impedance}

Each solid steel rotor homorolar machine has an internal resistance of $1.9 \mu \Omega$ plus the sliding bruish contact resistance of $0.5 \mu \Omega$ at $3 \mathrm{MA}$. The inductance of the air gaps a'dd nonferromagnetic conductors is approximately $15 \mathrm{nH}$. The rotor inductance is time variant with a maximum value of $510 \mathrm{nH}$ if the rotor does not saturate. A system of two single drum rotor machines with $6 \mathrm{~m}$ of interconnecting busbar and $19 \mathrm{~m}$ of load busbar to the superconducting coil terminals represents an impedance of $6.9 \mu \Omega$ and $1.3 \mu \mathrm{H}$ with a $2.8-\mathrm{V}$ brush contact resistance drop. The initial inductance of the circuit exclusive of the rotor Inductance is $260 \mathrm{nH}$. System resistance and inductance values are listed in Table III. It should be noted that no static contact resistance is included. Therefore, one must assume that internal machine joints and busbar connections are welded or silver soldered. 

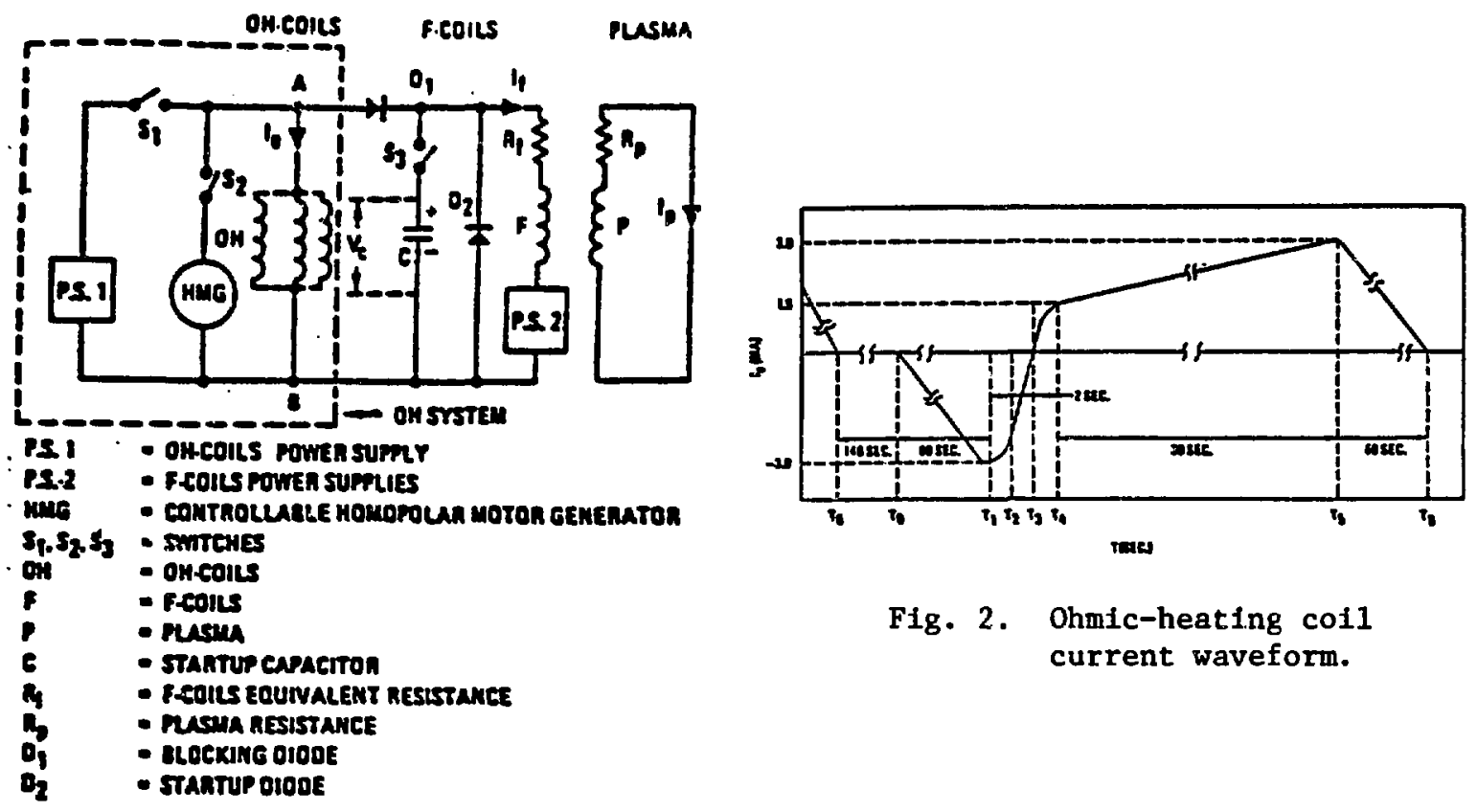

Fig. 2. Ohmic-heating coil current waveform.

Fig. 1. Schematic diagram of the poloidal colls circuit.

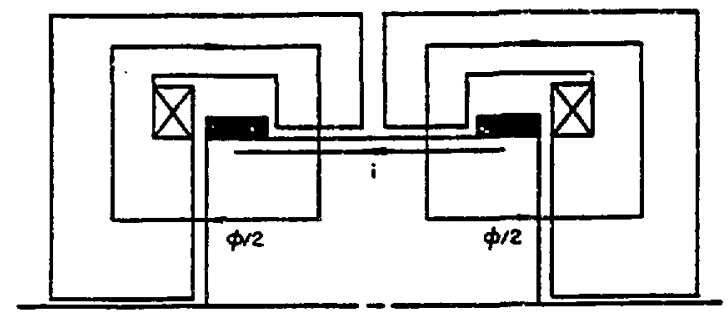

(a) Homopolar machine drum configuration $A$.
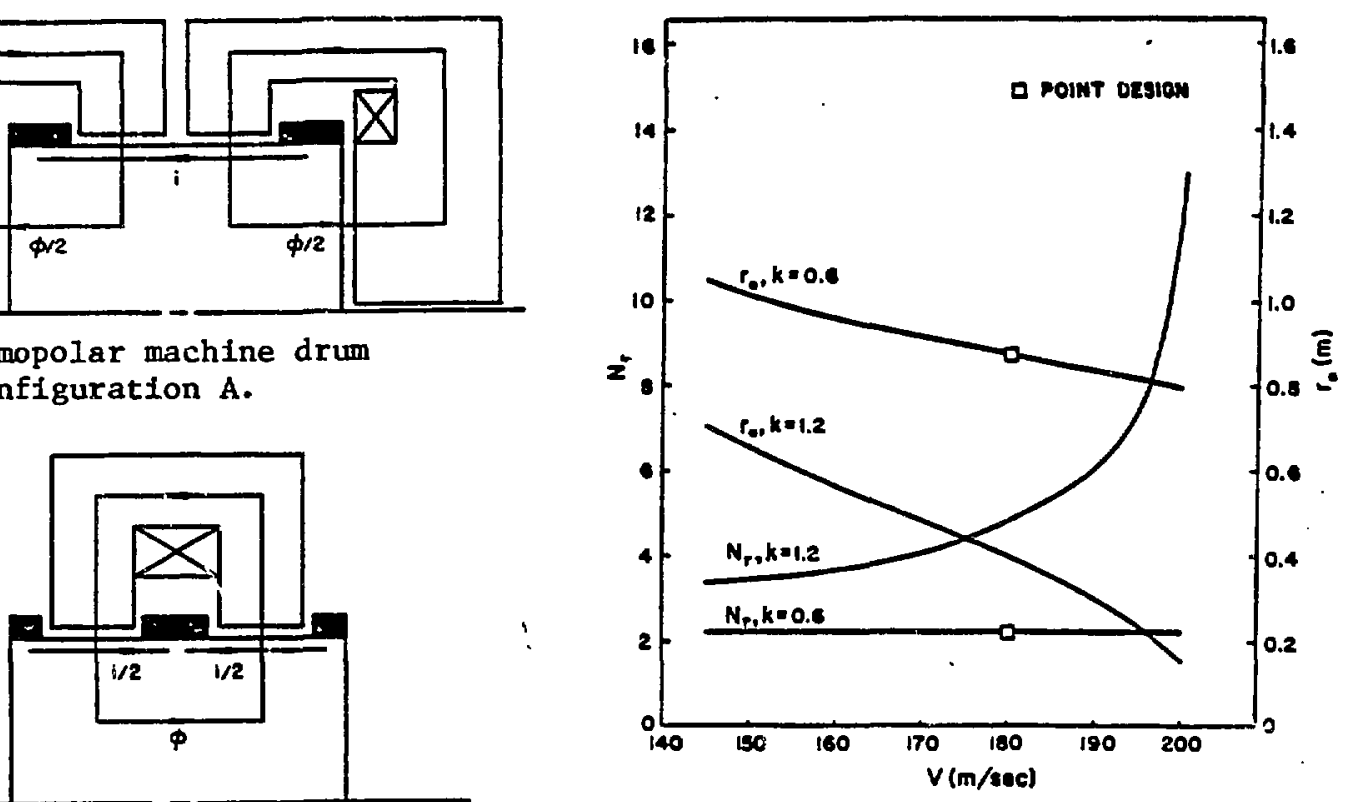

(b) Homopolar machine drum cōñfiguration $B$.

Fig. 4. Rotor radius and number of modules of $500-\mathrm{V}, 500-\mathrm{MJ}$ drum homopolar machine system vs rotor surface speed. 
1s approximately 8.4 tils/J. The cost of the machines plus busbar is approximately $10 \mathrm{mils} / \mathrm{J}$. If magnetic saturation of the rotors requires a copper clad rotor, the cost w111 be increased. A greater cost would occur if the rotor peripheral speed is reduced $20 \%$ to accommodate conventional ac generator rotor technology. In that case the cost would be on the order of $16.4 \mathrm{mils} / \mathrm{J}$. All costs are in 1977 dollars.

\section{REFERENCES}

1. W. E. Toffolo, W. Y. Chen, J. R. Purcell, and A. C. Wesley, "Parallel Connecting Pololdal Coll System for a Doublet Tokamak Fusion Reactor," General Atomic Company, Proceedings of the Seventh Symposium on Engineering Problems of Fusion Research, Knoxvilie, Tennessee, October 25-28, 1977.

2. W. L. Bird, G. B. Grant, W. F. Weldon, H. G. Rylander, and H. H. Wocdson, "System Engineering and Design of a Pulsed Homopolar Jenerator Power Supply for the Texas Experimental Tokamak," Center for Electromechanics, The University of Texas at Austin, Proceedings of the Seventh Symposium on Engineering Problems of Fusion Research, Knoxville, Pennessee, October 25-28, 1977 .

3. K. I. Thomassen, Editor, "Conceptual Engineering Design of a One-GJ Fast Discharging Homopolar Machine for the Reference Theta-Pinch Fusion Reactor," EPRI Semi-Annual Report, EPRI ER-246, August 1976.

4. F. M. Heck, E. I. KIng, Jr., and R. E. Stiliwagon, "Experimental Power Reactor Ohmic Heating Energy Storage Study," Westinghouse Electric Corporation, WFPS-TME-038, November 1976.

5. W. F. Weldon, M. D. Driga, H. H. Woodson, and H. G. Rylander, "The Design, Fabrication, and Testing of a Five Megajoule Homopolar Motor-Generator," International Conference on Energy Storage, Compression, and Switching, Torino, Italy, November 5-7, 1974.

6. M. D. Driga, W. L. Bird, K. M. Tolk, W. F. Weldon, H. G. Rylander, and H. H. Woodson, "Electromagnetic Torques and Forces Due to Misalignment Effects and Eddy Currents in the Homopolar Generator Power Supply for the Texas Experimental Tokamak (TEXT)," Center for Electromechanics, The University of Texas at Austin, Proceedings of the Seventh Symposium on Engineering Problems, of Fusion Research, Knoxville, Tennessee, October 25-28, 1977 . 
TABLE IV

OHEIT-HEATING HOMPPOLAR MACHIHE COSTS

Ioke:

(209,100 1b at $1.00 / 1 b)$

$\$ 209,100$

stator ateel

Mach ine mount ing structure

Fasteners and alsellaneous

Inarrubentation

Rotor.

$(61,06010$ at $12.71 / 10)$

165,500

Shart:

$(6,04710$ at $\$ 6.57 / 10)$

39,800

Field Coll:

(4,820 2b at $\$ 6.95 / 1 \mathrm{~b}$ )

33,500

Coll support structure

Coollng manifolds

Connection and atsollaneou*

Instrugenlation

Brushes:

(1,200 Br at $\$ 296 / 8 r)$

Brushes and shunts

$(120,000)$

ucturtion oechenis

Pneumatic Iines and connections

Instrumentsetion

Arveture conduotors:

(4,896 Ib at $\$ 6.95 / 1 \mathrm{~b}$ )

34,000

Coppor conductors

Insulation

Fasteners and miscellaneous

Instrunentation

Cooling:

Blowers and humidifiers

Ductwork

Pulters

Instrumentation

Puaps and reservoire

Defonlzed water oupply

Heat exchengors

lines and connoctions

Instrumentat 100

Bear1ngs:

$(67,00010)^{2 / 3}$ at $\$ 120$ (we1eht-10 $)^{2 / 3} 198,000$

Hydrostatic journal benringa (2)

Hydrostatic thrust bearing

Maln bearing supply

huxlliary bearing aupply

Seals

Cnnections and of scollanoous

Instmmentation

Controls:

100,000

Standby powar:

(250 MJ stored Inertial enercy at $8200 / \mathrm{MJ})$

50,000

Station battery bank

Control power battery-Inverter

Interconnect ions

Ins trumentat ion

Subtotel

$\$ 1,324,520$

$(1,089,750) \cdot$

Assembly:

250,000

Installation:

250,000 est

Total

$\$ 1,824,900$

$(1,589,700)=$

Project adainistrotior ot 20 s estimated

365,000

$(318,000)$

201,000

Mamufecturer's ree at 119 estinated

$(175,000)$

Totel cost per one-rotor enchine exciuding shipping

$\$ 2,390.900$

$(2.070 .560)$

-Less conplex brush aechanden. 
TABLE III

GENERATOR AND CIRCUIT IMPEDANCE

Component

Generator armature copper (2 machines)

Generator rotor (2 machines)

Generator interconnect bus

Load connect bus

Total

With 2.5-cm copper sleeve on rotor.
Resistance.

1.2

$2.6(0.32) *$

0.8

$2 \cdot 3$

$6.9(4.6) *$
Inductance, $\mathrm{nH}$

28

$1020(4.2) *$

52

150

$1250(234) *$

\section{v. SYSTEM COSTS}

The homopolar machine system costs are based on bids received during the TEXT englneering design pertod. The component costs include materials, manufacturing, and engineering costs. The assembly and installation costs are estimated. The contractors' markup of purchesed items and fee are also estimates. The rotor costs are for the solid steel rotor rather than for a copper sleeved rotor. The single rotor homopolar cost detall is listed in Table IV.

The two homopolar machine system cost then is approximately $\$ 4.8 \times 10^{6}$ based on extrapolated TEXT costs. However, it is probable that a less expensive brush actuation mechanism can be used so that the total cost is reduced to $\$ 4.2 \times 10^{6}$. It should be realized that extremely large cross-section copper bus is required to maintain high $(90 \%)$ system efficienoy. If the interconnecting bus length is $6 \mathrm{~m}$ and the bus to the load is $19 \mathrm{~m}$ in length, $150 \mathrm{~kg}(325,000 \mathrm{lb}$ ) of copper are required. The cost of the busbar installed w1ll add $\varepsilon i$ least $\$ 1.0 \times 10^{6}$ to the system cost.

VI. SUMMARY

A point design for the General Atomic TNS Doublet tokamak fusion reactor ohmic-heating power supply has been made. The pulsed power supply is composed of two, single rotor, homopolar machines in the drum rotor configuration connected in series. The machines have a ferromagnetic rotor and normal copper excitation colls. They are designed to be used only during start-up so that a separate burn power supply is required. The cost of the two howopolar machines 


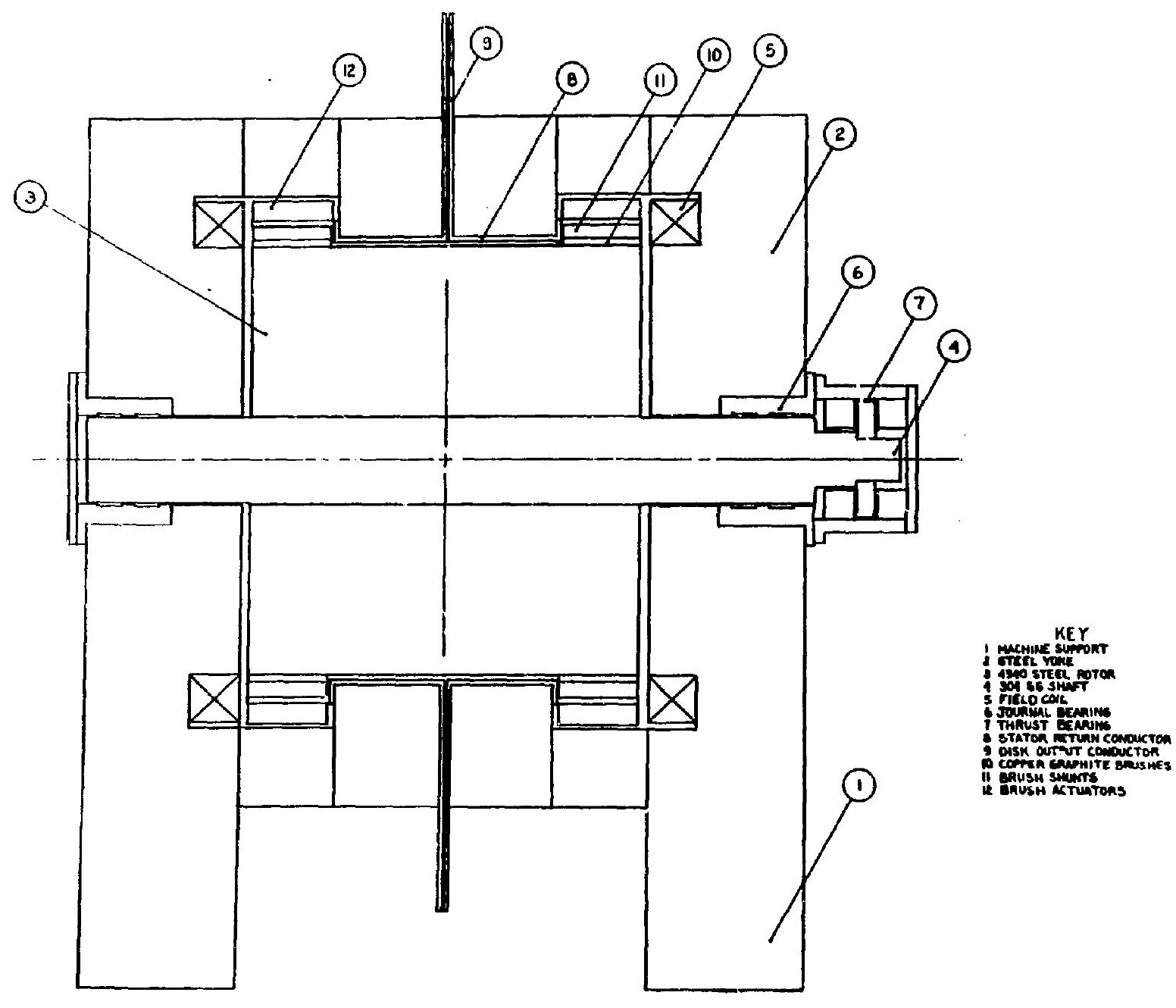

Fig. 5. Homopolar machine sketch showing major detalls. 


\title{
V. CIRCUIT BFEAKER AND BUS
}

\author{
H. F. Vogel
}

\begin{abstract}
Two olose-open operations are required each pulse oyole at approximately $3 \mathrm{MA}$ with the breaker in series with the burn supply, both forming a leg in parallel with the E-ooll and the homopolar. To oonduot the 3-MA ourrent, approximatley 30 breaker units are conneoted in parallel. Each unit is equipped with a counterpulse oapaoltor bank, and the bus for the 30 units is provided with a common saturable reactor core made of strip steel wound around the bus. Oll breakers of a special design are ohosen beoause of their high arc resistance raollitating the current transfer to the homopolar maohine and for obtaining precision timing in opening and closing of the contacts. The precision timing is achleved by a shock wave method with the oil serving as hydraulic medium. Each of the parallel breaker units possesses two sets of contacts, a stationary and a transient one. A $1-\mathrm{m} \Omega$ resistor in series with the transient contacts of each breaker unit is to improve the current sharing. The bus consists of room temperature copper, stranded and transposed to help provide current equalization under transient conditions.
\end{abstract}

\section{INTRODUCTION}

Two close-open operations are required each pulse cycle at approximately $3 \mathrm{MA}$ as shown in Fig. 1 of the first paper in this report. Conduction and interruption at 3 MA represent a breaker duty of a severity probably achieved never before. It is conselvable, however, that this might be accomplished with many, such as 30, relatively inexpensive breaker units operating in parallel and in synchronism. Some characteristic design numbers regarding the counterpulse circuit are indicated in the first section of this report, where it is shown that the cost of the counterpulse circuits increases with the effective duration of the counterpulse. The 30 circuits must be synchronized as accurately as possible to mintmize the counterpulse duration. Current interruption is facilitated by the large effective capacitance of the homopolar, which is most important in making the 3-MA current transfer possible. Aiding the current transfer further is the relatively large arc drop characteristic of air and oil breakers, whose selection is, therefore, also essential. 0 il breakers possess the greatest arc resistance, but their arc sharacteristic is not best for parallel operation. Air breakers, on the other hand, do not function well for interrupting the small currents present during the counterpulse while the 
reactor core is unsaturated. It would thus be necessary for an airbreaker to be provided for electromagnetic as well as pneumatic arc extinction. For this reason and because of the high precision desired for the breaker synchronization in opening and closing, an ofl breaker of a spectal design appears to be suitable. The ofl serves the dual function of a medium for hydraulic actuation to obtain the precision timing and of an arc cooling medium to provide high pressure and velocity. The high pressure is obtained in the oil by a "water hammer" type of action in which the duration of the high pressure pulse is set by the length of a shock wave channel that measures $5 \mathrm{~m}$, corresponding to 8-ms counting one wave reflection. The hydraulic pressure forces the fluid at high velocity through the space opening between the parting contacts. This configuration is shown in Fig. 1.

There are two sets of contacts. The stationary contacts are designed for operation at $3 \mathrm{MA}$ with a duty factor of 45\%, whereas the transient contacts are designed to operate in series with a $1-\mathrm{m} \Omega$ resistor for current equalization and to serve as electrodes for an arc at low current.

The connecting bus measures $0.5 \mathrm{~m}^{2}$ in cross section of room temperature copper, which is subdivided in multiple strands transposed to obtain equal surrent sharing even under transient conditions. The stranding is indicated in Fig. 2 of paper I of this report and is typified in Fig. 2 of this paper. The latter was drawn for a somewhat similar configuration designed for the test facility of the 1.5-MA, 30-ms HETS homopolar machine.

\section{SWITCH FEATURES}

The following sections give the details in outline form of a conceptually engineered spectal oll breaker as described above.

\section{A. Stationary Contact}

1. Contact materials; brass on brass, ${ }^{1} \mathrm{co}=6.7{\mathrm{~m} \Omega \mathrm{N}^{\mathrm{m}}}^{\mathrm{N}}$

2. Edge contact, form modulus ${ }^{2} \quad m=0.7$

3. Contact resistance $R_{c}=1.5 \mu \Omega$ for contact load $F_{c}=150 \mathrm{kN}$

where $F_{c}=\left(\rho_{c / R_{c}}\right)^{1 / m}$

4. Temperature rise $^{3}$ for $100 \mathrm{kA}, 0.45$ duty factor,

$$
\text { i.e., } I_{\text {rms }}=67 \mathrm{kA} \text {, contact }
$$

rms voltage drof $=107 \mathrm{mV}: \Delta \mathrm{T}=131 \mathrm{~K}$ 
5. Coefficient of static frlotion brass-brass $=0.19$

6. Binding wedge half angle $=\operatorname{ar}\left(s \sin 0.010=11^{\circ}\right.$

7. Cone half angie $\alpha=35^{\circ}$

8. Axial force necessary for obtatning ihy

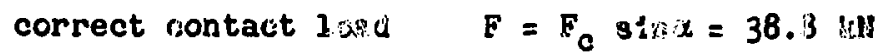

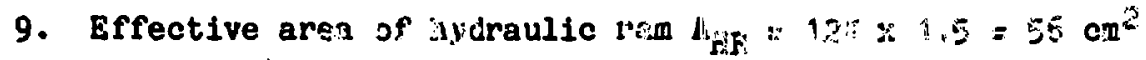

10. Requirec hy diandlo prossuris $=71 \mathrm{kmr}$

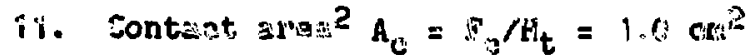

where $a_{t}=0.5 \times s_{3}=10^{3} \mathrm{~N} / \mathrm{m}^{2}$

with bineli hardnels $\mathrm{g}_{33}=1.7 \times 10^{9} \quad \mathrm{Hm}^{-2}$ and Porm tactor 0.5 for wedge shaped contast in which tho hose angjis of the plug $19 \sim 0.5^{\circ}$ smasler than

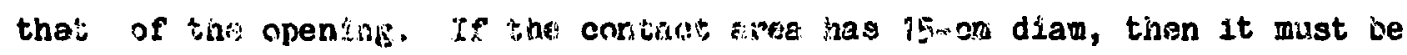
$0.2 \mathrm{~mm}$ wide. It $\therefore$ suffjolant, therefore; to bujld the contact $\mathrm{rdm} 2 \mathrm{~mm}$ wide.

\section{B. Transient Conteat}

1. Contact matertals: brass or boss, $O p=6.710 \Omega \mathrm{N}^{\mathrm{M}}$

2. Edge contact, form wodulus $\quad \mathrm{z}=0.7$

3. Contact resistance $\mathrm{B}_{c}=10 \mu \Omega$ for contact $20 a d$

$$
\mathrm{F}_{\mathrm{c}}=11 \mathrm{kN}
$$

4. Temperature rise for $100 \mathrm{kA}, 5 \times 10^{-5}$ duty factor (1.e., 15-ms conduction, $300 \mathrm{~s}$ off), of $I_{\text {rms }}=0.7 \mathrm{kA}$, rms voltage drop $10 \mathrm{mV}: \Delta \mathrm{T}=10 \mathrm{~K}$

5. 24 contact fingers, $1.5 \mathrm{~cm}$ wide, each, $450 \mathrm{~N}$, each modulus of elasticity $\mathrm{E}=$ $9 \times 10^{10} \mathrm{Nm}^{-2}$ finger thickness $=1.3 \mathrm{~cm} ;$ finger length = $2 \mathrm{~cm}$; fingar deflection $=0.1 \mathrm{~mm}$; stress $=500 \mathrm{~N} / \mathrm{mm}^{2}$, which requires the fingers to be made of high-strength bronze.

\section{c. 1-m? Series Registor}

Material: slectrographite, disk with inside radius $\sim 7.5 \mathrm{~cm}$, outside radius $=32 \mathrm{~cm}$; connected to the contact fingers on inside radius; thickness $2 \mathrm{~mm}$; average temperature rise, adlabatically, during $\leq 15-\mathrm{ms}$ conduction < $100 \mathrm{~K}$. Note, due to heat sinking, the outside radius may be reduced to $\sim 25 \mathrm{~cm}$.

\section{Hydraulte Flow}

1. Kinematic viscosity $v=n / \rho=0.196 / 850=230.8 \times 10^{-60} \mathrm{~m}^{2} \mathrm{~s}^{-1}$ 
2. Reynold's number for laminar flow $R_{e}=2300$

3. Hydraulic diameter $D=4 \mathrm{~A}_{\text {flow }}$ /perimeter

$$
v_{\text {crit }}=R_{e} \frac{v}{D}
$$

4. Flow through contact opening: $A_{\text {flow }}=2 \pi \times 7.5 \times 0.1=4.8 \mathrm{~cm}^{2}$

$$
D=0.4 \mathrm{~cm}
$$

5. Center passage flow:

$$
\begin{aligned}
v_{\text {crit }} & =132 \mathrm{~m} / \mathrm{s} \\
D & =4 \mathrm{~cm}
\end{aligned}
$$$$
v_{\text {crit }}=13.2 \mathrm{~m} / \mathrm{s}
$$

6. 7.5-cr pipe

$$
v_{\text {crit }}=7.0 \mathrm{~m} / \mathrm{s}
$$

The center passage determines, therefore, the maximum permissible mass flow rate, $1 . e ., 17 \mathrm{l} / \mathrm{s}$, corresponding to $7.2 \mathrm{~m} / \mathrm{s}$ between the coniacts if separated $0.5 \mathrm{~cm}$.

\section{E. Shock Waye Transmission}

1. Speed of sound in oil

$$
v_{\text {sound }}=1.2 \mathrm{~km} / \mathrm{s}
$$

2. Initial velocity due to the mass flow of $17 \mathrm{l} / \mathrm{s}$ in the 15-cm-diam shock tube

$$
\begin{aligned}
& v_{\text {initial }}=0.94 \mathrm{~m} / \mathrm{s} \\
& \gamma=0.85 \mathrm{t} / \mathrm{m}^{3}
\end{aligned}
$$

3. Density of the oil $v_{\text {initial }} v_{\text {sound }}=9.8$ bar

4. Pressure from water hammer action $\Delta p=\gamma$ (assuming infinitely stiff wall)

5. Pulse length for a 5-m-long shock tube $8 \mathrm{~ms}$

6. Kinetic energy of the flowing mass $w_{K}=33 \mathrm{~J}$

7. Fraction of $W_{K}$ used in lifting the contact piece weighing $16 \mathrm{~kg}$ by $5 \mathrm{~mm}$

8. Flow velocity between parting contacts with gap dimension $a=5$ for laminar flow between parallel walls distance "a" apart

$$
v_{0}=\Delta p a^{2} / 12 n \ell=18 \mathrm{~m} / \mathrm{s}
$$

Where $l \approx 0.029 R_{e} D$ is the equivalent flow path length. 


\section{Acknowledgment}

The assistance of $P$. Thullen, which was very helpful in the development of the special breaker concept, is acknowledged.

\section{References}

1. A. Erk and M. Schmelzle, "Grundlagen der Schaltgeräte-Technik, " Springer 1974, p. 147.

2. Ibid., p. 134 .

3. Ibid., Fig. 8.15. 


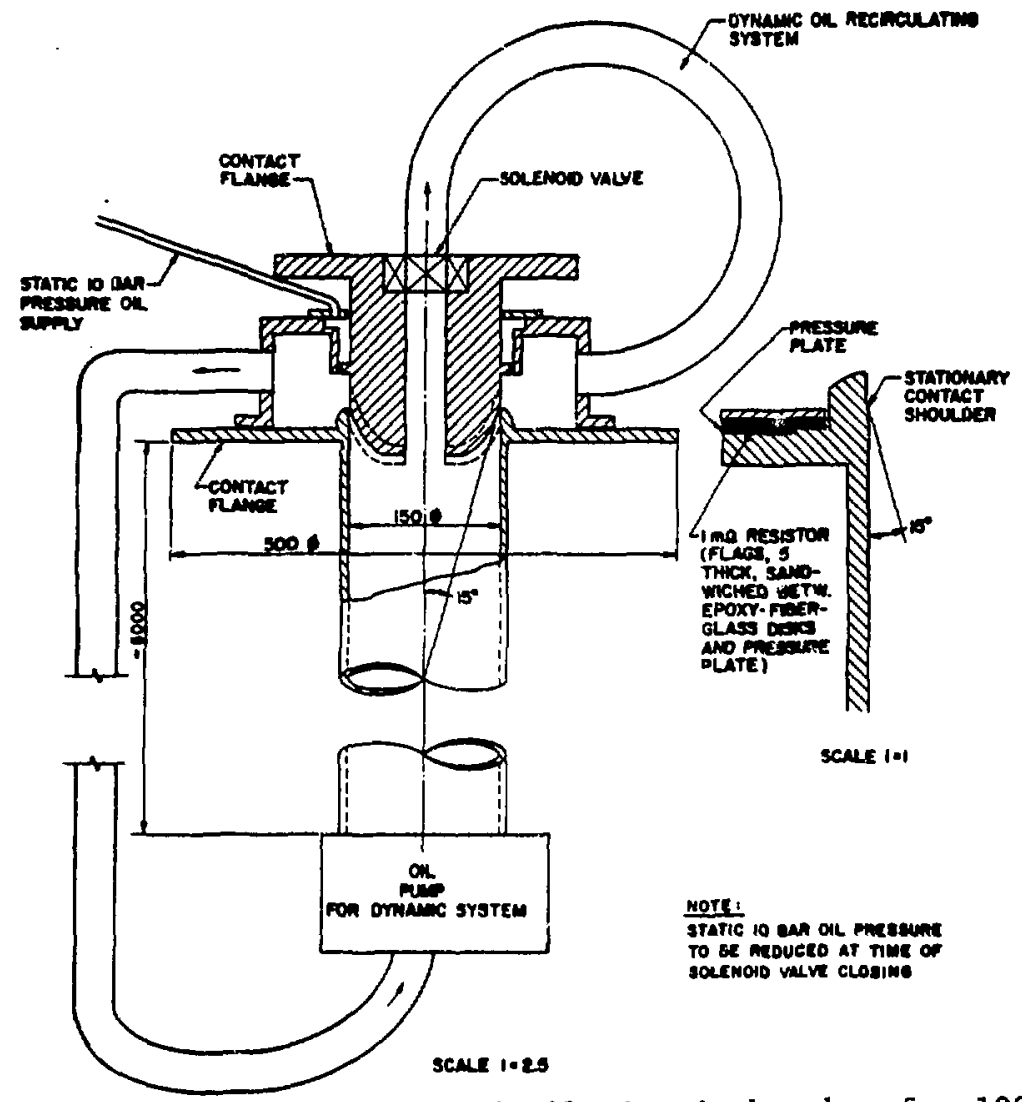

Fig. 1. Hydraulically actuated oil circuit breaker for 100-kA intermittent duty and approximately 2-kA, 500-V interrupting capacity.

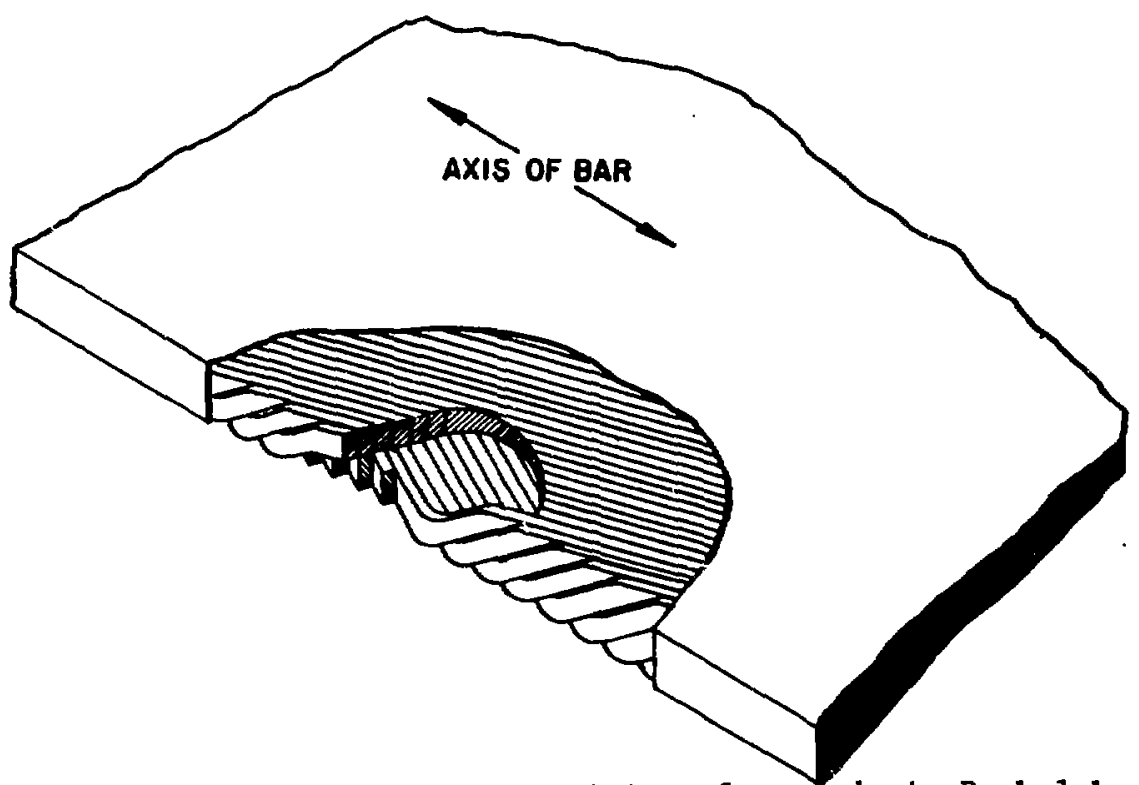

Fig. 2. Letail showing transposition of strands in Roebel bar. 
Some of the problems connected with a normal shutdown at the end of the burn phase (soft shutdown) and with a shutdown caused by disruptive instability (hard shutdown) have been considered. For a soft shutdown a cursory literature search was undertaken and methods for controlling the thermal wall loading were listed. Because shutdown computer codes are not widespread, some of the differences between start-up codes and shutdown codes were discussed along with program changes needed to change a start-up ccide to a shutdown code. For a hard shutdown, the major prcblems are large induced voltages in the ohmic-heating and equilibrium-field colls and high first wall erosion. A literature search of plasma-wall interactions was carried out. Phenomena that occur at the plasma-wall interface can be quite complicated. For example, material evaporated from the wall can form a virtual limiter or shield protecting the wall from major damage. Thermal gradients that occur during the interaction can produce currents whose associated magnetic field also helps shield the wall.

\section{INTRODUCTION}

Two general types of shutdown can be considered in terminating the burn phase of a large tokamak. In the first type, which will be called a soft shutdown, it is assumed that the plasma maintains its gross MHD equilibrium for several seconds. With this assumption the current, temperature, and density of the plasma can be manipulated by programming the current in the ohmic-heating $(\mathrm{OH})$ coll and the injection of deuterium or even high-z impurities into the plasma. The goal of this manipulation is mainly to regulate the power deposited on the first wall of the discharge chamber, although it may also be useful in recovering some of the magnetic energy stored in the plasma discharge.

In the second type of shutdown, which will be called a hard shutdown, it is assumed that a disruptive instability occurs and that the plasma discharge is terminated in a few milliseconds or less. Plasma current is transferred to the walls or $\mathrm{OH}$ colls and the plasma thermal energy is transferred to the wall. 
One important problem associated with this type of shutdown is erosion of the first wall, especially if the plasma thermal energy is deposited in some small area of the wall. If plasma current transters to the wall, there may also be erosion due to electrical arcs across bellows or insulator strips if these are present in the wall.

Large voltages induced in the ohmic-heating and equilibrium-field coils by the rapidly decaying plasma current are also possible problems. If necessary, this high voltage can be limited by connecting the coils to ground at intervals along their length through breakdown spark gaps. Resistors can be placed in series with the gaps to set the voltage. Precautions must be taken to insure that the coils do not remain shorted by the spark gaps in the event of a coil quench. Inductive transfer of plasma current to the first wall and to mechanical support structures might also be utilized to reduce voltage across the coils. As an alternative, the support structure, if conducting, might be deliberately connected by switches to make a shorted turn during a plasma disruption. Because the disruptive instability occurs in existing tokamaks and the mechanism producing the instability is not well understood, large tokamaks should be designed to withstand at least an occasional disruptive instability without suffering major damage.

\section{SOFT SHUTDOWN}

A. Plasma Modeling

Modeling of the shutdown phase requires consideration of some different problems from those considered in the start-up computer codes. During start-up the amount of energy contributed to the plasma by thermonuclear reactions san be neglected for temperatures below a kilovolt or so and useful information on the ohmic-heating system will still be obtained. Even the effects of neutral beam injection can be simulated by increasing the plasma termperature at some programmed rate, although this artifice does not directly give the amount of energy required in neutral beams to heat the plasma at the programmed rate. On the other hand, the plasma is ignited at the start of the shutdown phase so the energy contribution from thermonuclear reactions must be included.

It has also been pointed out that if refueling of the plasma is simply terminated at the start of shutdown, a sizeable increase in the plasma temperature can rocur because plasma thermal energy is no longer used to ionize and heat the replacement fuel. Temperature excursions of $30 \%$ seem possible, but it has also been suggested that the temperature rise be limited by adding pure 
deterium ${ }^{1}$ or impurities ${ }^{2}$ to the plasma during shutdown. If elther alternative is implemented, the equations used to model the plasma are made more complicated.

Control of plasma temperature during ignition will require some form of feedback control because the burning rate increases with increasing temperature. The feedback might be accomplished by controlling the refueling rate, the rate of addition of $\mathrm{hlgh-Z}$ impurities to the plasma, and the rate at which ions are lost to the walls. The ion confinement time can be controlled by imposing perturbations on the toroidal field. 3 Whatever methods are chosen will have some effect on the details of the shutdown because the shutdown starts from an ignited plasma. On the other hand, all of the complex phenomena associated with the initial breakdown of the plasma need not be considered for the shutdown modeling.

To bring into clearer focus the modifications needed in the start-up codes to model shutdown, possible modifications of the basic equations used in the LASL-UT ZEROD code 4 are discussed in the following sections:

1. D-T Neutral Density Balance. One form of this equation can be written $\mathrm{as}^{4}$

$$
\frac{d n_{0}}{d t}=\frac{v_{p}}{v_{v}} n_{e}\left(-n_{0} s_{\text {ion }}+\frac{1}{t_{p e}}+\frac{F}{n_{e} v_{p}}\right)
$$

where

$\mathrm{n}_{0}=$ the number density of D-T neutrals in $\mathrm{m}^{-3}$

$v_{p}=$ the plasma volume in $\mathrm{m}^{3}$

$v_{v}=$ the vo: ume of the vacuum chamber in $\mathrm{m}^{3}$

$\mathrm{n}_{e}=$ the eleciron number density in $\mathrm{m}^{-3}$

$S_{\text {ion }}=$ the ionization rate due to collisions in $\mathrm{s}^{-1} \mathrm{~m}^{-3}$

$t_{\text {pe }}=$ the electron particle confinement $t$ ime in $s^{-1}$, and

$F=$ rate of addition of neutrals to the vacuum chamber in $s^{-1}$.

The assumption is that equal numbers of $D$ and $T$ are always present, so $n_{0}$ represents the total number of $D$ and $T$ neutral atoms. Injection of more $D$ than $T$ during shutdown would not affect this equation, but another equation is required to keep track of the iensity of neutral $D$ atoms separately. The 
density of both the $D$ and $T$ ions is needed to calculate the thermonuclear reaction rate. A source term for injected $D$ neutral atoms is also needed. A quick comparison of zero-dimension codes used in the past to study TFTR and EPR showed only one code that had separate particle conservation equations for $D$ and $T$ ions, although several had separate equations for alpha particles and one had separate equations for fast and slow alpha particles. If high-l impurities are injected in any number, separate conservation equations for neutral and ionized impurities might be in order. The energy losses from the plasma, which stem from impurities, are a result of mass transport and line radiation so separate mass equations for high- and low-energy impurity ions might also be necessary. 2. Electron Density Balance. The electron conservation law can be written as

$$
\frac{d n_{e}}{d t}=n_{o} n_{e} s_{i o n}+\frac{d}{d t}\left(n_{o I} z_{e 1}\right)-\frac{n_{e}}{t_{p e}},
$$

where

$\mathrm{n}_{\mathrm{OI}}=$ the number density of impurity (oxygen) ions in $\mathrm{m}^{-3}$ and

$\mathrm{z}_{e 1}=$ the effective charge number of the impurity ions.

Injection of high-Z impurities would make both $v_{\text {oI }}$ nd $z_{e}$ time dependent.

3. D-T Ion Power Balance, The D-T ion ,ower balance can be written $a s^{4}$

$$
\frac{3}{2} \frac{d}{d t}\left(n_{1} T_{1}\right)=Q_{1 e}-Q_{c x}-\frac{3}{2} \frac{n_{1} T_{1}}{t_{1}},
$$

where 
$Q_{i e}=$ power given to $D-T$ ions and impurities by electrons in keV $\mathbf{s}^{-1} \mathbf{m}^{-3}$

$Q_{c x}=$ power given to $D-T$ neutrals by $D-T$ ions in $\mathrm{keV} \mathrm{s}^{-1} \mathrm{~m}^{-3}$

$n_{1}=D-T$ ion number density in $\mathrm{m}^{-3}$

$T_{1}=D-T$ Ion temperature in $\mathrm{keV}$, and

$t_{1}=D-T$ ion energy confinement $t$ ime in seconds.

Source terms representing ion energy from neutral beam injection and energy transferred from alpha particles should be included; energy sink terms representing energy transferred to high-Z impurities or low- energy D 1ons (or atoms through charge exchange) may also be needed. When neutral $D$ atoms are added to the plasma during shutdown, separate equations will be needed for $D$ and $T$ lons; and perhaps separate equations will be needed for high-and low-energy $D$ Ions.

4. Electron Power Balance, The equation for electron power balance can be written as

$$
\frac{3}{2} \frac{d}{d t}\left(n_{e} T_{e}\right)=P_{O H}-P_{1 O n}-Q_{1 e}-P_{\text {rad }}-\frac{3}{2} \frac{n_{e} T_{e}}{t_{e}}
$$

where

$P_{\text {OH }}=$ plasma joule-heating in $\mathrm{keV} \mathrm{s}^{-1} \mathrm{~m}^{-3}$;

$P_{\text {Ion }}=$ power lost in ionizing $D-T$ neutrals in $\mathrm{keV} \mathrm{s}^{-1} \mathrm{~m}^{-3}$;

$\mathrm{P}_{\text {rad }}=$ power lost as a result of impurity line radiation, bremsstrahlung, and cyclotron radiation in $\mathrm{keV} \mathrm{s}^{-1} \mathrm{~m}^{-3}$;

$\mathrm{T}_{\mathrm{e}}=$ electron temperature in keV;

$n_{e}=$ electron number density in $\mathrm{m}^{-3}$; and

$t_{e}=$ electron energy confinement time in seconds. 
The terms $P_{i o n}, Q_{i e}$, and $P_{\text {rad }}$ will have to be altered if large amounts of high-Z impurities are added.

\section{B. Shut down Scenarios.}

The quantity of work that has been done on tokamak shutdown is not large; and except for reporting of a few conclusions, documentation is sketchy. Assumptions that went into the few calculations which do exist have not been fully described. The scenario proposed for the ANL EPR 5,6 design had the following features.

1. About $5 \mathrm{~s}$ before the end of the discharge, the flow of cold D-T fuel is throttled back and regulated to maintain the $\beta_{\theta}$ required for equilibrium during the shutdown. The poloidal beta is related to the ion density, ion temperature, and plasma current by

$$
\beta_{\theta}=\frac{n_{i} T_{i}}{I_{p}{ }^{2}}
$$

with a fixed equilibrium field, this gives the rate at which $I_{p}$ can be changed for a given $n_{\mathfrak{i}}$ and $T_{\mathfrak{i}}$.

2. After the influx of fuel is reduced, the plasma density drops to about $1 \%$ of the value present during burn and the ion temperature rises linearly from $10 \mathrm{keV}$ to $13 \mathrm{keV}$. The neutron power decreases during the 5-s shutdown, but there is a net increase in energy transport to the first wall because of decreased particle confinement time at higher temperatures.

3. Plasma current is ramped back during the shutdown, perhaps in two stages. If the current is ramped down in two stages, the first (and slower) stage would return the current in the $\mathrm{OH}$ coil to the level present at the start of the burn. This might be done over a period of $5 \mathrm{~s}$. The second stage reverses current in the $\mathrm{OH}$ coll and completely extinguishes the discharge by driving the plasma current through zero. The time interval involved could be around $2 \mathrm{~s}$. One advantage of separately removing the current added during the burn is that the final current reversal during shutdown is symmetric to the reversal during start-up. Therefore, the $\mathrm{OH}$ coil is lef. in a condition ready for the next reactor pulse. A two-stage shutdown would seem to be an advantage 
only with certain power supply designs. The final drop of the 13-kev plasma temperature takes place in the last second of the shutdown.

Several scenarios for shutdown of a 2000-MW (thermal) gas cooled tokamak reactor were discussed by Sako ${ }^{1}$ as early as 1974. One scenarto is similar to that proposed by ANL for their EPR design. When the fuel injection is stopped, the ion density decreases several orders of magnitude and the temperature increases from $15 \mathrm{keV}$ to $20 \mathrm{keV}$. Bremsstrahlung and neutron power rapidly decreases with density while synchrotron radiation changes little because it depends strongly on temperature as well as density. Energy ilux to the wall increases and reaches a maximum of four times the flux during the burn.

Two other proposed scenarios stopped refueling of tritium at shutdown but continued the addition of deuterium at various rates. If deuterium addition is continued at the same rate as during the burn, there is a slight excursion in the plasma temperature and the peak power to the wail is roughly twice the power during the burn. The time taken for the shutdown is extended to about 10 seconds. If the tritium addition is cut off at the start of the shutdown, but the deuterium addition rate is doubled, the maximum power in the wall reaches only one and a half times the power during the burn. The plasma temperature excursion is negligible and the shutdown is extended to $12 \mathrm{~s}$.

\section{HARD SHUTDOWN}

The concern raised about possible wall damage in large tokamaks such as EPR and TNS stems from calculation of the thermal and magnetic energy of an ignited plasma. The thermal energy range is from 150 to $300 \mathrm{MJ}$ and the magnetic energy In the plasma poloidal field is comparable. Simple calculations show that even $200 \mathrm{MJ}$ of energy is sufficient to heat about $40 \mathrm{~kg}$ of tungsten to its melting point and vaporize it. The question of how the plasma energy is distributed to the wall in the event of a disruption is the crucial question and one which cannot be answered at present, There are several important effects that would tend to spread the energy over larger areas and so prevent the damage caused by a single disruption from disabling the experiment. Some of these effects are given below.

A. Mode Structure of the Disruption.

A discuptive instability is characterized by rapid contraction of the plasma major radius and expansion of the plasma minor radius in times as short as $500 \mathrm{\mu s}$. If the plasma major radius moves inward symmetrically around the major circumference, it will cause the plasma to touch the wall along a large 
area rather than at one point. Obvicusly, detailed description of the plasma behavior during the disruption is needed to predict the distribution of energy on the wall. A cursory search of the literature shows that this detailed information is not available, possibly because wall and limiter damage is not a major concern with present tokamaks. Only gross behavior of the plasma and few details about the spacial modes of the disruption are known.7,8

There has been some interes: in explaining the effect of the disruption on the external power supplies and current distribution in the walls. At the disruption, the plasma current is transferred to the walls in a complicated way. Some currents will flow in the wall even if there is an insulating strip to eliminate currents in the toroidal direction. Some work on this subject has supposedly been done at IPP (Garching) but few details are published. 15

\section{B. Interaction with the Wall.}

The interaction of a hot plasma with the first wall leads to a number of effects which tend to distribute the plasma energy over a wider area or to slow down the rate of energy deposition in the wall. Calculations by sestero 9 indicate that the first material vaporized from the wall acts as a "virtual limiter," which then absorbs most of the hot particles coming from the disrupted plasma. The absorbed energy is radiated in the form of soft $x$-rays, and this alone should reduce the energy flux to the wall at the area of contact between the plaama and the wall by a factor of 2 because half the energy is radiated away from the contact area. As the cloud of high-z material moves away from the wall, the radiated energy should be spread over wider areas and so protect the wall more effectively. The velocity of the spreading high-Z plasma cloud has been assessed, but time evolution of its density has not. Because the velocity depends upon the cloud density, the effectiveness of the virtual limiter in protecting the wall carnot be calculated precisely. Sestero estimates that 18 or less of the material that could be ablated from the wall based on the total thermal energy of the D-T plasma would actually be removed. He points out that this estimate does not include the effect of run-away elsctrons, including those induced by the high voltages accompanying the disruption itself.

If the amount of material vaporized from the wall appears to be too large even with this redustion by seve;nal orders of magnitude, the use of some easily replaced sacrificial limiter at the wall might bs considered. 
Several other studies exist of the interaction of hot plasmas with the first wall or with neutral gas blankets injected for the purpose of protecting the wall. The neutral gas blanket was studied by olipharit 10 et al. with a hydrodynamic fluid code that accounted for charge-exchange, Ionization, and energy transport in the regions where the plasma and neutral gas interact. The study by oliphant was carried out specifically to study the transient evolution of the neutral blanket. In both gas blanket and virtual limiter studies, a major question is whether the shield can be established rapidly enough, and not whether it will be effective once it is established. For the gas blanket studies, oliphant concluded that it could be established and maintained.

The Columbia11-14 group has done both experimental and theoretical studies of the interaction of hot, dense deuterium plasmas $w i t h$ a metal wall. Temperature of the plasma is $\sim 600 \mathrm{eV}$ and density is $\sim 10^{16} \mathrm{~cm}^{-3}$. For the theoretical studies they have developed a multifluid MHD computer program. If there is a magnetio field transverse to the wall embedded in the plasma, some of the effects that occur in the interaction of the plasma with the wall become complex. For example, cooling of the hot plasma at the wall redures the plasma pressure and causes more hot plasma to flow toward the wall. Movement of the plasma in the transverse magnetic field causes electric fields, which, in turn, produce electric currents. The magnetic field produced by these currents helps, in turn, to shield the wall from the hot plasma.

\section{HEFERENCES}

1. K. Sako, M. Onta, Y. Seki, H. Yamato, T. Hiraoka, N. Asami, and S. Mori, "Conceptual Design of a Gas-Cooled Tokamak Reactor," Nuclear Fusion, Supplement 1274, 27-49 (1974).

2. R. G. Mills et al., "A Fusion Power Plant," Princeton Plasma Physics Laboratory Report MATT-1050 (1974).

3. D. L. Jassby, "Temperature Control of Ignited Tokamak Plaswas by Vertically Asymmetric Toroidal-Field Ripple," The IEEE 1977 International Conference on Plasma Sclence, Troy, New York, May 23-25, 1977, Paper 3C5-6, Conference Record p. 91.

4. K. I. Thomassen et al., "Ohmic-Heating Systems Study for a Tokamak EPR," Los Alamos Scientific Laboratory, unpublished data, 1977.

5. W. M. Stacey, Jr., P. J. Bertoncini, J. N. Brooks, and K. Evans, Jr., "Iffect of Plasma Confinement and Impurity Level upon the Performance of a D-T Burning Tokamak Experimental Power Reactor," Nuclear Fusion 16, $211-223$ (1976). 
6. W. M. Stacey, Jr., Project Manager, "Tokamak Experimental Power Roaotor Gi:icoptual DesLgn," Argonne National Laboratory Report ANL/CTR-76-3 (1976).

7. H. H. Morton, "Disruptive Instability Mode Structure in the LT-3 Tokamak," Nuci Fusson 16, 571-577 (1976).

3. V.S. Ilasentios, V. M. Leonov, V. G. Merezhkin, and V. S. Mukhovatov, "Perturbation of a Magnetic Field During the Break-Up Instability in Tokamak-6," Froc. of the 5th Int. Conf. on Plasma Physics and Controlled Nuclear Fusinn Ressarch, Tokyo, p.33 (1975).

૬. A. Sestero, "protection of Walls from Hard Disruptions in Large Tokamaks," Nucl Fusion 12, i15-1?3 (1977).

10. T. A. Oliphant, G. E. Gryczkowski, and T. Kammash, "Transient Chiz:se-. Exchange Effects in a Neutral-Gas Layer," Nucl Fusion 16, 263-268 $(7976)$.

i1. ล. A. Cross, B. Jensen, J. K. Tien, and N. Panayotou, "Plasma-Wall Interacticas," Proceedings of the International Symposium on Plasma-Wall Interactions, Juelich, Federal Republic of Germany, Pergamon Press.

12. R. A. Cross, J. K. Tien, B. Jensen, N. F. Panayotou, and B. Feinberg, "A Shock-Tube study of Fusion Plasma-Hall Interactions," Proceedings of $11 \mathrm{th}$ International Symposium on Shock-Tubes and Waves, Seattle, Washington, July 11- 14, 1977.

13. R. A. Gross, J. Tien, N. Panayotou, B. Jensen, and B. Feinberg, "Hot Plasma-Wall Interactions for Fusion Reactors," Energy 1, 196-199 (1977).

14. R. A. Gross, J. K. Tien, and N. Panayotou, "Hot Plasma Wall Interactions," Proceedings of the AIAA 15th Aerospace Sciences Meeting, Los Angeles, CA, Jan. 24-26, 1977.

15. K. Lackner and F. Karger, "Models for the Influence of Resonant Helical Windings on Tokamak Discharges and for the Current Decay Following the Disruptive Instability," Proceedings of the Eighth European Conference on Controlled Fusion and Plasma Physics, Prague, Czechoslovakia, 19-23 Sept. 1977.

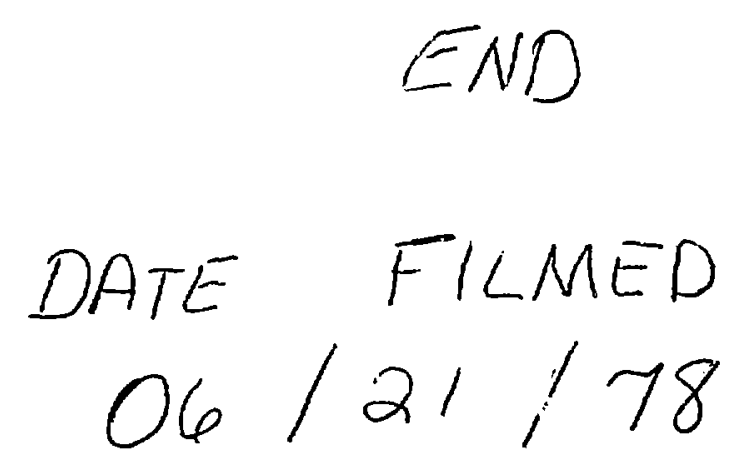

